\title{
EFFECTS OF AN EDUCATION PROGRAM \\ UTILIZING THE DIETARY GUIDELINES \\ AND FOOD GUIDE PYRAMID ON \\ DIET AND HEALTH
}

\author{
By \\ STARLETTE LYNN HEINTZ \\ Bachelor of Arts \\ University of Northern Colorado \\ Greeley, Colorado \\ 1994
}

Submitted to the Faculty of the

Graduate College of the

Oklahoma State University

in partial fulfillment of

the requirements for

the Degree of

MASTER OF SCIENCE

May, 1998 


\section{EFFECTS OF AN EDUCATION PROGRAM \\ UTILIZING THE DIETARY GUIDELINES \\ AND FOOD GUIDE PYRAMID ON \\ DIET AND HEALTH}

Thesis Approved:

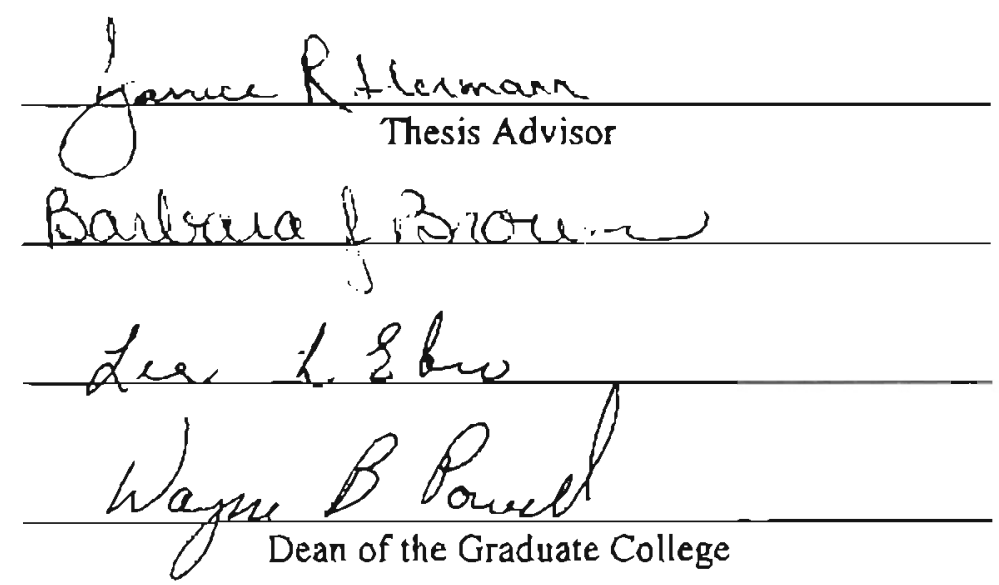




\section{ACKNOWLEDGMENTS}

I wish to express my deepest appreciation to my major advisor. Dr. Janice Hermann, for her countless hours spent guiding me through every phase of this thesis. She was there every step of the way with encouragement, laughter, and advice and continues to be an inspiration for me. Sincere appreciation is also extended to my research committee members Dr. Lea Ebro and Dr. Barbara Brown. Dr. Ebro, I want to thank you for all your support throughout my dietetic internship and graduate school. Dr. Brown, it has been a pleasure working with you and 1 appreciate all your insights during the final revisions of this thesis.

Special thanks to Andrea Arquitt, Assistant Professor Nutritional Sciences, Mary Selk, Payne County Home Economist, Billie Johnson, Cooperative Extension Service Secretary, and Pam, Cooperative Extension Service Secretary.

This research thesis is dedicated to my parents, Jack \& Shelby Morrison, my sister, Debbie Morrison, my brother, Mark Morrison, and my husband, David Heintz. I want to thank you for all your encouragement, support, unconditional love, and belief in me. Last but not least, 1 want to thank Ben for all of the warmhearted tail wags that greeted me after some very challenging days. 


\section{TABLE OF CONTENTS}

$\begin{array}{lll}\text { Chapter } & \text { Page }\end{array}$

I. INTRODUCTION $\ldots \ldots \ldots \ldots \ldots \ldots \ldots \ldots \ldots \ldots \ldots \ldots$

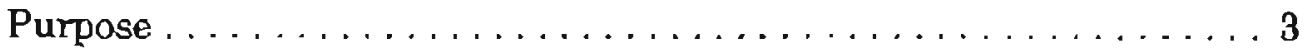

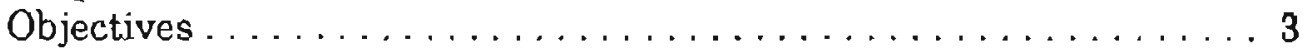

Null Hypotheses . . . . . . . . . . . . . . . . . . 4

Assumptions and Limitations . . . . . . . . . . . . . . . 5

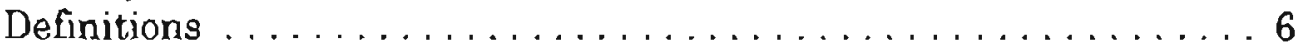

II. REVIEW OF LITERATURE . . . . . . . . . . . . . . . . . . . 8

Introduction . . . . . . . . . . . . . . . . . . . 8

Nutrition Education Tools for Helping Americans Eat Healthy . . . . . 9

Dietary Guidelines ......................... . . . . . .

The Food Guide Pyramid . . . . . . . . . . . . . . . . 11

Nutrition Facts Label . . . . . . . . . . . . . . . . . . . 13

Nutritional Status of Americans . . . . . . . . . . . . . . . 18

Blood Pressure . . . . . . . . . . . . . . . . . . . . . 19

Weight . . . . . . . . . . . . . . . . . . . . 19

Blood Cholesterol. . . . . . . . . . . . . . . . . . . . 24

Dietary Intake. . . . . . . . . . . . . . . . . . . 25

Cognitive and Behavioral Skills of Food and Nutrition . . . . . . . 31

Health Attitudes . . . . . . . . . . . . . . . . . . 31

Nutrition Knowledge . . . . . . . . . . . . . . . . . 34

Dietary Behavior . . . . . . . . . . . . . . . . . . 36

Food Safety . . . . . . . . . . . . . . . . . . . 42

Improving the Health of Americans $\ldots \ldots \ldots \ldots \ldots \ldots$

Health Promotion . . . . . . . . . . . . . . . 48

Nutrition Education . . . . . . . . . . . . . . . . 52

Theories of Behavior Change . . . . . . . . . . . . . . . . 55

Evaluating Dietary Intake . . . . . . . . . . . . . . . . . 60

Dietary Assessment Methods . . . . . . . . . . . . . . . . . 60

Summary . . . . . . . . . . . . . . . . . . 66 


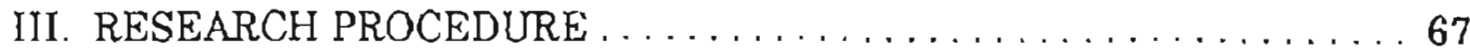

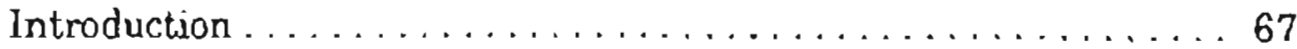

Development of the Oklahoma Cooperative Extension Service

Healthy Living Program . . . . . . . . . . . . . . . . . 68

The Healthy Living Program Assessment Forms . . . . . . . . . . 71

Food and Nutrition Behavior Questionnaire ............ 71

Health Habits and History Questionnaire ... . . . . . . . . . . 71

Healthy Living Program Measurement Form . . . . . . . . . . 71

Subject Recruitrnent . . . . . . . . . . . . . . . . . . 71

Experimental Study . . . . . . . . . . . . . . . . . . . 72

Healthy Living Nutrition Education Program . . . . . . . . . . 73

Anthropometric Measures . . . . . . . . . . . . . . . . . . . 73

Biochemical Measures . . . . . . . . . . . . . . . . . . 77

Clinical Measures . . . . . . . . . . . . . . . . . . . . . . . . . . . 79

Dietary Measures . . . . . . . . . . . . . . . . . . . . . .79

Statistical Analysis . . . . . . . . . . . . . . . . . . . 82

IV. RESULTS AND DISCUSSION $\ldots \ldots \ldots \ldots \ldots \ldots \ldots \ldots \ldots \ldots \ldots$

Introduction ............................ 83

Description of Subjects ...................... 83

Baseline Data on Food and Nutrition Behavior ............. 84

Effects of the HLP On Food And Nutrition Behavior . . . . . . . . . 85

Baseline Data On Dietary Intake .................. 88

Effects of the HLP on Dietary Intake . . . . . . . . . . . . . . 89

Baseline Data on Anthropometric and Biochemical Measures ..... . 93

Effects of the HLP on Anthropometric and Biochemical Measures . . 93

V. SUMMARY, CONCLUSIONS, AND RECOMMENDATIONS . . . . . 97

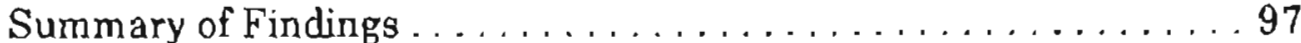

Discussion of Hypotheses . . . . . . . . . . . . . . . . 97

Conclusions . . . . . . . . . . . . . . . . . . . . . . . . . . 100

Recommendations ........................

BIBLIOGRAPHY . . . . . . . . . . . . . . . . . . . . . 103 
APPENDIX A - APPROVAL FORM FOR OKLAHOMA STATE UNIVERSITY INSTITUTIONAL REVIEW BOARD FOR HUMAN SUBJECTS RESEARCH . . . . . . . . . . 112

APPENDIX B - HEALTHY LIVING PROGRAM SUPERMARKET TOUR HANDOUTS . . . . . . . . . . . . . . . . . . . . 114

APPENDIX C - HEALTHY LIVING PROGRAM VISUAL MODELS .

APPENDIX D - HEALTHY LIVING PROGRAM LESSON OBJECTIVES . . . . . . . . . . . . . . . . . . . . . 139

APPENDIX E - HEALTHY LIVING PROGRAM NEWS RELEASE . . . . . . . . . . . . . . . . . . . . . . . 148

APPENDIX F - HEALTHY LIVING PROGRAM FOOD BEHAVIOR QUESTIONNAIRE ..................... 151

APPENDIX G - HEALTH HABITS AND HISTORY QUESTIONNAIRE 154

APPENDIX H - HEALTHY LIVING PROGRAM MEASUREMENT FORM . . . . . . . . . . . . . . . . . . . . . . 157

APPENDIX I - HEALTHY LIVING PROGRAM CONSENT FORM . . . . . . . . . . . . . . . . . . . . . . . 159

APPENDIX J - HEALTHY LIVING PROGRAM FASTING BLOOD VALUES FORM

APPENDIX K - HEALTH HABITS AND HISTORY NUTRIENT VALUES 


\section{LIST OF TABLES}

Table

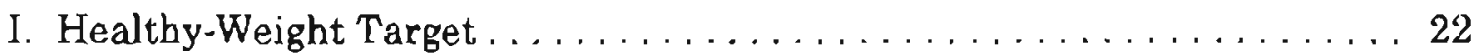

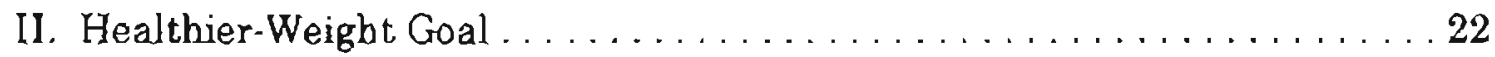

IIl. Recommended Dietary Allowances . . . . . . . . . . . . . . . 29

IV. Common Foodborne Illnesses Caused by Bacteria ............. 45

V. Top 12 Mishandling Food Practices in Homes ............... 46

VI. Characteristics of Dietary Assessment Tools . . . . . . . . . . . . 64

VII. Concentration Values in Healthy Living Nutrition Education Program . . . . . 78

VIII. Baseline Characteristics of Subjects .................... 84

IX. Survey Score and Subscores Education Group . . . . . . . . . . 85

X. Dietary Intake By Education Group . . . . . . . . . . . . . . . . 89

XI. Dietary Intake Compared to Recommended Daily Values ......... . . 91

XII. Anthropometric and Biochemical Measures By Education Group . . . . . . . 94 


\section{LIST OF FIGURES}

$\begin{array}{lll}\text { Figure } & \text { Page }\end{array}$

1. Food Guide Pyramid $\ldots \ldots \ldots \ldots \ldots \ldots \ldots \ldots \ldots \ldots \ldots \ldots \ldots$

2. Nutrition Facts Label $\ldots \ldots \ldots \ldots \ldots \ldots \ldots \ldots \ldots \ldots \ldots$

3. Determinants of Food Intake Behavior . . . . . . . . . . . . . 37

4. Determinants of Label Use $\ldots \ldots \ldots \ldots \ldots \ldots \ldots \ldots \ldots \ldots$

5. Safe Handling Instructions $\ldots \ldots \ldots \ldots \ldots \ldots \ldots \ldots \ldots \ldots \ldots$

6. Experimental Study . . . . . . . . . . . . . . . . . . . 72

7. Wrist Circumference Measurement $\ldots \ldots \ldots \ldots \ldots \ldots \ldots \ldots \ldots$

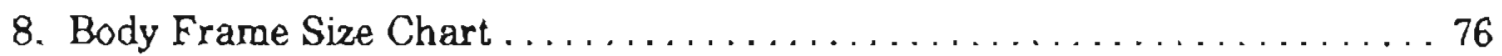




\section{NOMENCLATURE}

$\begin{array}{ll}\text { ADA } & \text { American Dietetic Association } \\ \text { FDA } & \text { Food and Drug Administration } \\ \text { FMI } & \text { Food Marketing Institute } \\ \text { HHS } & \text { U.S. Department of Health and Human Services } \\ \text { IFIC } & \text { International Food Information Council } \\ \text { IOM } & \text { Institute of Medicine } \\ \text { NAS } & \text { National Academy of Science } \\ \text { NCI } & \text { National Cancer Institute } \\ \text { NHLBI } & \text { National Heart, Lung, and Blood Institute } \\ \text { USDA } & \text { United States Department of Agriculture }\end{array}$




\section{CHAPTER I}

\section{INTRODUCTION}

The role of diet in the etiology and prevention of chronic disease has been well established (IOM, 1991). With an increased incidence of nutrition-related chronic diseases, there have been various coordinated efforts to improve America's diet and health. For example, the following federal publications address the need for improved and healthier lifestyles (IOM, 1991):

- Healthy People 2000: National Health Promotion and Disease Prevention Objectives

- The Surgeon General's Report on Nutrition and Health

- The Dietary Guidelines for Americans

- Diet and Health: Implications for Reducing Chronic Disease Risk

Despite increasing scientific understanding of the relationship between diet and disease, Americans still have misconceptions about healthy eating. This lack of understanding contributes to rising health care costs. An estimated $\$ 2.3$ billion is spent daily on health care in the United States. In 1992 alone, diet-related disease accounted for a large portion of the $\$ 838.5$ billion cost for the nation's health care ("Health Care Reform," 1993). Furthermore, the treatment of diet-related illness such as heart disease, high blood pressure, cancer, diabeles, and obesity is more than $\$ 200$ billion ("Health Care Reform," 1993).

Although the Dietary Guidelines for Americans and the Food Guide Pyramid have been established to assist Americans in food choices, they continue to have difficulty in interpreting and applying these guidelines (Schwartz, 1996; Hudnall \& Wellman, 1992). This confusion hinders Americans from achieving healthy eating 
behaviors that promote good health and reduce certain disease risk. To correct this, the Committee on Dietary Guidelines Implementation has developed goals for improving America's eating behaviors. The goals specifically apply to increasing consumer awareness, understandiag, and compliance of dietary recommendations as well as creating legislative, regulatory, and educational environments that support dietary recommendations (IOM, 1991, p. 3).

The United States Department of Agriculture has the responsibility for providing Americans with current dietary information and providing nutrition education to improve dietary intake (Daniels, 1994). The goal is to help consumers make informed decisions on food selection, preparation, and intake that will improve nutritional health and well-being (Daniels, 1994). The United States Department of Agriculture has a total of 10 agencies, which coordinate nutrition education programs and activities. The Cooperative Extension Service is one of the agencies and is responsible for providing nutrition education and applied research on an individual basis or directly to the public (Daniels, 1994).

Oklahoma Cooperative Extension Service is committed to improving diet. health, nutritional status, food quality, and food safety by developing nutrition education programs. In response to the critical issues cited above, Oklahoma Cooperative Extension Service designed a five-year impact program where nutrition education efforts focused on diet, nutrition, and health. The first year includes the Healthy Living Program, which is an eight-week food and nutrition education program designed to help Oklahoman's apply the Dietary Guidelines for Americans and the Food Guide Pyramid to food selection, food preparation, and food safety. 


\section{Purpose and Objectives}

'The purpose of this study was to evaluate the effects of an eight-week Oklahoma Cooperative Extension Service nutrition education program, Healthy Living Program, in a rural county in Oklahoma on food selection, preparation, and food safety practices and behaviors, dietary intake, and anthropometric and biochemical health measures. Specific objectives included the following:

1. Payne County, Oklahoma, subjects will engage in healthy lifestyle practices that promote healthy living.

2. Payne County, Oklahoma, subjects will adopt the United States Department of Agriculture (USDA) Food Guide Pyramid dietary recommendations.

3. Payne County, Oklahoma, subjects will adopt the United States Department of Agriculture-Health \& Human Service (USDA-HHS) dietary guidelines/dietary recommendations.

4. Payne County, Oklahoma, subjects will adopt safe food selection, food preparation, and storage practices.

5. Payne County, Oklahoma, subjects will improve personal health status indicators. 


\section{Null Hypotheses}

Ho1: There will be no significant difference as a result of an eight-week Healthy Living Program on changes in subjects' Food and Nutrition Behavior Questionnaire Scores compared to controls for:
a. Food Safety
b. Food Selection and Preparation
c. Food Intake

Ho2: There will be no significant difference as a result of an eight-week Healthy Living Program on changes in subjects' number of servings from the Food Guide Pyramid groups compared to controls for:
a. Breads, Cereals, Rice, and Pasta group
b. Vegetable group
c. Fruit group
d. Milk, Yogurt, and Cheese group
e. Meat, Poultry, Fish, Dry beans, Eggs, and Nuts group
f. Fats, Oils, and Sweets group

Ho3: 'There will be no significant difference as a result of an eight-week Healthy Living Program on changes in subjects' percentage of calories compared to controls for:
a. Fat
b. Protein
c. Carbohydrates 
Ho4: There will be no significant difference as a result of an eight-week Healthy Living Program on changes in subjects' anthropometric and biochemical measures compared to controls for:
a. Total Body Weight
b. Body Mass Index
c. Blood Pressure
d. Fasting Total Serum Cholesterol
e. Fasting Serum LDL-Cholesterol
f. Fasting Serum HDL-Cholesterol
g. Fasting Serum Triglycerides
h. Fasting Serum Glucose

Assumptions

In the study, researchers assume subjects will accurately report their dietary intake on the Health Habits and History Questionnaire and correctly indicate which box represents their food and nutrition behavior on the Healthy Living Program Survey. In addition, researchers will assume subjects will fast 12 hours prior to blood collection and complete the entire eight-week Healthy Living Program.

\section{Limitations}

A small sample size, lacking randomization, was a limitation of the Healthy Living Program study. This could have resulted from a number of factors. At the time of this study, the Healthy Living Program was in its first year of programming. Although promotional posters, flyers, news releases, and video materials were 
marketed, County Home Economists were responsible for recruiting subjects and many of the Healthy Living Program participants had attended other food and nutrition programs conducted by the County Home Economists. In addition, a small fee of $\$ 20$ was charged to cover the cost of the program.

Another limitation was the time of day the Healthy Living Program was conducted. The program was conducted in the morning, which could have limited the number of subjects who could have participated in the study. Finally, the size of the group that one person could teach effectively was also considered to be a limitation.

\section{Definitions}

1. Healthy Living Program: The Healthy Living Program (HLP) was developed by the Oklahoma Cooperative Extengion Service in order to help Oklahomans apply recommendations from the USDA-HHS Dietary Guidelines and the USDA Food Guide Pyramid to food selection and preparation practices to improve dietary intake and reduce the risk for disease. In addition, the HLP included food safety principles for food selection and preparation. The HLP consists of eight sessions and were designed to follow the food groups within the Food Guide Pyramid and provide information on nutrition, label reading, food selection, food preparation, and food safety measures.

2. Healthy Living Program Survey: This is a Food and Nutrition Behavior Questionnaire that was adapted from the 1993 USDA Expanded Food and Nutrition Education Program (EFNEP) Survey. The questionnaire consisted of 18 questions on food safety, food selection and preparation, and food intake. Participants were 
instructed to place a check in the appropriate box (never, seldom, sometimes, most of the time, and almost always) that best answered each of the questions.

3. Food and Nutrition Behavior Questionnaire Score: The Food and Nutrition Behavior Questionnaire Score is the total score obtained from answering 18 questions from the Food and Nutrition Behavior Questionnaire on food selection, preparation, and food safety practices and behaviors.

4. Food Safety Score: The Food Safety Score is the total score obtained from answering three food safety questions from the Food and Nutrition Behavior Questionnaire, using a 5-point Likert scale ranging from "never" to "almost always".

5. Food Selection and Preparation Score: The Food Selection and Preparation Score is the total score obtained from answering 10 food selection and preparation questions from the Food and Nutrition Behavior Questionnaire, using a 5-point Likert scale ranging from "never" to "almost always".

6. Food Intake Score: The Food Intake Score is the total score obtained from answering five food intake questions from the Food and Nutrition Behavior Questionnaire, using a 5-point Likert scale ranging from "never" to "almost always".

7. Health Habits and History Questionnaire: The Health Habits and History Questionnaire is a food frequency questionnaire and computer dietary analysis system developed by Block et al., (1986). 


\title{
CHAPTER II
}

\section{REVIEW OF LITERATURE}

\author{
Introduction
}

There is an overwhelming amount of scientific evidence suggesting that diets high in total fat, saturated fat, and cholesterol and low in complex carbohydrates and fiber are linked to coronary heart disease, stroke, some cancers, and diabetes (HHS, 1990; ADA position paper, 1993; Rimm et al., 1996; Steinmetz \& Potter, 1996). Designing, implementing, and evaluating different nutrition education intervention methods that effectively convey the Food Guide Pyramid's message of variety, balance, and moderation and applying the recommended Dietary Guidelines to appropriate food choices is challenging; however, the improvement in nutritional status could prevent nutrition-related mortality and diet-related health problems and reduce both direct and indirect health care costs. This chapter contains a review of the literature on the federal government as well as private and voluntary group efforts designed to improve America's diet and health status. In addition, this chapter will examine the nutritional status, nutrition knowledge, dietary behavior and practices, and safe food handling practices of individuals. This chapter will also define nutrition education and explore theoretical frameworks that seek to improve health and nutritional status. Finally, this chapter will review dietary assessment methods. 


\section{Nutrition Education Tools For Helping Americans Eat Healthy}

Introduction

The Dietary Guidelines for Americans consist of seven principles based on the most current advise from experts to reduce the risk of disease. The challenge for nutrition education is to convey the Dietary Guidelines in a clear, concise, and easyto-understand format. The Food Guide Pyramid, a visual representation of the Dietary Guidelines, can guide consumers in choosing a healthy diet. In addition, the "Nutrition Facts" label enables consumers to apply the Dietary Guidelines to appropriate food choices and compare different foods within the same group or among different groups within the Food Guide Pyramid.

\section{The Dietary Guidelines for Americang}

The Dietary Guidelines for Americans were developed by USDA and HHS to provide information on what individuals should eat to stay healthy. Specifically, the Dietary Guidelines represent the federal government's advise based on current scientific and medical knowledge about nutrition and dietary guidance for Americans two years of age and older to promote health and reduce the risk for chronic disease (Bialostosky \& St Jeor, 1996).

The first Dietary Guidelines were published in 1980 and were revised in 1985 and again in 1990. The National Nutrition Monitoring and Related Research Act of 1990 required secretaries from both USDA and HHS to publish the Dietary Guidelines at least once every five years; however, in 1995, Congress mandated the Dietary Guidelines be reviewed and revised. In the 1995 Dietary Guidelines, more 
emphasis was placed on total diet, rather than individual foods. In addition, emphasis was placed both on diet and physical activity. The 1995 Dietary Guidelines no longer have a higher weight category for older adults and include both weight maintenance and weight loss (Kennedy, Meyers \& Layden, 1996).

The 1995 Dietary Guidelines for Americans are as follows (USDA, 1995):

- Balance the food you eat with physical activity - maintain or improve your weight

- Choose a diet with plenty of grain products, vegetables, and fruits

- Choose a diet low in fat, saturated fat, and cholesterol

- Eat a variety of foods

- Choose a diet moderate in salt and sodjum

- Choose a diet moderate in sugars

- If you drink alcoholic beverages, do so in moderation

The Dietary Guidelines are an important document that serves as the basis for the federal government's nutrition policies and procedures (IOM, 1991, p. 2). "Each federal agency is required to promote these guidelines in carrying out any federal food, nutrition, or health program" (Bialostosky \& St Jeor, 1996, p. 7).

The Dietary Guidelines for Americans focus on recommendations from nutrition experts that recognize the link between diet and health and understand that certain dietary practices can reduce the incidence of obesity and the chances of getting some types of diseases, such as heart disease, high blood pressure, stroke, diabetes, and some forms of cancer (USDA, 1990). Specifically, the Dietary Guidelines provide information on what Americans should be eating to stay healthy, the importance of diet and health, food components that affect health, physical activity, healthy food choices, and other tools to help achieve a healthy diet. 


\section{The Food Guide Prramid}

The Food Guide Pyramid was developed by USDA and supported by the Department of HHS. The Food Guide Pyramid represents a food guidance system based on extensive research about what and how much Americans should eat to achieve a healthy diet. The Food Guide Pyramid illustrates foods from the five major food groups and places them into sections within the pyramid (Figure 1). The base of the pyramid includes all foods from the grains. The first level includes foods from plants, the second level includes foods primarily from animals, and the tip represents sweets, fats, and oils (USDA, 1992).

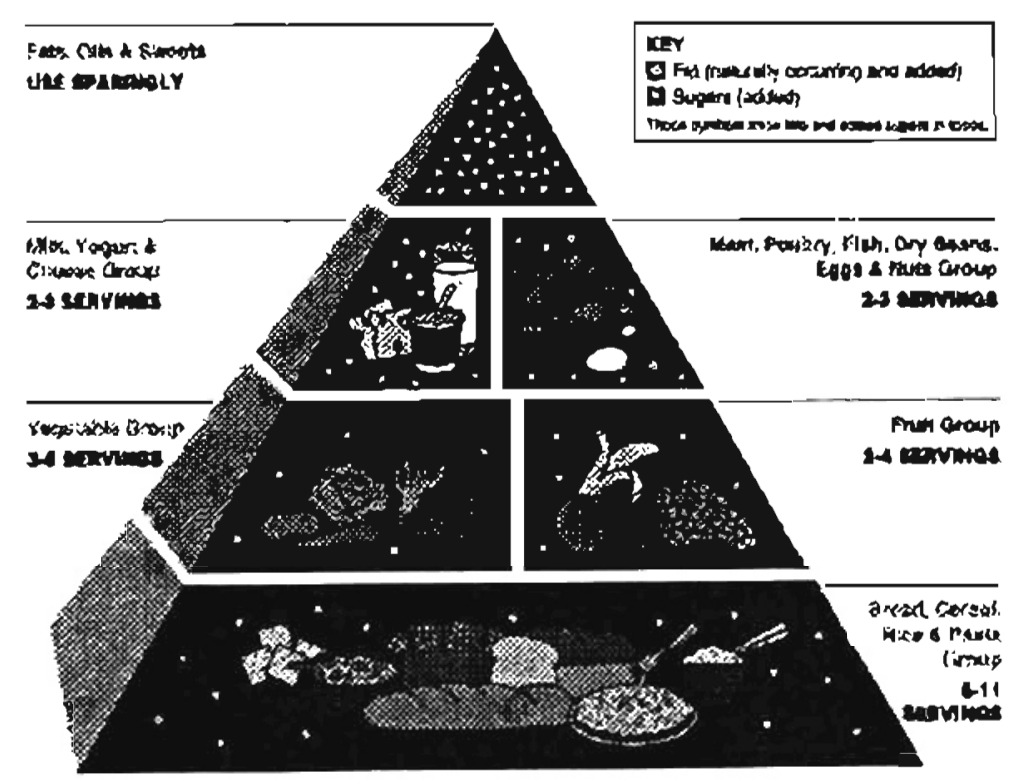

Figure 1. Food Guide Pyramid (USDA and HHS). 
The pyramid illustrates the recommended servings by the amount of space given for each food group. Not only does the pyramid visually represent the food groups. but it also recommends the number of servings from each food group. For example, the Food Guide Pyramid recommends 6 to 11 daily servings of breads, cereals, rice, and pasta: 3 to 5 servings of vegetables; 2 to 4 servings of fruits; 2 to 3 servings of milk, yogurt, and cheese; and 2 to 3 servings of meats, poultry, fish, dry beans, eggs. and nuts. In addition, it recommends fats, oils, and sweets be consumed sparingly (USDA, 1992). The number of servings for an individual depends on their caloric needs. An individual's caloric needs are based on their age, sex, and activity level (Saltos, Welsh \& Davis, 1994).

The Food Guide Pyramid conveys the key concepts of a healthy diet: proportion. variety, and moderation. Proportion can be defined as consuming more foods from the larger areas of the pyramid and less foods from the smaller areas of the pyramid. Variety can be described as eating a wide selection of foods both within each group and among other groups within the pyramid. Finally, moderation can be defined as consuming food portions according to recommended serving sizes and eating sweets, fats, and oils sparingly (Achterberg, McDonnell \& Bagby, 1994). 
Nutrition Facts Label

The goal of the new food label is to help consumers choose healthy diets in accordance with the Dietary Guidelines for Americans, encourage food companies to improve the nutritional value of their products, and eliminate consumer confusion (FDA Backgrounder, 1995). In the past, nutrition labeling focused on the avoidance of nutritional deficiencies like scurvy, pellagra, and beriberi (Foulke. 1992). In addition, nutrition labels lacked uniformity, displayed unclear descriptive terms, and contained misleading health claims. The American Dietetic Association (ADA) urged government agencies to reform food and nutrition labeling practices and announced in a position paper that "nutrition and ingredient information on food labels must be mandatory and uniform" (ADA position paper, 1990, p. 583). Furthermore, ADA stated "health and nutrient content claims, whether on food labels or in advertising, must be based on scientific evidence" (ADA position paper, 1990, p. 583).

In 1990, the Nutrition Labeling and Education Act was signed into law and required nutrition labeling for most foods to be displayed in a new easy-to-read format, which included comprehensive ingredient listings, standardized serving sizes, and uniform definitions. The act also allowed the use of food or nutrient health claims that had been approved by the Food and Drug Administration (FDA) (Backgrounder, 1995). In the past, a food product carrying a health claim on the label was considered to be a drug unless the claim was supported by an authorized new drug application. Presently, the Nutrition Education Labeling Act allows food labels to display health claims describing the relationship between certain foods or nutrients in relation to health status (Foulke, 1992). Specifically, calcium and 
osteoporosis; fat and cancer; saturated fat and cholesterol and heart disease; fber and cancer; fiber and heart disease; sodium and high blood pressure; fruits and vegetables and cancer; and folic acid and neural tube defects (FDA backgrounder, 1995). In addition to health claims, FDA and USDA have defined eleven terms to describe a food's nutrient content. The terms are as follows: free, low, reduced, fewer, less, light, lean, extra lean, high, more, and good source (FDA, 1993).

In 1994, the new food labeling regulations took effect and the "Nutrition Facts" panel was delivered to the public on most packaged foods (Saltos, Welsh \& Davis, 1994). The new food labeling changes were designed to provide consumers with accurate, useful, and complete information in order to help them make informed decisions about food selection (Kurtzweil, 1994).

The "Nutrition Facts" label (Figure 2) assists consumers when comparing food groups within the Food Guide Pyramid and emphasizes how all foods can fit into a healthy diet. With servings sizes based on standards set by the FDA and USDA, consumers can easily compare nutritional values of similar products (Saltos et al., 1994). The "Nutrition Facts" label must disclose the following components: total calories, calories from fat, total fat, saturated fat, cholesterol, sodium, total carbohydrate, dietary fiber, sugars, protein, vitamin A, vitamin C, calcium, and iron (FDA Backgrounder, 1995). 


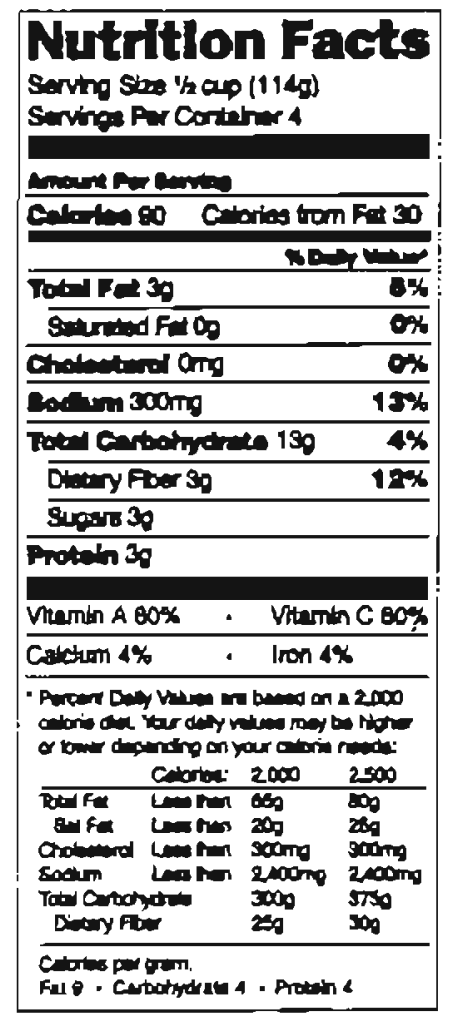

Figure 2. Nutrition Facts Label (FDA, 1994).

Few studies have been conducted to determine the effectiveness of the Dietary Guidelines, the Food Guide Pyramid, and the "Nutrition Facts" label as educational tools for improving diet and decreasing the risk for disease; however, Gambera, Schneeman \& Davis (1995) examined whether the Food Guide Pyramid and the Dietary Guidelines coupled with an exercise component were effective in reducing the risk of cardiovascular disease. Thirty-two Air Furce members consisting of twenty men and twelve women, who were participating in a ninety day fitness program, were randomly assigned to either an exercise-only group or an exerciseplus-diet group. Gambera and associates observed significant dietary effects on reducing risk factors associated with coronary heart disease. For instance, total cholesterol (9\%), low-density lipoproteins (13\%), and body mass index (2\%) were 
significantly lowered. Also, the percentage of total calories from total fat decreased from $39 \%$ to $23 \%$ along with saturated fat from $14 \%$ to $6 \%$. Thus, weight loss was observed by researchers in the exercise-plus-diet groups. Additionally, dietary improvements were acknowledged and adhered with recommendations from the Food Guide Pyramid and the Dietary Guidelines for Americans. Gambera and associates concluded that the Food Guide Pyramid can be used as an educational tool that instructs a nutritionally-adequate diet with preventative measures for disease (Gambera et al., 1995).

Schuette, Song, \& Hoerr (1996) evaluated whether the Food Guide Pyramid was an effective quantitative tool for assessing both nutritional adequacy and nutritional quality of 2,489 college students' food records. In the study, researchers determined Dutritionally inadequate diets by examining whether students consumed the minimum number of recommended servings from the food groups within the Food Guide Pyramid along with one serving from each of the food groups. They also determined whether diets with the minimum number of recommended servings comprised $30 \%$ or less calories from fat and $10 \%$ or less calories from sugar. Researchers found $31 \%$ of students consumed less than $30 \%$ of calories from fat and $61 \%$ consumed $10 \%$ or less calories from sugar; however, only $4 \%$ reached both guidelines for fat and sugar. Of the 2,489 diets, $70 \%$ were nutritionally adequate. Researchers concluded the Food Guide Pyramid "can be used as a quantitative tool for screening nutritional inadequacy with high sensitivity (correctly classifying nutritionally inadequate diets), but with moderate to low specificity (correctly classifying nutritionally adequate diets)." Researchers concluded a good indicator for screening nutritionally inadequate diets is to determine whether the diet 
included at least one serving from each of the five groups within the Food Guide Pyramid (Schuette et al., 1996).

Kennedy, Meyers, \& Layden (1996) report that USDA and HHS are conducting focus group research "to better understand how to successfully communicate the concepts of the Dietary Guidelines." The focus groups consist of four target audiences that have potentially different viewpoints on the Dietary Guidelines. The target audiences, which include elderly, overweight individuals, African-Americans, and food stamp recipients, have different health and dietary needs, attitudes, and practices. Furthermore, these individuals provide helpful information for identifying perceived barriers to following the Dietary Guidelines and making healthy food choices. Kennedy and associates reported four findings from the focus groups: consumers want dietary guidance translated into specific behaviors; consumers want clear and understandable terms used when communicating nutrition information; consumers want meaningful or specific reasons to change their current dietary behavior; finally, consumers distinguish between nutrition promotion and dietary guidance (Kennedy et al., 1996).

A study by Meier \& Straub (1993) compared the FDA's definitions of descriptive claims ("free", "no", "without", and "low") and relative claims ("fewer", "reduced", "light", "lite", and "less") with consumers perceptions. In the study, 192 subjects were administered twelve questions consisting of terms used to describe reduced amounts of energy, fat, or cholesterol found on food labels. Subjects were asked to place an $\mathrm{X}$ on a scale ranging from zero amounts to high amounts of energy, fat, or cholesterol. Meier \& Straub (1993) concluded that their findings agreed with the FDA's definitions of both descriptive and relative claims. 


\section{Nutritional Status of Americans}

\section{Introduction}

Although efforts have been made by various professional health organizations to inform the public about coronary heart disease and associated risk factors, coronary heart disease remains the major cause of death in the U.S. (Posner et al., 1995). Risk factors and lifestyle behaviors that may contribute to the development of coronary heart disease included: elevated blood pressure, elevated total blood cholesterol. cigarette smoking, diabetes mellitus, and a history of cardiovascular disease. In addition, obesity and physical inactivity are also risk factors for the development of coronary heart disease (Posner et al., 1995). A study looking at secular trends in diet and risk factors for cardiovascular disease using three periods of the Framingham Study (1957-1960, 1966-1969, and 1984-1988) revealed a decrease in total blood cholesterol concentration, systolic and diastolic blood pressures, and cigarette smoking during $1984 \cdot 1988$ compared to previous years whereas during the same time period, mean Body Mass Index, hypertension, and the prevalence of overweight were higher than previous years. Trends in both dietary intake and risk factors in the development of cardiovascular disease are important in the development and implementation of nutrition education programs (Posner et al., 1995). The following review will provide current information for blood pressure, weight, total blood cholesterol, and dietary intake. 


\section{Blood Pressure}

An estimated 50 million, or one out of every four, adults have high blood pressure in the U.S. (HHS, 1993). High blood pressure is defined as a mean systolic blood pressure of $\geq 140 \mathrm{~mm} \mathrm{Hg}$ and a mean diastolic blood pressure of $\geq 90 \mathrm{~mm} \mathrm{Hg}$ (HHS, 1994). In $1990,87 \%$ of adults in the U.S. had their blood pressure checked within the past year and approximately $16 \%$ of adults were informed on at least two occasions that they had high blood pressure (CDC, 1993). High blood pressure contributes to the development of cardiovascular disease, stroke, and renal failure (McCarron \& Ruesser, 1996). The strongest indicator of blood pressure is body weight in association with age. It is estimated that about $50 \%$ of adults in the U.S. could alleviate high blood pressure being managed pharmacologically with only moderate reductions in body weight (McCarron \& Reusser, 1996).

\section{Weight}

"Obesity is a condition in which excess fat may put a person at health risk" (ADA position paper, 1997, p. 71). Health risks associated with obesity include elevated blood pressure, elevated serum cholesterol levels, Type II diabetes, and coronary heart disease (HHS, 1990). In addition, obesity is associated with gallstones. osteoarthritis, sleep apnea, and cancers of the reproductive organs (Cummings et al., 1997). The estimated annual health care costs represented by obesity-related medical conditions in the U.S. is approximately $\$ 70$ billion (ADA position paper. 1997). As mentioned earlier, Healthy People 2000 has set national objectives for Americans in health promotion and disease prevention. Of the 21 nutrition objectives, overweight is addressed and states "reduce overweight to a prevalence of 
no more than $20 \%$ among people aged 20 and older and no more than $15 \%$ among adolescents ages 12 through 19" (Danford \& Stephenson, 1991; HHS, 1990, p. 30).

Studies indicate the prevalence of overweight in the U.S. has increased. For example, Kuczmarksi, Flegal, Campbell, \& Johnson (1994), examined trends in the prevalence of overweight and body mass index of the U.S. adult population from phase I of the third National Health and Nutrition Examination Survey (NHANES) study. Results indicate for the period of $1988-1991,33.4 \%$ of U.S. adults ages 20 years and older were estimated to be overweight with an increase of $8 \%$ since the second NHANES (1976-1980). The age-adjusted prevalence of overweight for men was $31 \%$ and for women $35 \%$. Overweight was defined as Body Mass Index (BMI) $>27.8$ for men and $>27.3$ for women. Furthermore, mean body mass increased from 25.3 to 26.3 and mean body weight increased $3.6 \mathrm{~kg}$. These data indicate that approximately one-third of adults in the U.S. are overweight.

In another study, Galuska, Serdula, Pamuk, Siegel, \& Byers (1996) examined trends in overweight among U.S. adults from 1987-1993. Researchers analyzed data from the Behavioral Risk Factor Surveillance System (BRFSS) from the years 1987-1993 and found the prevalence of overweight among American adults has increased by $5 \%$. In addition, the increased prevalence of overweight was observed in all subgroups of the population. Researchers hypothesized that changes in physical activity or smoking status may have contributed to the increase in prevalence of overweight; however, this could not provide an explanation for the increase in overweight.

Measures of obesity can be defined by Body Mass Index (BMI), waigt-to-hip ratio, and waist measurement. BMI is defined as weight in kilograms divided by height in meters squared. A BMI $>27$ represents obesity and the individual may be at health 
risk. Waist-to-hip ratio is considered to be a measure of regional fat distribution. A waist-to-hip ratio $>1.0$ for men and $>0.8$ for women is associsted with increased bealth risks. Finally, waist measurement can be associated with health risk if the measurement is $>40$ inches for men and $>35$ inches for women (ADA position paper, 1997).

The Expert Panel on Healthy Weight set forth to define healthy weight. The panel identified a healthy weight target and a healthier-weight goal (Tables 1 and 2). A healthy-weight target was defined as "a reasonable upper limit for body weight that would offer a reduction in disease risk and be within reach for most overweight adults" (Meisler \& St Jeor, 1996, p. 475S). The target healthy-weight is associated with a BMI of $<25$ for adults, which is converted to a height-to-weight ratio in inches and pounds for the public. This does not include children, adolescents, or the elderly as they have special needs and research revealed insufficient data for making necessary recommendations. The target healthy-weight specifically avoids a weight range as the panel believed that emphasis should be placed on reducing the risk of disease rather than allowing attention to be focused on achieving the endpoint as an ideal weight. Thus, incurring large weight losses that are not achievable and maintainable (Meisler \& St Jeor, 1996). 
Table 1. Healthy-Weight Target

(Meisler and St Jeor, 1996).

\begin{tabular}{|c|c|}
\hline Heighr lin) & weight maximum (Ib) \\
\hline s & 110 \\
\hline sy & 124 \\
\hline 60 & 128 \\
\hline (1) & 132 \\
\hline 6 & 136 \\
\hline $6 ?$ & 141 \\
\hline 6 & 145 \\
\hline 6.5 & 150 \\
\hline$\infty$ & 155 \\
\hline 0 & 199 \\
\hline$\omega^{\circ}$ & 164 \\
\hline$\infty$ & 169 \\
\hline 70 & 174 \\
\hline 71 & 179 \\
\hline 7: & 180 \\
\hline $7:$ & 187 \\
\hline 71 & 196 \\
\hline 7.4 & 200 \\
\hline 76 & 2005 \\
\hline
\end{tabular}

'To consere values io SI wite: beighe in inches $\times 2.54$ - height in centimeters: weight in pounds $\times 0.4536=$ wight in kilograme.
Table 2. Healthier-Weight Goal (Meisler and St Jeor, 1996).

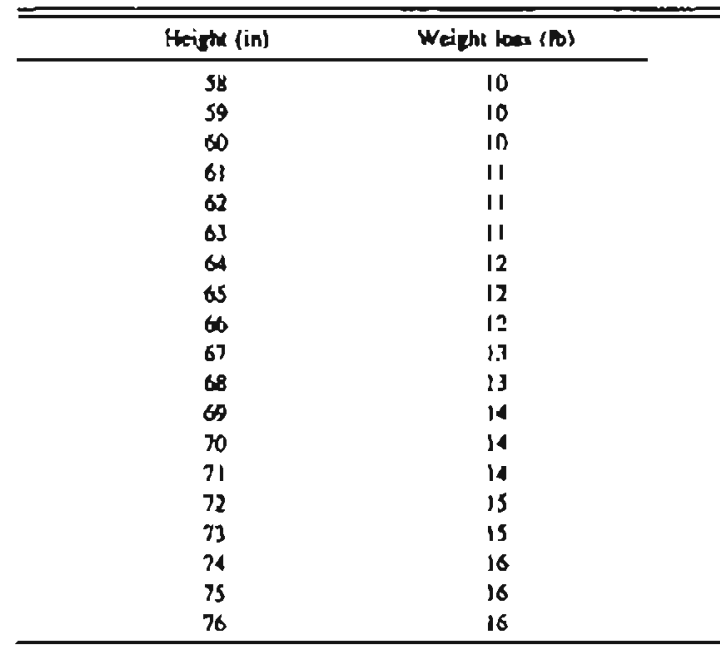

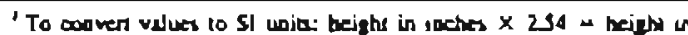

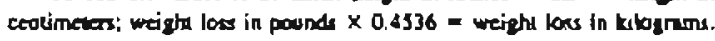

Since about one-third of the U.S. population exceeds the healthy-weight target. the panel developed the healthier-weight goal. The healthier-weight goal emphasizes weight loss at an amount that reduces disease risk and emphasizes that even moderate amounts of weight loss are considered to be sufficient. The healthierweight goal is achieving a weight loss of about $4.5-7.3 \mathrm{~kg}$ (10-16 pounds) or the equivalent to approximately two BMI units. This is for individuals who exceed the healthy-weight goal, but have not been diagnosed with a weight-related disease or condition (Meisler \& St Jeor, 1996).

The Expert Panel on Healthy Weight also emphasized the importance of stabilizing weight for a period of six months or more after weight loss has been achieved so that the new weight becomes the usual body weight. In addition, the panel recommended maintaining a constant body weight, adopting a healthy diet, and performing at least 30 minutes of moderate physical exercise daily (Meisler \& St 
Jeor, 1996). This is in agreement with the goal of Healthy People 2000 objective 2.7 that states "increase to at least $50 \%$ the proportion of overweight people aged 12 and older who have adopted sound dietary practices combined with regular physical activity to attain an appropriate body weight" (HHS, 1990, p. 33). This is also consistent with the 1995 Dietary Guidelines that recommends balancing the food you eat with physical activity - maintain or improving your weight. Although experts agree that a weight loss of 5 to 10 pounds may help to lower blood pressure, blood lipids, glucose tolerance, insulin resistance, and protect heart muscle mass, $24 \%$ of American adults are sedentary and $54 \%$ spend inadequate time performing physical activity (USDA, 1995; Meisler \& St Jeor, 1996; ADA position paper, 1997).

Obesity is complex in origin, but research has identified factors such as genetic, biochemical, metabolic, physiological, and psychological that may contribute to overweight (ADA position paper, 1997). Furthermore, environmental, socioeconomic, as well as cultural factors play a role in obesity (HHS, 1990). The treatment of obesity is centered around the concept of weight management or achieving the best weight possible for overall health. Weight management is defined as adopting and maintaining healthy eating and exercise behaviors that reduce the risks of disease (ADA position paper, 1997). The American Dietetic Association recommends that weight management programs focus on lifestyle changes with three goals in mind: gradual change in healthy eating patterns, a nonrestrictive approach to eating with close attention to hunger and satiety cues, and a gradual increase to 30 minutes of physical activity per day (ADA position paper, 1997).

Approximately $40 \%$ of adult women and $20 \%$ of adult men are trying to lose weight at any one time (Heaton \& Levy, 1995). Whether the weight loss is 
successful depends on a number of factors. For example, the traditional weight loss approach is that a person can control their weight and redesign their body shapes regardless of genetics. Also, weight goals were set according to standardized tables and restrictive dieting was used to accomplish the unmaintainable goals. This approach to weight loss has failed to produce lasting weight loss as weight cycling and disordered binge eating may result from very-low-calorie diets (Cummings et al., 1997). According to the American Dietetic Association, successful weight management for adults requires a lifelong commitment to both a healthy lifestyle and healthy eating behaviors. Weight management interventions that are based on cognitive-behavioral methods, such as counseling about self-esteem and body image, coping with societal pressures of weight, and problem-solving approaches to weight maintenance, have been successful. Finally, a support system whether a group or a family member is important (ADA position paper, 1997).

\section{Blood Cholesterol}

A study looking at the prevalence of high blood pressure among U.S. adults was conducted based on guidelines from the second report of the National Cholesterol Education Program (NCEP) Adult Treatment Panel (Sempos et al., 1993). In this study, data from 7,775 participants ages 20 years and older were used from phase 1 of the third National Health and Nutrition Examinations Survey (NHANES III) and data from 9,797 participants ages 20-74 years were used from NHANES II. The data revealed that the proportion of adults with high blood cholesterol levels fell from $26 \%$ to $20 \%$ while the proportion with desirable levels rose from $44 \% .49 \%$ (Sempos et al., 1993). Furthermore, adults who have been informed that they have 
high blood cholesterol are taking steps to lower it (Anderson \& Waters, 1995). Blood cholesterol levels $>240 \mathrm{mg} / \mathrm{dL}$ are considered to be high and $<200 \mathrm{mg} / \mathrm{dL}$ are considered to be desirable (U.S. Department of Health and Human Services, 1994). According to a Cholesterol Awareness Survey, improvements in blood cholesterol knowledge, attitudes, and practices have increased. For example, in 1986 only $46 \%$ of people responded yes when asked if they have ever had their blood cholesterol checked. In 1990, $65 \%$ of people surveyed responded yes when asked if they have ever bad their blood cholesterol checked (Van Horn et al., 1995). High blood cholesterol levels contribute to coronary heart disease and experts suggest that a $10 \%$ reduction in serum blood cholesterol levels, achieved by diet alone, could decrease coronary heart disease rates of about 20\% (AHA, 1990).

\section{Dietary Intake}

Objective 2.6 of Healthy People 2000 states "increase complex carbohydrate and fiber-containing foods in the diets of adults to five or more daily servings for vegetables (including legumes) and fruits, and to six or more daily servings for gram products" (HHS, 1990). The importance of consuming fruits and vegetables has been well documented. Steinmetz \& Potter (1996) have conducted a review of vegetables, fruits, and cancer prevention. Not only does research indicate the protective effects of fruits and vegetables for cancers, but for cardiovascular disease, diabetes, obesity, stroke, cataracts, and diverticulosis as well. Despite this evidence, fewer than one-third of Americans consume the recommended daily intake of fruits and vegetables (Anderson \& Waters, 1995). According to the Executive Summary from the Third Report on Nutrition Monitoring in the United States, between 1989. 
1991, the average daily intake of fruits and vegetables is about 4 servings (Anderson \& Waters, 1995). Similar findings were reported by Krebs-Smith et al. (1995), who examined Americans' fruit and vegetable intakes based on the Continuing Surveys of Food Intakes by Individuals from 1989-1991. They determined that the mean intake of fruits and vegetables was 4.3 servings per day. In particular, mean intake of fruits was 1.2 servings per day and mean intake of vegetables was 3.1 servings per day. Both studies suggest a need for identifying barriers to eating fruits and vegetables and furthermore, provide practical advice on how to consume more fruits and vegetables. Dittus, Hillers \& Beerman (1995), conducted a study examining attitudes toward nutrition and reported fruit and vegetable intake of 1.069 subjects. In the study, attitudes relating to nutritional benefits, cancer-preventative characteristics of fruit and vegetable intake, and perceived barriers to fruit and vegetable intake where scored. Using a multiple regression analysis, results indicated $16 \%$ of the variance in fruit and vegetable intake accounted for attitude variables, while perceived barriers to fruit and vegetable intake accounted for the greater amount of variability in nutrition behavior. Researchers reported the likeliness of perceived barriers that prevent healthy behavior may decrease concern about health issues. Potential barriers to fruit and vegetable intake may include availability, preparation, cost, and concern about pesticides (Dittus et al., 1995). A diet that emphasizes complex carbohydrates and fiber is recommended by several professional health care organizations because of their preventive and therapeutic properties (ADA position paper, 1993). Dietary fiber has been shown to be beneficial in the management of cardiovascular disease, diabetes, and obesity and health professionals recommend a diet containing 20.35 grams of dietary fiber from a variety of foods (ADA position paper, 1993). According to the Executive Summary 
from the Third Report on Nutrition Monitoring in the U.S., median intakes of total carbohydrate and dietary fiber were lower than recommended values in 1989-1991 (Anderson \& Waters, 1995). Furthermore, USDA 's Healthy Eating Index revealed that $<20 \%$ of Americans consumed the recommended daily servings of grains, fruits, and vegetables (USDA website, 1997).

Another objective of Healthy People 2000 is to increase the intake of calcium (HHS, 1990). Calcium is essential in the development and maintenance of bones and teeth and is one of the factors that affect peak bone mass (HHS, 1990; Fleming \& Heimbach, 1994). Low calciura levels is just one factor in the development of osteoporosis; however, the optimal level of calcium intake for development of peak bone mass and how much calcium is needed to prevent osteoporosis is still being debated (HHS, 1990). Current recommendations suggest $800 \mathrm{mg}$ for children 4 to 8 years of age, $1300 \mathrm{mg}$ for youth 9 to 18 years of age, $1,000 \mathrm{mg}$ for adults 19 to 50 years of age, and $1200 \mathrm{mg}$ for adults over 50 years of age (NAS website, 1997). Fleming \& Hembach (1990) conducted a study investigating the consumption of calcium in the U.S. revealed that mean daily intake of calcium for the total U.S. population was only $737 \mathrm{mg}$ and varied by household income, ethnic group, sex, agc, and region of the country. The study found that at least $50 \%$ of calcium was provided by milk and milk products and calcium intake generally decreased with age for both males and females. Furthermore, USDA's Healthy Eating Index found that fewer than one-third of Americans consumed the recommended number of daily servings of milk (USDA website, 1997).

The Recommended Dietary allowance (RDA) of protein for females and males is different depending on age as is shown Table 3 (National Research Council, 1989). The Dietary Pattern and Intake Report, commissioned by the National Live Stock 
and Meat Board (1994), surveyed 2,000 households on their protein intake. The report found that Americans on the average are consuming about 67.5 grams of protein per day, with meat accounting for about $55 \%$ of intake. According to the Executive Summary from the Third Report on Nutrition Monitoring in the United States, the median intake of protein in the American diet is above Recommended Dietary Allowances (RDA) for most demographic groups (Anderson \& Waters, 1995). Another objective of Healthy People 2000 is to reduce both the intake of dietary fat to $<30 \%$ of calories and saturated fat to $<10 \%$ of calories (HHS, 1990). Studies suggest that high levels of dietary fat intake increase risks of obesity, some types of cancer, and coronary heart disease (HHS, 1990). According to the Executive Summary from the Third Report on Nutrition Monitoring in the United States, total fat and saturated fat intakes have continued to stay above recommended levels and mean total fat, expressed as a percentage of calories, was $34 \%$ (Anderson \& Waters, 1995). Similar findings are reported in USDA's Healthy Eating Index. The Healthy Index suggests that less than $20 \%$ of Americans consume $30 \%$ or less of calories from fat and less than $10 \%$ of calories from saturated fat (USDA website, 1997). 
FUOD AND NUTRITION BOARO. NAJIONAL ACADEMY OF SCIFANCES-NATIONAL RESEARCH COUACIL MECOMMENDED DIETARY AIIINWANCES" Revined ISAG

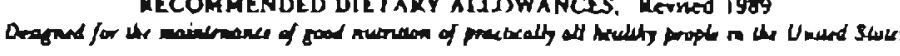

\begin{tabular}{|c|c|c|c|c|c|c|c|c|c|c|c|c|c|c|c|c|c|c|c|c|c|c|c|c|}
\hline \multirow[b]{2}{*}{ corrony } & \multirow[b]{2}{*}{$\begin{array}{l}\text { Age (yesrs) } \\
\text { or Candition }\end{array}$} & \multirow{2}{*}{\multicolumn{2}{|c|}{ Weighe" }} & \multirow{2}{*}{\multicolumn{2}{|c|}{ Heyslin" }} & \multirow[b]{2}{*}{$\begin{array}{l}\text { Prulkin } \\
\text { (k) }\end{array}$} & \multicolumn{4}{|c|}{ Fis Soluble Yirames } & \multicolumn{7}{|c|}{ Wyernsalubte Viumins } & \multicolumn{7}{|c|}{ Mineralt } \\
\hline & & & & & & & $\begin{array}{l}\text { Viu. } \\
\min \hat{A} \\
(\mu k M)^{\prime}\end{array}$ & $\begin{array}{l}\text { Vics. } \\
\text { tuin } \\
(\mu, s)\end{array}$ & 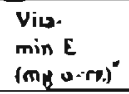 & 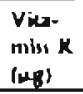 & $\begin{array}{l}\text { Vitz. } \\
\text { nin } 6: \\
\text { (mik) }\end{array}$ & $\begin{array}{l}\text { This- } \\
\text { ninin } \\
\text { (nik) }\end{array}$ & $\begin{array}{l}\text { Yibor } \\
\text { Azsin } \\
\left(m_{y}\right)\end{array}$ & $\begin{array}{l}\text { Nixuri } \\
\text { ('ing Mal' }\end{array}$ & $\begin{array}{l}\text { vira } \\
\text { min } B_{k} \\
\text { (ang) }\end{array}$ & $\begin{array}{l}\text { Fo } \\
\text { lace } \\
(\mu K)\end{array}$ & $\begin{array}{l}\text { Viumin } \\
B_{i t} \\
(1 \mu y) \\
\end{array}$ & $\begin{array}{l}\text { cil. } \\
\text { ciuin } \\
\text { (nnp) }\end{array}$ & $\begin{array}{l}\text { Phos: } \\
\text { gnesr ut } \\
\text { (iing) }\end{array}$ & $\begin{array}{l}\text { Mag. } \\
\text { najum } \\
\text { (mg) }\end{array}$ & $\begin{array}{l}\text { Iron } \\
\text { (mpl) }\end{array}$ & $\begin{array}{l}2 i_{1 k} \\
\left(m_{\beta}\right)\end{array}$ & $\begin{array}{l}\text { lodine } \\
\text { (He) }\end{array}$ & $\begin{array}{l}\text { Solk. } \\
\text { nium } \\
(k y)\end{array}$ \\
\hline \multirow[t]{2}{*}{ Ingint } & $0.0-0.5$ & 6 & 13 & 的 & 24 & I & 973 & 73 & 9 & 3 & 30 & 0.9 & 0.4 & 3 & 0.3 & 23 & 0.1 & now & $s(x)$ & 40 & 6 & $\mathbf{s}$ & 10 & 10 \\
\hline & $0.9-1.0$ & $\mathbf{y}$ & $\$ 0$ & 71 & 28 & 14 & Y73 & 10 & 1 & 10 & 35 & 0.4 & 0.3 & 0 & 0.5 & 35 & 0.5 & WOS & 3011 & اله & 10 & 3 & 30 & 19 \\
\hline \multirow[t]{3}{*}{ Oilsen } & $1-9$ & is & 29 & \$0 & y5 & 16 & 400 & in & 0 & 15 & 10 & u.7 & 0.4 & ! & 1.0 & so & 0.7 & 800 & dext & Bu & 10 & 10 & 70 & $=0$ \\
\hline & 46 & 80 & 14 & 118 & 14 & 24 & $5(x)$ & 30 & 7 & 20 & 15 & 0.0 & 1.1 & 12 & 1.1 & 73 & 10 & 800 & B04 & 120 & 10 & 10 & 90 & 20 \\
\hline & $7-10$ & 29 & 68 & 198 & $5 \%$ & $8 \%$ & 700 & 10 & 7 & 10 & 45 & 1.0 & 1.2 & 15 & 14 & 100 & 1.4 & 804 & 2000 & 1713 & 10 & 10 & 190 & so \\
\hline \multirow[t]{5}{*}{ בע山 } & $11-14$ & is & 99 & 197 & $6 x$ & is & 1,000 & 20 & 10 & 45 & 50 & 1.9 & 15 & 17 & 1.7 & 150 & 20 & 1.800 & 1.900 & 270 & IY & is & 150 & 10 \\
\hline & $|s-|||$ & 66 & $1+19$ & 176 & 69 & 39 & 1.000 & 10 & 10 & 63 & 60 & 1.5 & 1.8 & 90 & 2.0 & 200 & 2.0 & 1.900 & 1,200 & 100 & 12 & is & 130 & 30 \\
\hline & $19-21$ & 72 & 160 & 177 & 70 & 38 & 1,000 & 10 & 10 & 70 & 60 & 18 & 1.7 & 19 & 2.4 & 100 & 8.0 & 1,200 & 1.200 & ISN & 10 & 15 & 130 & 70 \\
\hline & $2 x-30$ & 79 & 174 & 176 & 70 & Gs & 1,000 & 5 & 10 & 80 & 60 & 1.5 & 17 & פו & 2.0 & 200 & 20 & 800 & 800 & $35 n$ & 10 & 15 & 150 & 70 \\
\hline & $31+$ & 77 & 170 & 273 & is & 63 & 1,4000 & 3 & 10 & 10 & 60 & 1.2 & 1.4 & 15 & 2.0 & 200 & 2.0 & 800 & 500 & $\$ 50$ & 10 & is & 130 & 70 \\
\hline \multirow[t]{5}{*}{ 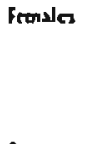 } & $11-14$ & 46 & 101 & 157 & $0^{4}$ & 16 & 800 & 10 & 8 & 45 & so & 1.1 & 1.9 & 15 & I. & 150 & 2.0 & 1,800 & 1.800 & 280 & is & 18 & 130 & 45 \\
\hline & $13-18$ & 35 & 180 & 109 & bit & 11 & 800 & 10 & 8 & 35 & 60 & I.I & 1.9 & 13 & 1.3 & 180 & 8.0 & 1,800 & 1.200 & 900 & 15 & 12 & 150 & 50 \\
\hline & $14-21$ & 58 & 120 & 104 & 63 & 46 & 800 & 10 & 8 & 60 & 60 & L. I & 1.9 & 13 & 1.6 & I 80 & 2.0 & 1,100 & 1.200 & 280 & 15 & 18 & 130 & 55 \\
\hline & rs-so & 63 & 198 & 165 & of & 50 & 000 & 5 & A & 63 & $\infty$ & i. & $1 . y$ & 15 & 1.6 & 180 & 2.0 & 800 & 800 & 280 & is & 18 & 150 & 53 \\
\hline & $31+$ & B5 & 149 & 160 & as & 5t & 800 & 3 & $y$ & 65 & 60 & 1.0 & 1.2 & 13 & 1.6 & 160 & 2.0 & 800 & 800 & $2 U U$ & 10 & 18 & 130 & 55 \\
\hline & & & & & & 60 & 800 & 10 & 10 & 63 & 20 & 1.5 & 16 & 17 & 2.2 & 400 & Q. .9 & 1,800 & 1.200 & 9(1) & 90 & 13 & 175 & 65 \\
\hline \multirow{2}{*}{ Lausing } & lal 6 manusu & & & & & os & 1,900 & 10 & 12 & 63 & 95 & 1.6 & 1.8 & 80 & 2.1 & 280 & 2.6 & $1.2(x)$ & 1.200 & 355 & is & 19 & 200 & 73 \\
\hline & 2nd 6 mumbs & & & & & 68 & 1,200 & 10 & II & 6.5 & 9s & 1.6 & 1.7 & $2 n$ & 11 & 200 & 4.6 & 1.200 & 1.200 & 940 & 13 & 16 & 200 & 35 \\
\hline
\end{tabular}

derigrand age. Ja reperired by NHANE'S II. The medan weights and heighu of Illase under

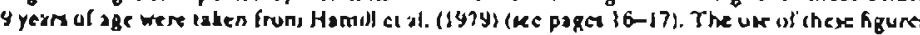
lil ivions ate idlest. 
Subar et al., (1994) examined dietary patterns associated with either low or high fat intake. Data from the 1987 National Health Interview Survey were used and of 20,143 adults, the mean percentage intake of calories from fat was $38.4 \%$. The study showed that the percentage of calories from fat in the diet was correlated with specific nutrients and food groups across demographic variables, such as sex, age, race, income, and education. A high positive correlation was found between the percentage of calories from fat and high fat food groups and negative correlations were found with folate, fiber, vitamin $C_{1}$ carotene, carbohydrate, and similar food groups. The study also found that a decrease in percentage of calories from fat was compensated with an increase in percentage of calories from carbohydrate rather than protein, since protein and fat occur together in foods (Subar et al., 1993).

Millen et al. (1997) conducted a study investigating nutrient intake levels and adherence to current dietary recommendations in 2,520 Framingham men and women for the years of 1991-1995. The study found that only $37 \%$ consumed $<30 \%$ of calories from fat and $43 \%$ met the recommendation for saturated fat intake. Participant's adherence to recommended amounts of carbohydrate was moderate (43\%), while dietary fiber was low $(28 \%)$. Furthermore, only one third of participants consumed the dietary recommendation for calcium while more than $75 \%$ met the recommendations for protein. In addition, $70 \%$ met the recommended intakes of polyunsaturated and monounsaturated fat, cholesterol, vitamins $C$ and $B$. 12, and folacin; however, about half or fewer met the recommendations for betacarotene, vitamins A, E, and B-6 (Millen et al., 1997). 


\section{Cognitive and Behavioral Skills of Food and Nutrition}

Introduction

The development of the Food Guide Pyramid, the Dietary Guidelines for Americans, and the passage of the Nutrition Labeling and Education Act are efforts to reduce the risk of chronic disease and enhance health. Diel is considered a key component in health promotion and disease prevention. It is critical to examine consumer's health attitudes, nutrition knowledge, dietary behavior, and safe food handling practices in order to promote healthy eating and lifestyles and to identify areas for improvement.

\section{Health Attitudes}

America's concern about health and interest in nutrition is growing. The American Dietetic Association (ADA, 1993) in joint sponsorship with Kraft General Foods, surveyed 1,000 adults ages 25 and older to determine their attitudes. knowledge, and behavior toward nutrition and diet. The results indicated that $82 \%$ of adults recognized the importance of good nutrition. In addition, $69 \%$ cited the reason for being concerned about diet and nutrition was the general desire for health maintenance.

The Food Marketing Institute (FMI, 1996) along with Prevention magazine also surveyed 1,000 adults to determine their understanding and concern about nutrition and health issues, and how these issues affected purchasing behavior. The survey found that $51 \%$ of consumers bad changed their diets within the last three years because of health concerns. In addition, consumers cited "losing weight" as the primary reason for making dietary changes (32\%), followed by "high cholesterol" 
(17\%), and "heart disease" (15\%). Finally, 10\% cited "high blood pressure" as a reason for making a change in their diet. Consumers are also becoming seemingly aware of the relationship between diet and overall health. For example, $96 \%$ viewed diet as a major factor for high blood cholesterol and $93 \%$ thought diet had a role in heart disease. In addition, consumers believed that high blood pressure (92\%). stroke (81\%), and diabetes (74\%) were linked to diet (FMI, 1996).

Another survey (FMI, 1997) examined consumer attitudes and the supermarket. Ninety-three percent of 1,011 shoppers were concerned about the overall nutritional content of their food. Fifty-six percent of shoppers were concerned with fat, $23 \%$ were concerned with sodium, and $20 \%$ were concerned with cholesterol. Concern does not necessarily lead to action as $73 \%$ of shoppers believed their diets could be healthier.

Price, convenience, and taste are also important factors for consumers when shopping for healthier diets. The FMI (1996) reported that $83 \%$ of 1.000 shoppers agreed that nutrition is more important than price; however, $57 \%$ agreed with the statement that eating healthy foods costs more. Furthermore, $57 \%$ of shoppers disagreed with the statement taste is more important than nutritional quality. Finally, 29\% believed healthy foods were not convenient to make. For the most part, consumers view taste, nutrition, product safety, and price as imporiant factors when shopping for food, but perceive taste, time, and confusion as obstacles for good nutrition (FMI, 1997; ADA, 1993).

Today, shoppers have a wider variety of healthy products to choose from. Manufacturers have expanded their product lines to include "low-calorie", "sugarfree", "reduced-fat", "fat-free", "low cholesterol", "cholesterol-free", "reduced-sodium", and "sodium-free." Consumers who opt for low-fat alternatives do so primarily for 
health reasons. When making bealthy food selections, consumers do not believe taste has to be compromised. For example, consumers "think that 'low-fat' or 'fatfree' products can taste as good as, if not better than, the regular variety" (FMI, 1996). In fact, consumers often select the lower-fat alternative when shopping. For instance, "low-fat" or "fat-free" products that consumers tend to choose include salad dressing (74\%), ice-cream (57\%), crackers (55\%), mayonnaise (55\%), cookies (51\%), sour cream (51\%), and cheeses (50\%). Also, "low-fat" or "fat-[ree" chips and cakes were selected over the higher fat equivalents (FMI, 1996).

The terms "low-fat" or "fat-free" do not necessarily imply that shoppers can indulge entirely. Although $61 \%$ of the 1,000 shoppers agreed that a food labeled "low-fat" or "fat-free" does not mean that they can eat more, $34 \%$ felt that it was okay to do so. Furthermore, $14 \%$ admitted to eating more of the "low-fat" or "fatfree" foods rather than the original food (FMI, 1996). Although consumers' attitudes express concern about diet and bealth, accurate nutrition knowledge is also a factor in achieving a healthy diet.

\section{Nutrition Knowledge}

Although the public is concerned about diet and health, surveys show that consumers lack the knowledge and skills in applying dietary recommendations toward food choices and overall diet quality (IOM, 1991). The ADA (1993) revealed that $27 \%$ of 1,000 consumers rated themselves as being knowledgeable about dietary guidelines; however, only $9 \%$ could correctly identify the recommended guideline for the percent of calories from fat and only $6 \%$ of consumers could 
correctly identify the recommended fat grams per day. In addition, no one could identify the recommended guideline for sodium or cholesterol.

The National Live Stock and Meat Board (1994) also revealed consumer confusion surrounding dietary recommendations. Although dietary guidelines recommend choosing a diet with no more than $30 \%$ of calories from fat, only $9 \%$ of consumers were able to recognize the false statement "No more than $30 \%$ of the calories in a food should come from fat." It appears that consumers are unclear about the dietary guideline for fat as it applies to the overall diet rather than one particular food. The results of this study indicate that consumers demonstrated low levels of knowledge when asked to identify specific dietary guidelines.

Similar findings were reported by the International Food Information Council (IFIC, 1993) for consumer's knowledge on diet and nutrition. Only $30 \%$ of 754 adults surveyed were familiar with the Food Guide Pyramid. Despite the lack of familiarity with the Food Guide Pyramid, 94\% agreed that balance, variety, and moderation were important for healthy eating. In addition, $60 \%$ of those surveyed agreed that high-fat foods can be incorporated into a healthy diet as long as they are. balanced with low-fat food choices, and $56 \%$ agreed that any food can be part of a healthy diet. Furthermore, $92 \%$ agreed that controlling serving size is important to maintain a healthy diet.

Consumers may seek nutrition advice from unreliable sources to increase their knowledge and understanding of diet and nutrition. According to FMI (1996), 64\% of 1,00 consumers read magazines for information on food and nutrition while $58 \%$ of consumers referred to books. Other sources for information on food and nutrition included friends or family (55\%), television (51\%), newspapers (49\%), and displays or handouts in grocery stores (47\%). Unfortunately, a health professional (42\%), was 
the last source consumers turned to for nutrition information. Not using reliable sources for nutrition information can lead to consumer confusion and misinformation.

Although major health organizations agree on the general principles of healthy eating, consumers fail to grasp them clearly because of the overwhelming amount of information and seemingly conflicting advice (Hudnall \& Wellman, 1992). According to the IFIC (1994), $27 \%$ of 754 adults surveyed reported feeling very or somewhat confused about how to eat a healthy diet. Consumers surveyed were most confused about "deciding what to eat" (14\%), followed by "conflicting reports" on nutrition and health (11\%) and "labeling of foods" (11\%). Finally, $9 \%$ of consumers were confused about the "amount of fat in foods".

Not only are consumers confused with knowing how to eat a healthy diet, but they also have misconceptions about a healthy diet. For example, The National Live Stock and Meat Board (1994) reported that only $47 \%$ of 2,000 consumers agreed with the statement "All foods in moderation provide a healthy diet". Furthermore, only $32 \%$ disagreed with the statement "trying to eat healthy is too complicated and confusing".

Although consumers are aware of the basic concepts of balance, variety, and moderation, they are not putting them into practice (Hudnall \& Wellman, 1992). Consumers still believe in the concept of "good" and "bad" foods and that in order to have a healthy diet, they must give up the foods they like (ADA, 1993). An individual's knowledge about diet and health alone is unlikely to change dietary behavior (IOM, 1991). 


\section{Dietary Behavior}

Understanding human-nutrition related behavior guides in the development of models that demonstrate how consumers make decisions, why they decide on a particular course of action, and how they implement their action as sustained behavior change (Schwartz, 1996). There are many factors that influence the development, maintenance, and change of dietary patterns (O'Donnell \& Harris, 1994). Health promotion strategies that are centered around factors that affect individual food choices have a greater chance of producing positive dietary change (Frankle \& Owen, 1993). As Figure 3 illustrates, food intake behavior is based on the sociocultural environment, the ecological environment, and the biological environmeat (Parraga, 1990). The sociocultural environment includes societal variables, cultural variables, and individual variables. The societal variables involve national economy, technology, politics, and social organization. The cultural variables consist of values, beliefs, customs, and symbolisms. The individual variables are income, education, occupation, socialization, nutrition knowledge. attitudes, and food preferences. The ecological environment include geography, climate, topography, and soil. Finally, the biological environment includes nutrient. requirements, life cycle, health status, genetic limitations, and taste physiology (Parraga, 1990). 


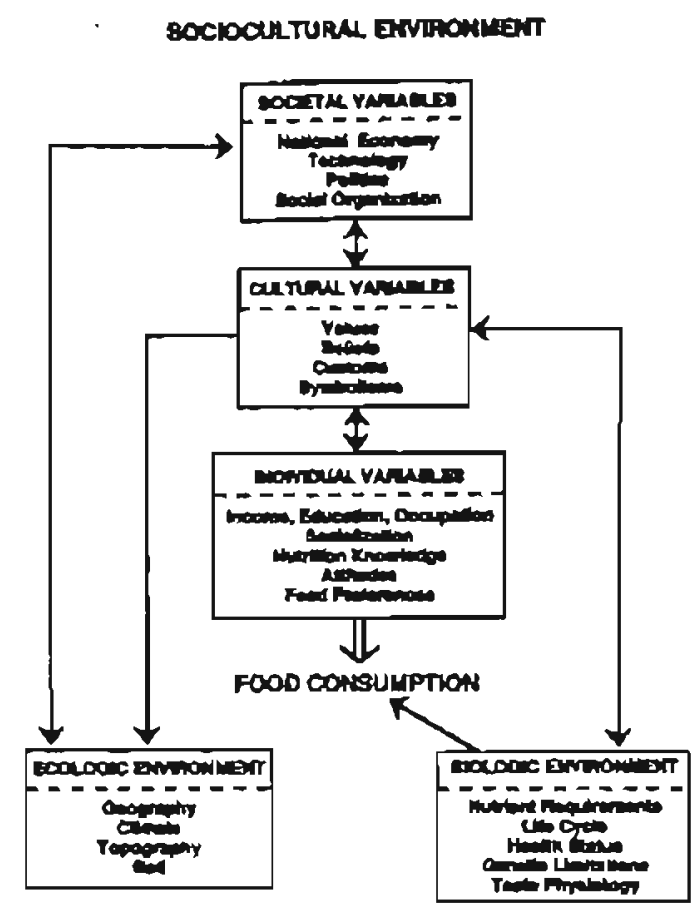

Figure 3. Determinants of Food Intake Behavior (Parraga, 1990).

Although consumers are aware of the importance of nutrition and its impact on health, action to improve dietary patterns and behavior are not easy to achieve. Food selection, food preparation, and food label reading can be considered measures of dietary behavior.

The ADA (1993) found that only $37 \%$ of 1,000 consumers are "highly" careful in food selection in their efforts to achieve an overall healthy diet. When asked to indicate what things they specifically did to achieve a healthy diet, consumers said they added more fruits and vegetables and monitored fat intake. In addition, consumers are most careful about the consumption of saturated fat, vitamins and minerals, cholesterol, and sodium.

Few studies evaluate food preparation techniques; however, the percentage of consumers who say they cook or prepare foods differently since 1985 has increased 
(IOM, 1991). Consumers have reported eating less fried foods and red meat, using fewer fats and oils, and consuming less salt. In addition, consumers have indicated eating more fruits and vegetables and chicken (FMI, 1997).

Another measure of dietary behavior is the use of the "Nutrition Facts" Label. Nutrition labeling on food packages is an educational tool that can help consumers make informed choices on the product they are purchasing. By comparing the nutritional values of different brands or foods, the nutrition food label enables consumers to make more healthy food choices. The food label can also assist consumers in comparing new food products with more familiar ones (Bender \& Derby, 1992). Food labels also provide information to assist consumers in counting calories or selecting certain foods for special diets.

Guthrie, Fox. Cleveland \& Welsh (1995) conducted a study investigating characteristics of individuals who use the food label and the effect the food label has on overall diet quality. Researchers used a theoretical model of determinants influencing label use, shown in Figure 4. Determinants affecting label use included individual characteristics, situational variables, marketing environment, producl importance, knowledge, and consumer decision-making strategy. In the study, individual characteristics were age, sex, and education. Situational variables accounted for employment, household type, and physical health concerns. The marketing environment was comprised of geographical regions and the level of urbanization. Product importance consisted of taste, nutrition, price, ease of preparation, product safety, and how well a food keeps. Knowledge was assessed by scoring responses to several nutrition knowledge questions. Finally, the consumer decision-making strategy included those individuals who displayed health-seeking values and attitudes, such as following the Dietary Guidelines for Americans 
(Guthrie et al., 1995). Of the 1,901 respondents surveyed, $71 \%$ of meal planners/preparers were considered to be label users. Label users were defined as using the nutrition label "sometimes" or "always." The remaining $29 \%$ were considered to be nonusers who "rarely" or "never" used the "Nutrition Facts" label. Guthrie et al. (1995), found in their study that individuals most likely to use the nutrition label were the following: women who lived with others and had at least some college education; knowledgeable about nutrition, believed that nutrition and product safety were more important than taste when shopping for food; and displayed health-seeking values and attitudes, sucb as following the Dietary Guidelines for Americans. The researchers also found the food label had an effect on diet quality. In the study, "label users had a lower cholesterol intake per 1,000 calories." In addition, diets of label users were higher in vitamin C.

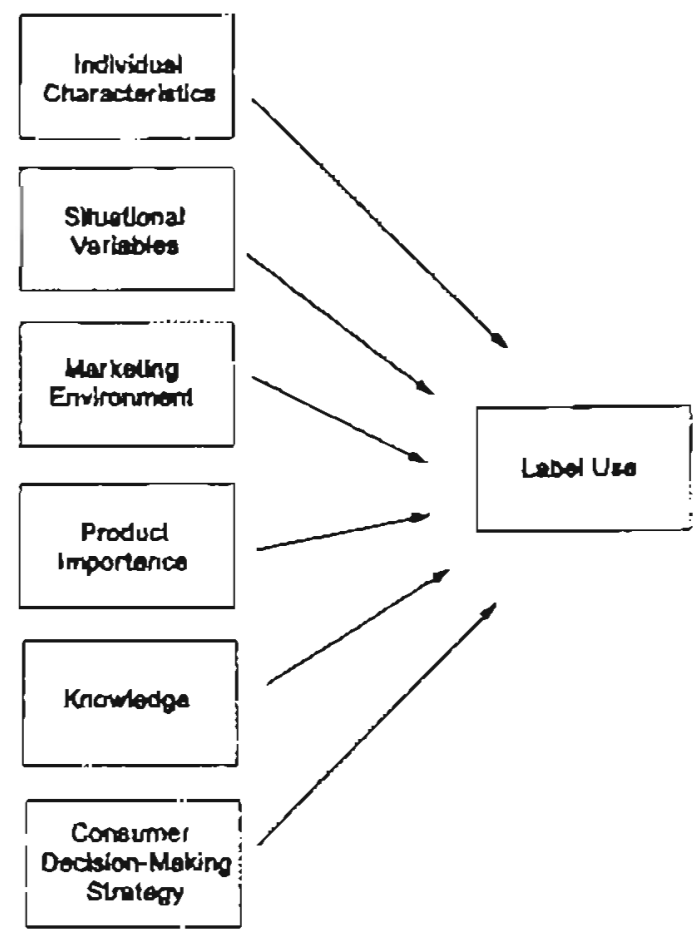

Figure 4. Determinants of Label Use (Guthrie, et al., 1995) 
Bender \& Derby (1992) observed similar findings when they compared several Food and Drug Health and Diet Surveys administered in 1982-1988 that identified consumers who said they read nutrition and ingredient information on food labels. They looked at variables such as demographics, measures of health status, nutrition knowledge, and adherence to special diets, in order to distinguish between label users and nonusers. They found that users of both nutrition and ingredient information on food labels were young educated women who were following a "selfinitiated" or "doctor-prescribed" low sodium diet.

The FMI (1996) also reported that shoppers who changed their diets and eating habits for health reasons were more likely to read the food label and ingredient list before making a purchase. For instance, $58 \%$ of 1,000 shoppers "almost always" read the nutrition label when buying a product for the first time compared to $17 \%$ who "hardly ever" or "never" read the nutrition label before making a first-time purchase. Similar findings were reported with the ingredient label.

According to another survey (FMI, 1997), 90\% of the 1,011 shoppers considered the nutrition label format and wording "very useful" and "somewhat useful." When shoppers were asked what they considered to be useful on the food label, $61 \%$ thought fat content was useful and $37 \%$ felt the list of ingredients was helpful. In addition, 30\% felt the number of calories and the amount of sodium was useful on the food label and $61 \%$ of shoppers said they had "changed purchases because of information on the product nutrition label." The survey also revealed that shoppers were inclined to buy products labeled "low-fat", "low-cholesterol", and "low-sodium." 


\section{Food Safety}

Safe food handling practices result from awareness and knowledge of food pathogens and methods of transmission. It is estimated that 12.6 million cases of foodborne illness occur in the U.S. each year incurring a substantial cost of $\$ 8.4$ billion (Todd, 1989). In the prevention of foodborne ilness, consumers play an important role in food safety during acquisition, preparation, serving, storage, and proper handling of leftovers (Knabel, 1995).

Studies have been conducted to investigate consumer knowledge of foodborne hazards and safe food-handling practices. In a study by Altekruse, Street, Fein, and Levy (1996), 1,620 consumers at least 18 years of age were surveyed on their recognition of foodborne pathogens and foods at risk for transmission. In addition, consumers were surveyed about their awareness and knowledge of food safety principles and their food handling practices such as washing hands, cooking meat thoroughly, and taking precautions to prevent cross contamination.

The pathogens that consumers were most aware of were salmonella $(80 \%)$ and botulism (75\%). The pathogens that consumers were least aware of were listeria $(10 \%)$ and campylobacter $(5 \%)$. When consumers were asked what foods were specifically associated with the risk for transmission of foodborne pathogens, responses where highest for salmonella (54\%), trichinosis (26\%), and botulism (23\%). Less than $15 \%$ surveyed knew foods associated with the risk for transmission of hepatitis, cholera, staphylococcus, listeria, and campylobacter (Altekruse et al., 1996).

According to Altekruse et al. (1996), consumers are aware of safe food handling practices. Eighty-six percent of the consumers surveyed were aware that hand 
washing reduces the risk for food poisoning. Furthermore, $80 \%$ knew that serving meat on a plate that once held the raw meat increased the risk for food poisoning. Although consumers are aware of safe food handling practices, there is a disparity between knowledge and practice. For example, only $66 \%$ washed their hands after handling raw meat or poultry and only $67 \%$ cleaned their cutting board after contact. with raw meat or poultry. Altekruse et al., (1996) found that gender, age, and frequent food preparation were related to safe food handling practices for both hand washing and taking precautions to prevent cross contamination; however, adequate cooking of meat or poultry was not associated with variables such as gender, age. and frequent food preparation. Researchers concluded that adequate cooking of meat or poultry may be seen as a type of behavior or a food preference instead of a food safety issue. In addition, researchers found that knowledge of food handling practices did not increase with age, but safe practices did.

Klontz, Timbo, Fein, \& Levy (1995) assessed self-reported food consumption and preparation behaviors associated with increased risks of foodborne illness of 1,620 adults ages 18 years and older. Results indicate that certain high-risk food consumption practices and preparation behaviors are common. For example. $53 \%$ of the respondents reported eating foods that contained raw eggs. The most common foods that contained raw eggs were cookie batter $(27 \%)$, homemade ice cream (19\%). homemade eggnog (15\%), Caesar salad (12\%), and frosting (11\%). Furthermore. $23 \%$ reported serving hamburgers "either rare or medium with some pink in the middle" and $17 \%$ reported eating raw clams or oysters. Researchers also found that $26 \%$ of those surveyed reported not cleaning the cutting board with soap or bleach after using it to cut raw meat or poultry. The study revealed that those who are 
more likely to have reported eating raw animal food were males, people ages 18-39 years, and those with an education beyond high school (Klontz et al., 1995).

Fein, Lin, \& Levy (1995) assessed the perceptions, experience, and preventive behaviors of 3,200 adults in 1988 and 1,620 adults in 1993 living in the U.S. Researchers administered a survey with questions about perceived foodborne illness. food-safety and food-handling practices, and consumption of raw animal protein. They reported that people who believed that they had experienced a foodborne illness were more likely to report unsafe food-handling practices and food consumption behaviors. Researchers also found in the study that people who believed that they had experienced a foodborne illness were more likely to express concern over food safety issues and identify foodborne microbes. Furthermore. Fein et al., (1995) found that younger adults ages 18 to 39 years of age were more likely to report if they had experienced a foodborne illness.

Knabel (1995) assessed factors related to foodborne pathogens and common causes of foodborne diseases in a Scientific Status Summary report. The report stated that demographics and lifestyles have increased the demand for quicker ways in food preparation. This means more convenience foods and minimally processed foods. Knabel (1995) also reported that in order to meet the demands for these types of foods, new processing, preservation, and packaging techniques have been implemented with new microbiological risks emerging. Additionally, Knabel (1995) identified changes in family structure, lack of knowledge in safe food handling and preparation practices. and convenience foods to be other factors of foodborne illness. Foodborne illness may result from pathogenic bacteria, viruses, protozoa, parasites. and toxins. Table 4 shows the most common foodborne illness caused by bacteria (Knabel, 1995). Although consumers believe that food manufacturing plants are the 
most likely place for food safety problems, the home is by far more common (USDA website, 1997). For example, Table 5 represents the top 12 mishandling and/or mistreatment of foods resulting in foodborne illness outbreaks in the U.S. between the years of 1961-1982 that were reported to the Center of Disease Control (Knabel, 1995).

The FMI (1997) surveyed 1,011 consumers on their attitudes toward food safety. Consumers cited food spoilage as the greatest perceived threat to food safety $(69 \%)$. Other perceived threats to food safety were improper handling and storage (34\%), product freshness, shelf life and expiration date (20\%), bacteria and germ contamination (17\%), and lack of refrigeration (17\%). Consumers were also asked if they were doing anything differently as a result of the safe-handling labels on poultry and meat products. Forty-five percent of those surveyed said they changed their behavior due to safe-handling labels. For example, $18 \%$ of those surveyed reported washing and disinfecting counters, cooking areas, and utensils after contact with meat. Another $13 \%$ reported washing their hands more often before and after handling meat, while $13 \%$ indicated cooking to appropriate temperatures. Finally, $10 \%$ did not leave meat out to thaw on a counter (FMI, 1997). 
Table 4. Common Foodborne Illnesses Caused by Bacteria (Knabel, 1995).

\begin{tabular}{|c|c|c|c|c|c|}
\hline 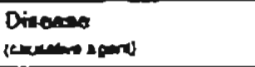 & $\begin{array}{l}\text { Letency } \\
\text { Pertod andero }\end{array}$ & $\begin{array}{l}\text { Prinelpy } \\
\text { Sympinger }\end{array}$ & $\begin{array}{l}\text { Tyoled } \\
\text { Food }\end{array}$ & 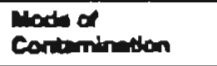 & $\begin{array}{l}\text { Prinnion } \\
\text { of Climine }\end{array}$ \\
\hline $\begin{array}{l}\text { (Bentes coned } \\
\text { tood posoring anmad }\end{array}$ & $\begin{array}{l}B-16 r \\
(12-24 h)\end{array}$ & 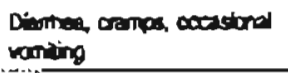 & 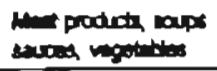 & From war a d a & Theragh noing \\
\hline 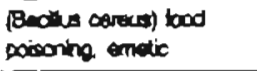 & $\begin{array}{l}1-5 \mathrm{rr} \\
(6-24 \mathrm{r})\end{array}$ & 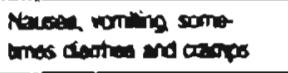 & $\begin{array}{l}\text { cootod to } \\
\text { and pot }\end{array}$ & From sol od der & $\begin{array}{l}\text { Tharagh hasp and } \\
\text { nidd oroing of bods }\end{array}$ \\
\hline 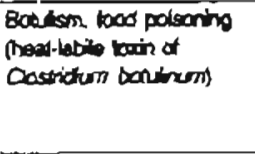 & $\begin{array}{l}12-35 \mathrm{n} \\
\text { (mants) }\end{array}$ & 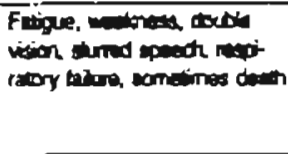 & 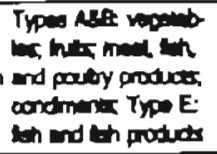 & 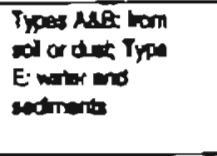 & 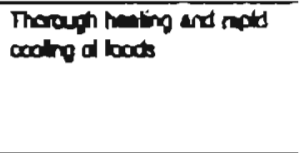 \\
\hline $\begin{array}{l}\text { Eoufum; } \\
\text { food poisoning } \\
\text { intant intector }\end{array}$ & Unknom & 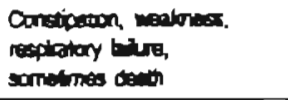 & Honey, col & 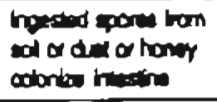 & Do nat lad rangy bletsts \\
\hline $\begin{array}{l}\text { Camoylobactacosts } \\
\text { (Campyosider ifurt) }\end{array}$ & $\begin{array}{l}3-5 \text { doys } \\
(2-10 \text { dars })\end{array}$ & 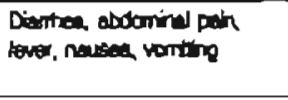 & 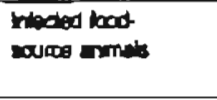 & Oriber m n m & 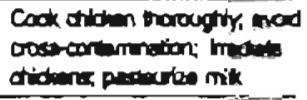 \\
\hline $\begin{array}{l}\text { Grolen } \\
\text { (Vurio onolonae) }\end{array}$ & $\begin{array}{l}20 \text { doys } \\
\text { houss boys }\end{array}$ & 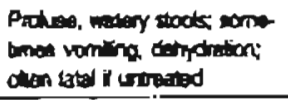 & $\begin{array}{l}\text { Rew ox } \\
\text { undaroohed } \\
\text { sedood }\end{array}$ & $\begin{array}{l}\text { Henen was in } \\
\text { mitns } \\
\text { extrommont }\end{array}$ & Cook bedood noroughty. \\
\hline $\begin{array}{l}\text { (Costrofum parsingerst) } \\
\text { loos poisoring }\end{array}$ & $\begin{array}{l}8-22 \mathrm{~h} \\
(12-24 \mathrm{~h})\end{array}$ & 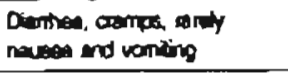 & $\begin{array}{l}\text { cooted min } \\
\text { and goully }\end{array}$ & Soll, and bosts & $\begin{array}{l}\text { Thooved hating and apd } \\
\text { coolng od taod }\end{array}$ \\
\hline 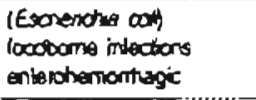 & $\begin{array}{l}12-60 \mathrm{~K} \\
(2-9 \mathrm{days})\end{array}$ & Watery, thoos dathisa & $\begin{array}{l}\text { Row or } \\
\text { underoonted } \\
\text { bod, row ind }\end{array}$ & Inowd calle & 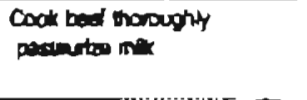 \\
\hline $\begin{array}{l}\text { (Escherictia cot) } \\
\text { loctiong blections } \\
\text { entroinasive }\end{array}$ & $\begin{array}{l}\text { at wast } 18 \text { ) } \\
\text { (uncerting) }\end{array}$ & $\begin{array}{l}\text { Crompe, demed lever. } \\
\text { dysanion }\end{array}$ & Rew troots & 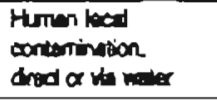 & Coct bods noroughty. \\
\hline 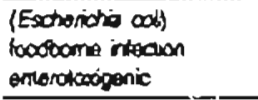 & $\begin{array}{l}10-72 \mathrm{r} \\
(3-5 \text { days })\end{array}$ & 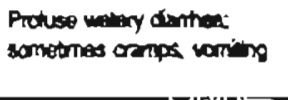 & Rint lood & $\begin{array}{l}\text { Human bos } \\
\text { contarintion, } \\
\text { creat or ta wer }\end{array}$ & 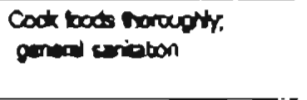 \\
\hline $\begin{array}{l}\text { Listenosis (Listond } \\
\text { manocyoginos) }\end{array}$ & $3-70$ dass & 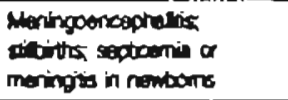 & $\begin{array}{l}\text { Paw mik chase } \\
\text { and vagobles }\end{array}$ & $\begin{array}{l}\text { Sol or intedid } \\
\text { onmmin dreaty } \\
\text { orva minue }\end{array}$ & 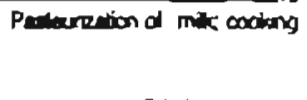 \\
\hline $\begin{array}{l}\text { Saimmoliosta } \\
\text { (Sainoneth species) }\end{array}$ & $\begin{array}{l}3-72 x \\
(1-4 d+y)\end{array}$ & 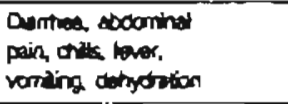 & $\begin{array}{l}\text { Row, undoncoded } \\
\text { Bofl rew milk } \\
\text { med and poildy }\end{array}$ & 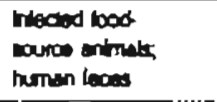 & 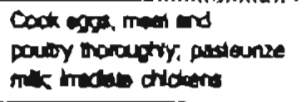 \\
\hline $\begin{array}{l}\text { Shigeloses (STyged } \\
\text { speoss) }\end{array}$ & $\begin{array}{l}12-6 \text { 18 } \\
{[4-7 \text { days })}\end{array}$ & 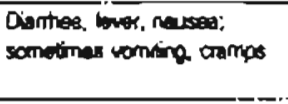 & Rerw boots & 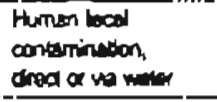 & 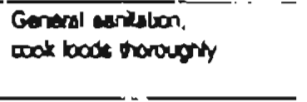 \\
\hline 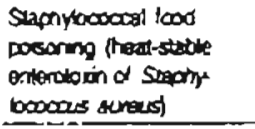 & $\begin{array}{l}1-6 \mathrm{n} ! \\
{[6-24 \mathrm{nn}}\end{array}$ & $\begin{array}{l}\text { Naced uniting dither } \\
\text { carps }\end{array}$ & 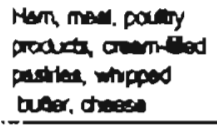 & 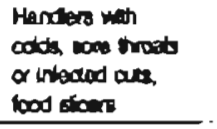 & $\begin{array}{l}\text { Thereugh hatiog and ispid } \\
\text { coofing of hoos }\end{array}$ \\
\hline 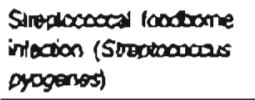 & $\begin{array}{l}1-3 \text { doys } \\
\text { (vates) }\end{array}$ & 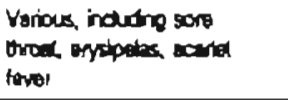 & $\begin{array}{l}\text { Row mil anded } \\
\text { exp }\end{array}$ & 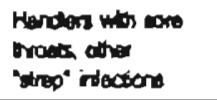 & 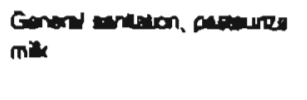 \\
\hline 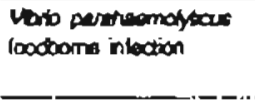 & $\begin{array}{l}32-24 \text { tr } \\
(4-7 \text { dons })\end{array}$ & 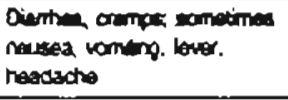 & Fath and ach & $\begin{array}{l}\text { Nimi conth } \\
\text { erikionmant }\end{array}$ & $\begin{array}{l}\text { Cook th wentods } \\
\text { hocoupty }\end{array}$ \\
\hline 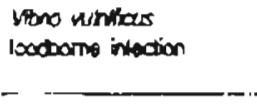 & $\begin{array}{l}\text { In porsons whin } \\
\text { high sonm inar } \\
\text { l day }\end{array}$ & 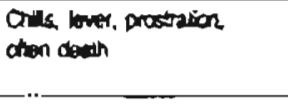 & $\begin{array}{l}\text { Porr options and } \\
\text { dans }\end{array}$ & $\begin{array}{l}\text { Matis poest } \\
\text { minconmant }\end{array}$ & $\begin{array}{l}\text { Cook thatith } \\
\text { booughty }\end{array}$ \\
\hline $\begin{array}{l}\text { Yersinices (Yersinia } \\
\text { ondercorisical }\end{array}$ & $\begin{array}{l}3-7 \mathrm{das} \\
(2-3 \text { was })\end{array}$ & 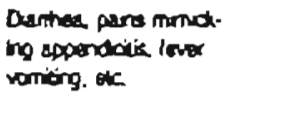 & 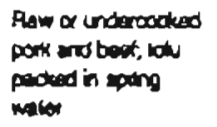 & 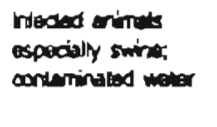 & 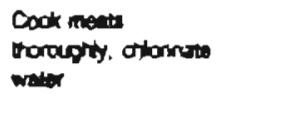 \\
\hline
\end{tabular}


Table 5. Top 12 Mishandling Food Practices in Homes (Knabel, 1995).

\begin{tabular}{|c|c|c|}
\hline$\overline{R a n k}$ & Contributing Factor & Percenl" \\
\hline 1. & $\begin{array}{l}\text { Contaminatod raw food } \\
\text { Ingredlent }\end{array}$ & 42.0 \\
\hline 2. & $\begin{array}{l}\text { Inadequate cookingl } \\
\text { canning/heat processing }\end{array}$ & 31.3 \\
\hline 3. & $\begin{array}{l}\text { Obtained lood from unsele } \\
\text { saurce }\end{array}$ & 28.7 \\
\hline 4. & Improper cooling & 22.3 \\
\hline 5. & $\begin{array}{l}\text { Lapse of } 12 \text { or more hours } \\
\text { Detween propering and ealing }\end{array}$ & 12.8 \\
\hline 6. & $\begin{array}{l}\text { Colonized person handling } \\
\text { implicated lood }\end{array}$ & 9.9 \\
\hline 7. & Mislaken tor lood & 7.0 \\
\hline 8. & Impropes fermentations & 4.6 \\
\hline 9. & Inedequate reheating & 3.5 \\
\hline 10. & Toxic containers & 3.5 \\
\hline 11. & improper trol holding & 3.2 \\
\hline 12. & Cross-contamination & 3.2 \\
\hline
\end{tabular}

Preventing foodborne illness in the home requires educating consumers on food safety knowledge and safe handling practices. To inform consumers on safe handling practices, USDA has applied the Hazard Analysis and Critical Control Points (HACCP) concept in developing educational materials. The messages focus on areas least understood by consumers, but are critical in preventing foodborne illness (Knabel, 1995). In addition, USDA has required a safe food handling label that provides information on critical control points to be placed on packages of raw and partially-cooked meat and poultry products (Knabel, 1995) (Figure 5). 


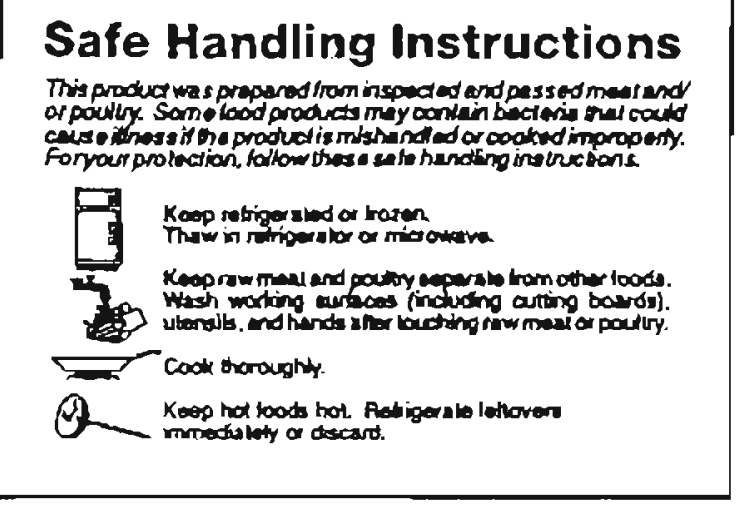

Figure 5. Safe Food Handling Label (Knabel, 1995)

Other efforts to inform consumers have been made by USDA and FDA. For example, a Foodborne Illness Education Information Center was established in 1994 as part of a national campaign to reduce the risk of foodborne illnegs and increase knowledge on food safety principles. The center is responsible for developing an educational database to assist with educational and training materials for consumers and food service workers. Also, USDA's Food Safety and Inspection Service has a Meat and Poultry Hothine for consumers to call if they have any questions on safe handling of meat and poultry. Likewise, the FDA has a Seafood Hotline for consumers to call about seafood safety (Knabel, 1995).

By exploring consumers' health attitudes, nutrition knowledge, dietary behavior, and safe food handling practices, nutrition educators can identify areas where consumers need to strengthen their existing practices or change their behavior to achieve or maintain optimal health. Changing nutrition-related behavior is difficult, but nutrition education programs can be effective by applying theoretical frameworks or models of health behavior to promote adherence to dietary recommendations and long-term compliance. 


\section{Improving the Health of Americans}

Improving America's health status is a challenge to nutrition educators. Unfortunately, adherence to a bealthy diet that follows the recommendations of the Food Guide Pyramid and the Dietary Guidelines for Americans is difficult and progress has been slow. The following section will provide an overview of health promotion, nutrition education, and theories of behavioral change in nutrition education.

\section{Health Promotion}

There are many factors that influence the development, maintenance, and change of dietary patterns (O’Donnell \& Harris, 1994). Health promotion strategies that are centered around factors that influence dietary patterns have a greater chance of producing positive dietary change (Frankle \& Owen, 1993).

Traditionally, the approach to changing dietary behavior has been to focus on the individual's knowledge, attitudes, behavior, and practices (Glanz \& Mullis, 1988); however, this approach often overlooked other variables that affect health-related behavior resulting in a "victim-blaming" approach (McLeroy, Bibeau. Steckler. \& Glanz, 1988). According to McLeroy and associates, an ecological approach to health promotion focuses on health behavior of individuals and environmental situations. McLeroy states "the importance of ecological models in the social sciences is that they view behavior as being affected by, and affecting the social environment" (McLeroy et al., 1988, p. 355). The model, which McLeroy and associates mention consists of five components that are considered to influence health-related behavior. They include intrapersonal factors, interpersonal processes and primary groups, 
institutional factors, community factors, and public policy (McLeroy et al., 1988). Intrapersonal factors are characteristics of the individual such as attitudes, behavior, knowledge, and skills. Interpersonal processes and primary groups involve formal and informal social networks and social support systems like family, friends, and co-workers. Institutional factors can be described as being social institutions having organizational characteristics with formal and informal rules and regulations for operation. Community factors are considered to be the relationships among institutions, organizations, and informal networks within defined boundaries. Finally, public policy consists of national laws and policies of local, state, and national government (McLeroy et. al., 1988).

There are several federal govermment and national health organizations that recognize nutrition education as a key factor in health promotion and disease prevention and have implemented several programs to assist the public in reaching certain health goals. For instance, Healthy People 2000: National Health Promotion and Disease Prevention Objectives, The National Cholesterol Education Program, The National High Blood Pressure Education Program, The National 5-A-Day Program. National Nutrition Month\&, and The Foodborne Illness Education Information Center.

Healthy People 2000, which began in the 1980's, is a national effort that seeks to improve the health and longevity of the American people within the next decade (Feinleib, 1995). The three goals of Healthy People 2000 for Americans are the following: (1) increase healthy life span, (2) reduce health disparities, and (3) provide access to preventative services (HHS, 1990). The U.S. Public Service in conjunction with the Institute of Medicine of the National Academy of Sciences/National Research Council developed measurable objectives in 22 priority 
areas including health promotion, health protection, and preventive services (Danford \& Stephenson, 1991; McGinnis \& Lee, 1995). There are 21 nutrition objectives listed in the nutrition priority area and are classified according to health status, risk reduction, or services and protection objectives (HHS, 1990).

The National Cholesterol Education Program (NCEP) was initiated in 1985 by the National Heart, Lung, and Blood Institute (NHLBI). The goal of the NCEP is to reduce elevated blood cholesterol levels that contribute to death and disparity from coronary heart disease. The NCEP educates both professionals and the public to increase awareness and understanding of the relationship between high blood cholesterol and the risk of coronary heart disease. Not only does the program emphasize the importance of having blood cholesterol levels checked, but the importance of adopting healthy eating patterns that are low in saturated fat and cholesterol (NHLBI website, 1997).

The National High Blood Pressure Education Program (NHBPEP) was established in 1972 as a joint effort among professional and voluntary health agencies, State health departments, and many community groups. The goal of the NHBPEP, which is administered and coordinated by the National Heart, Lung, and Blood Institute (NHLBI), is to reduce death and disability related to high blood pressure by building public awareness through education programs aimed at the public and health professionals (NHLBI website, 1997).

The 5-A-Day for Better Health Program, initiated in 1992, is designed to promote public awareness of the importance of consuming 5 or more servings of fruits and vegetables a day and to provide information on how to increase fruit and vegetable intake as part of daily eating patterns. The program is jointly sponsored by the National Cancer Institute (NCI) and the Produce for Better Health Foundation, a 
nonprofit foundation representing the fruit and vegetable industry. Several unique components make up the 5-A-Day for Better Health Program, such as the simple, positive message, industry participants, mass media, State health departments, and research to determine the effectiveness of interventions ( $\mathrm{NCI}$ website, 1997).

The Foodborne Illness Education Information Center, established in 1994 by the USDA and the Food Safety and Inspection Service (FSIS) provides information on foodborne illness prevention. In order to help reduce the risk of foodborne illness، the center was established as part of a national campaign to increase knowledge of food-related risks. The center is also responsible for the development and maintenance of two databases: the Foodborne Illness Educational Materials Database and the Hazard Analysis Critica) Control Points (HACCP) Training Programs and Resource Database (USDA website, 1996).

National Nutrition Month®, initiated in March of 1973, is sponsored annually by the National Center of Nutrition and Dietetics (NCND) of ADA. It is a nutrition education and information campaign designed to provide the public with nutrition knowledge that enables them to make informed decisions concerning food selection. preparation. and intake. To promote sound eating habits, a different slogan is developed each year and key messages are emphasized. For example, the slogan for 1997 was "All Foods Can Fit" and the message focused on the idea of Lotal diet. Messages emphasized that all foods can be a part of healthy eating as long as they are consumed in moderation and balanced over one or more days (ADA website, 1997). 
Nutrition Education

Nutrition education can range from providing nutrition information in newspapers or magazines to satisfy consumer interests to implementing nutrition intervention programs that incorporate behavior change strategies. Nutrition education can also involve nutrition communication (informing consumers about food and nutrition) and nutrition promotion (translating dietary guidance into clear messages). Ultimately, nutrition education should be viewed as the foundation for nutritional advances in public health (ADA position paper, 1996). Although there are several frameworks in which nutrition education takes place, the focus or message about food and food choices must be consistent.

Nutrition education can be defined as "any set of learning experiences designed to facilitate the voluntary adoption of eating and other nutrition-related behaviors conducive to health and well-being" (Contento et al., 1995, p. 279). Although there are science-based research studies that support the relationship between diet and chronic disease, there is little research in factors that influence the change in nutrition-related behavior.

Nutrition-related behavior can include nutrient intake, food intake, food selection and preparation, physical activity, weight, and other clinical measures (Schwartz, 1996). Understanding nutrition-related behavior involves looking at factors that influence behavior such as cognitive and behavioral skills (attitudes, beliefs, knowledge. and practices about nutrition, food selection and preparation). In addition, personal factors such as values, intent, and self-efficacy influence nutrition-related behavior. Finally, environment support can influence the ability to achieve and sustain nutrition related behavior (Schwartz, 1996). 
Although nutrition education efforts have been made to promote healthy eating along with a healthy lifestyle, these efforts are challenged by nutrition misinformation. Nutrition misinformation can include health fraud quackery and nutrition-related misbeliefs (ADA position paper, 1995). According to the American Dietetic Association, nutrition misinformation has harmful effects both on consumer's health and economic status. The medical consequences of nutrition misinformation may result in the lack of seeking medical attention, nutrient deficiencies, nutrient toxicities, undesirable nutrient-drug interactions, and interference with sound nutrition education and practices (ADA position paper, 1995). Economic consequences of nutrition misinformation arise when the perceived health benefit does not take place resulting in needless buying of products.

In order to protect the nutritional well-being of individuals, nutrition education programs must be designed to meet the needs, behaviors, motivations, and desires of individuals and furthermore be presented in a form that individuals understand and can apply to their daily lives (ADA position paper, 1996).

The goal of nutrition education is to promote healthy eating behavior that reduces the risk of chronic disease (Frankle \& Owen, 1993). The American Dietetic Assaciation recommends that nutrition education for the public should include the following: focus on total diet rather than individual foods; have a positive approach toward foods and food choices; include messages of balance, variety, and moderation as part of a healthy diet; and finally, specify there are no good or bad foods (ADA position paper. 1996). In order to achieve and maintain optimal health, nutrition education should be an important component of all health promotion disease prevention and health maintenance programs (ADA position paper, 1996). 
Contendo and associates (1995) reviewed 217 nutrition intervention studies and concluded that nutrition education programs can be effective if behavioral change is clearly stated as a goal, and both communication and educational strategies are centered on enhancing awareness and understanding motivations of the individual. For example, motivations and reinforcements include self-efficacy, social norms, social support, perceived benefits and barriers, perceived threat, and personal, social and cultural values (Contento et al., 1995). Thus, educational strategies that rely on dissemination of information alone may not result in dietary behavior change. Gambera et al. (1995) illustrates in their study how "nutrition information alone does not seem to be enough to cause changes in behavior" (p. 1271). Significant changes were observed in total cholesterol, LDL levels, and dietary intake when nutrition education was combined with individual dietary intervention compared to the contral group who only received exposure to the Food Guide Pyramid posters without a nutrition education component.

Contento and associates (1995) also concluded nutrition education programs that, specifically taught behavioral change strategies, actively involved both individuals and communities, and attempted to provide a health-promoting environment were more likely to be effective. According to ADA, effective nutrition education programs not only have a variety of behavioral, educational, communication, and environmental strategies, but they are developed with the appropriate use of theoretical frameworks (ADA Position paper, 1996). 


\section{Theories of Behavioral Change in Nutrition Education}

Dietary change is complex and involves the interaction of several variables. Nutrition education research is addressing the question as to whether the application of theory contributes to a program's success in nutrition education (Smith \& Lopez, 1991). Diet and health-related behavior can be best understood by examining different approaches used in psychology to account for certain behaviors. For example, the behavioral approach emphasizes behavior and its environment determinants whereas the cognitive approach emphasizes thought processes (Santrock pp. 10-14).

Smith \& Lopez (1991) define a theory as "a set of interrelated definitions, concepts and propositions that present an organized view or interpretation of phenomena" (p.59). In addition, they define a theoretical model as being a simplified representation of principles that make up a theory and can be easily applied to nutrition education. Several theories exist and have been documented in nutrition education research, but it is beyond the scope of this literature search to discuss each theory in detail. Instead, a brief description is provided on theoretical frameworks that Contento and associates (1995) identified as most often used in nutrition education research. The following provides a brief description of the knowledge-attitude behavior model, the Health Belief Model, Social Cognitive Theory, the Consumer Information Processing Model, the Social Marketing Model, Diffusion of Innovations theory, and the Stages of Change Theory.

The knowledge-attitude behavior model implies a gain in new knowledge will lead to changes in existing attitudes, which in turn, will result in improved dietary behaviors or practices. However, this applies only to those who are already 
motivated and for those who are not motivated, the new knowledge is just information. In addition, the new knowledge must be motivational in changing attitudes and behaviors. According to Contento et al. (1995) most nutrition education programs have been in the form of dissemination of information rather than in the form of "how to" or "skills", which produce positive or negative consequences of behavior and have personal relevance. Consequently, the programs that use this model are not very effective in bringing about behavior change.

The Health Belief Model emphasizes perceived threat as a motivating force and perceived benefits as providing a preferred path to action. According to the Health Belief Model, the higher the perceived threat or the more vulnerable a person feels, the more motivated the person will be to take action to reduce the threat. Furthermore, if the person perceives the action as being effective and they believe they have the ability to successfully perform the action with few negative consequences, the more likely the action will occur (Contento et al., 1995).

Social Cognitive Theory is the "interactive nature of the effects of cognitive and other personal factors and environmental events on behavior" (Conento et al., 1995, p. 288). Furthermore, Social Cognitive Theory characterizes human behavior as being "reciprocally determined" or rather the person's behavior affects and is also affected by the environment. Social Cognitive Theory combines basic concepts of behavior modification with cognitive, interpersonal, and environmental infuences on behavior and has developed concepts such as observational learning, reinforcements, self-control, and self-efficacy (Frankle \& Owen, 1993, pp. 259-260). Self-efficacy is critical in the behavioral change process as it influences the choice of new behavior, the effort required to change existing behavior, and the thought and emotional reactions that follow (Baldwin \& Falciglia, 1995). 
The Consumer Information Processing Model was developed from earlier studies of consumer behavior and emphasizes how consumer's decision making is a multistage process of information acquisition and evaluation, decision making, use, and learning. Since consumers can only process a limited amount of information at a time, they develop rules of thumb to help make reasonable decisions quickly. Thus, consumers tend to seek enough information to make a satisfactory choice, bul Irot necessarily the best choice (Frankle \& Owen, 1993, p. 258).

The Social Marketing Model emphasizes marketing principles and techniques to increase the acceptability of social ideas and practices. Social Marketing involves the four P's of marketing: price, product (or service), placement, and promotion (or communication). Social marketing serves as a framework for focusing creative efforts on the design, implementation, and control of programs, which in turn, will affect the target audiences that marketers want to persuade (Conento et al., 1995).

The Diffusion of Innovations Theory suggests that if the innovation (idea, practice, or service) is compatible with current beliefs, values, and lifestyles; is flexible and viewed as more advantageous compared to current practices; is reversible or allows returning to previous practices; is minimal risk; and is cost effective or rather is perceived to have greater benefits than costs, then the adoption of the innovation is more likely (Frankle \& Owen, 1993, pp. 262-263; Contento et al.. 1995). The innovation will diffuse throughout the community from opinion leaders and early adopters to late adopters over time (Contento et al., 1995).

The Stages of Change Model implies that behavior change is a dynamic process involving several distinct stages and people may be at various stages along the continuum of change readiness: precontemplation (unaware and not interested in changing), contemplation (thinking about changing), decision (being determined to 
change), action (actively modifying habits), and maintenance (maintaining new, healthier habits) (Frankle \& Owen, 1993, p. 259; O'Donnell \& Harris, 1994, p. 280). Furthermore, people may relapse and return to previous behavior and move through the stages of change in a straight line (O'Donnell \& Harris, 1994, p. 280). Knowing where people are along the continuum can help nutrition educators focus on strategies that are specifically directed at each stage of change.

Glanz and Rudd (1993) also examined the use of theory by researchers and practitioners in both consumer behavior and nutrition education. A total of 284 professionals were surveyed on the importance of concepts from selected theories for explaining food choices, their familiarity with the selected theories, and their opinions on research and theory. Altogether, respondents agreed that theoretical based concepts are important in understanding how people make food choices: however, it is interesting that respondents were neutral or pessimistic about whether research and theory-based research was practical, useful, and timely in designing effective consumer nutrition education. The theories that were most familiar to more than half of respondents were social marketing (58\%), consumer information processing (56\%), and social learning (55\%). In addition, Glanz \& Rudd (1993) report a statistically significant difference in familiarity between professionals in nutrition education and consumer behavior respondents. Consumer behavior professionals were more familiar with the consumer information processing model and nutrition educator professionals were more familiar with the Health Belief Model.

Contento et al. (1995) found that nutrition education programs that use a combination of theoretical models that guide dietary change at the individual level, social level, and environmental level were effective. Furthermore, a variety of 
theoretical models enables nutrition educators to provide effective dietary guidance to target audiences because it takes into consideration the complexity of food choices and dietary behavior change (ADA position paper, 1996). Nonetheless, Schwartz (1996) states that understanding human.nutrition related behavior guides in the development of models that demonstrate how consumers make decisions, why they decide on a particular course of action, and how they implement their action as sustained behavior change.

Achterberg \& Clark (1992) conducted a review of nutrition education research to identify the use of theoretical frameworks and found that of the 346 research papers or abstracts, only $23.5 \%$ cited a specific theory or model. The theories were from the psychological literature and classified as the following: $36 \%$ were cognitive, $33 \%$ were social psychological, $19 \%$ were behavioral, and $12 \%$ could not be classified as a combination of theories and models were used.

In another study, Smith \& Lopez (1991) investigated whether there was an association between the use of theory and a nutrition education program's success. A program's success was defined as having measurable differences in knowledge. attitude, and behavior. Smith and associates (1991) reviewed 105 research reports, but only 63 qualified as measuring effectiveness. Of the 63 articles. $71 \%$ were theory based and $29 \%$ were method based. Smith and associates (1991) reported $60 \%$ of the studies that were theory-based used theories from one of three learning theories: Cognitive (27\%), Social-psychological (22\%), and behavioral (11\%). The remaining $11 \%$ were a combination of the three. In addition, theory use was either explicit (27\%), implicit (71\%), or both (2\%). Although there was no significant difference found between application of theory and program effectiveness, researchers associated it to implicit use of theory, inconsistencies in application of 
theory, and inadequacies in the measurements of change. In addition, researchers noted that failure to examine use of theory vs. non-theory in nutrition education or to explore each theory separately may have accounted for the lack of association between theory use and nutrition education program effectiveness (Smith \& Lopez, 1991).

Promoting healthy eating to Americans sounds easy enough; however, dietary behavior change is a complex issue that involves social, cultural, and economic factors as well as physiological and psychological factors. Furthermore, acquired food practices and knowledge are determinants of food intake (Glanz \& Mullis, 1988). By understanding the multitude of factors mnolved in dietary behavior change, nutrition educators can implement strategies from theoretical frameworks that are tailored to the needs, values, behaviors, motivations, and desires of the target audience (ADA position paper, 1996). Some theoretical frameworks are more effective if directed at interventions at the individual level, while others are more effective at the social level or environmental level (Contento et al., 1995). Nonetheless, nutrition educators that incorporate a variety of theoretical models of individual, social, and environmental change have been found to be effective (Contento et al., 1995).

\section{Evaluating Dietary Intake}

\section{Dietary Assessment Methods}

Dietary assessment methods are important for investigating relationships between diet and disease, nutrition monitoring, policy making, dietary intervention trials, and planning health promotion and disease prevention activities (Howat et al., 1994; Briefel et al., 1992). Methods for evaluating dietary assessment include 
both quantitative and qualitative measures. Quantitative rneasures involve actual weighing of foods whereas qualitative measures include dietary histories (Howat et al., 1994). There is no ideal standard or method for evaluating dietary intake; however, a researcher can choose a method that best represents the purpose and objectives of the study (Howat et al., 1994). Furthermore, the validity and reliability of dietary methods are important issues as well. Validity describes how well a method or instrument measures what it intends to measure whereas reliability describes the overall consistency or reproducibility of the method or instrument in retests under the same conditions (Zulkilli \& Yu, 1992; How at et al., 1994). The most common instruments used to measure dietary intake include: dietary history, 24-hour recall, food records, and food frequency questionnaires (Howat et al., 1994) (Table 6).

A diet history is a dietary assessment in which a respondent reports their past diet. The diet history includes foods eaten and factors related to food intake (Wylie. Rosett, Wassertheil-Smoller \& Elmer, 1990). In addition, amounts of foods and frequency of intake are obtained from the respondent (Thompson \& Byers, 1994). The strengths and weaknesses of a diet history are included in Table 6.

In the 24-hour dietary recall, the most commonly used method, the individual is asked to recall and report all food and beverages consumed during the previous 24 hours (Wylie-Rosett et al., 1990). Professionals, who are experienced interviewers and have a knowledge about foods and preparation practices, are important in administering a 24 -hour dietary recall because of the manner in which dietary information is collected (Thompson \& Byers, 1994). For example, during the interview much of the dietary information is collected by asking probing questions to help respondents remember all foods they consumed within the previous 24 hours. 
Probing is useful in collecting necessary details, such as how foods were prepared or in retrieving food items not originally reported (Thompson \& Byers, 1994). The strengths and weaknesses of the 24-hour dietary recall are provided in Table 6.

A food record is a record of all foods and beverages, with exact amounts consumed over a period of days (Thompson \& Byers, 1994). The amounts are measured by respondents using scales, household measuring cups or spoons, food models, or pictures at the time the food is consumed. Furthermore, the respondent must be responsible for important details, such as brand names, preparation methods, recipes for food mixtures, and serving sizes (Thompson \& Byers, 1994). Table 6 includes the strengths and weaknesses of the food record as a dietary assessment tool.

For the food frequency questionnaire, a number of food items are listed and the respondent is asked how many times a day, week, month, or year each food item is consumed (Wylie-Rosett et al., 1990). Only information on frequency is collected. with little detail on other factors that relate to intake, such as preparation methods and food mixtures (Thompson \& Byers, 1990). Estimations of nutrient intake are then calculated (nutrient estimate $=$ food frequency $\times$ serving size $\times$ nutrient standard) (Zulkifli \& Yu, 1992). Table 6 reports the strengths and weaknesses of the food frequency questionnaire as a dietary assessment tool.

Several studies have been conducted to determine the accuracy of diet histories and most question the reliability of self-reported food intake (Mertz, 1992). For example, the Beltsville Human Nutrition Research Center reported consistent discrepancies between self-reported food intake and the intake that was determined for weight maintenance. Of the 266 well-trained volunteers, $18 \%$ were below maintenance intake. Furthermore, $81 \%$ of the volunteers underestimated their 
intake by 700 kcalories, $11 \%$ were within 100 kcalories, and $8 \%$ overestimated their intake by $400 \mathrm{kcalories}(\mathrm{Mertz}, 1992)$. Although researchers use quantitative methods to assess dietary intake, qualitative aspects of data collection cannot be overlooked (Mertz, 1992).

Studies have shown that individuals have difficulty in estimating portion sizes of foods and as a result underestimate amounts eaten (Thompson \& Byers, 1994). To increase the accuracy of self-reporting, researchers have examined the effect of training sessions for estimating portion sizes (Slawson \& Eck, 1997). When subjects were trained in portion size estimations, using actual foods, researchers reported increased validity of portion size estimation (Slawson \& Eck, 1997).

Regardless of which method is used to evaluate dietary intake, it is important to realize that all dietary assessment tools are not equal and that they all have limitations. The decision as to which dietary assessment method to use depends on the goals of the assessment, the information needs of the study, the time frame, and the dimensions of diet (Thompson \& Byers, 1994). 
Table 6. Characteristics of Dietary Assessment Tools (Shils, Olson \& Shike, 1994)

\begin{tabular}{|c|c|}
\hline METHODS AND ADVANTAGES & DISADVANTAGES \\
\hline $\begin{array}{l}\text { Food frequency questionnaire } \\
\text { May be either self-administered or } \\
\text { interviewer-administered } \\
\text { Inexpensive } \\
\text { Quick to administer } \\
\text { Good al describing food intake patterns } \\
\text { for diet and meal planning } \\
\text { No observer bias } \\
\text { Can be used for large population } \\
\text { studies } \\
\text { Useful when purpose is to study } \\
\text { association of a specific food or a } \\
\text { small number of foods and disease } \\
\text { such as alcohol and birth defects } \\
\text { Specific information about nutrients can } \\
\text { be obtained if food sources of } \\
\text { nutrients are confined to a few } \\
\text { sources } \\
\text { Can be analyzed rapidly for nutrients or } \\
\text { tood groups using a computer } \\
\text { Foods can be ranked in relation to } \\
\text { intakes of certain food items or } \\
\text { groups of foods }\end{array}$ & 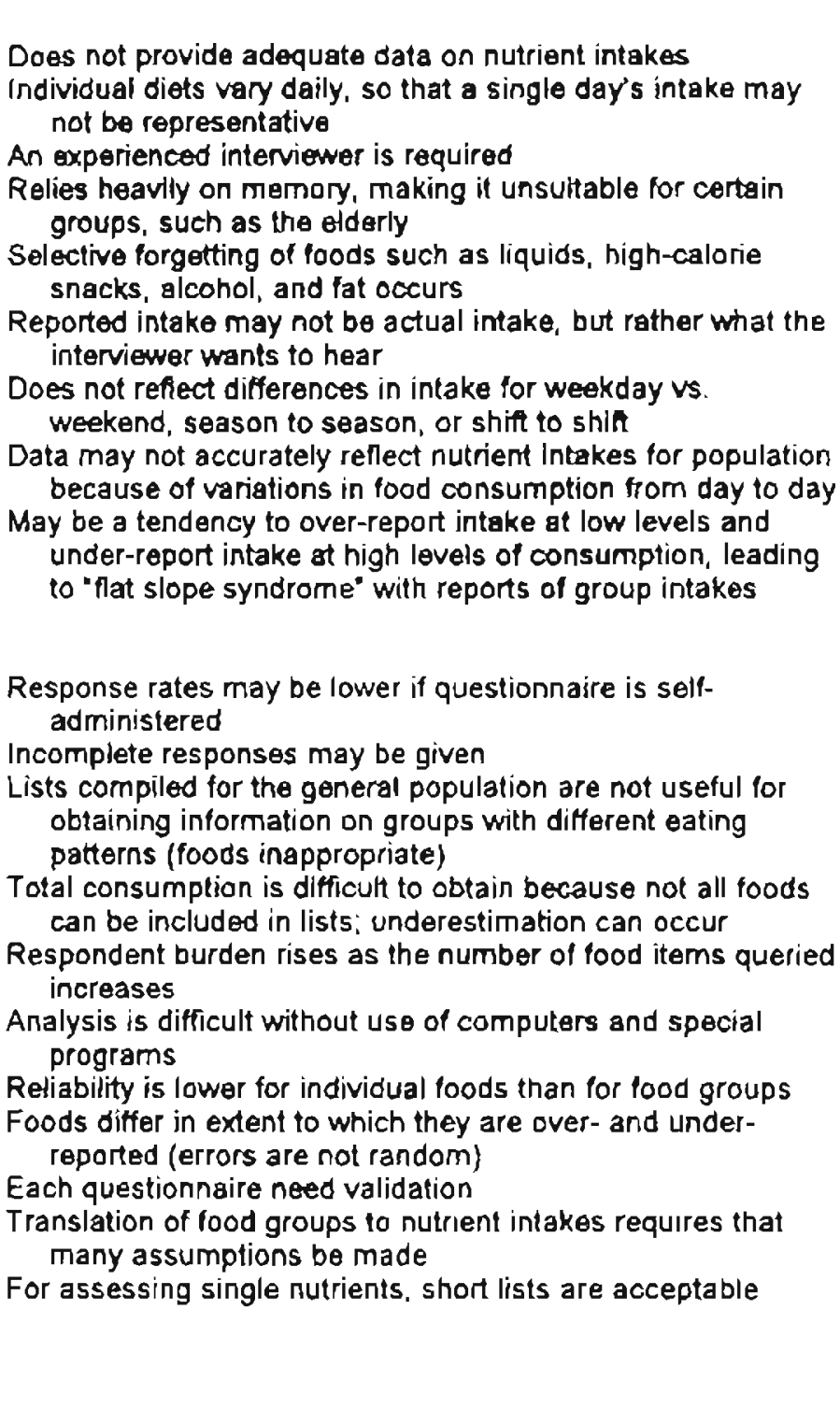 \\
\hline
\end{tabular}


Table 6. Characteristics of Dietary Assessment Tools continued (Shils, Olson \& Shike, 1994)

\begin{tabular}{|c|c|}
\hline METHODS AND ADVANTAGES & DISADVANTAGES \\
\hline $\begin{array}{l}\text { 8urke-type dietary history } \\
\text { Produces a more complete and detailed } \\
\text { description of both qualitative and } \\
\text { quantitative aspects of food intake } \\
\text { than do food records, 24-hour } \\
\text { recalls, or food frequency } \\
\text { questionnaires } \\
\text { Eliminates individual day-to-day } \\
\text { variations } \\
\text { Taxes into consideration seasonal } \\
\text { variations } \\
\text { Good for longitudinal studies } \\
\text { Provides good description of usual } \\
\text { intake } \\
\text { Provides some data on previous diet } \\
\text { before beginning prospective studies } \\
\text { Food diary } \\
\text { What is eaten is recorded (or should be } \\
\text { recorded at time of consumption) } \\
\text { Recording error can be minimized if } \\
\text { subjects are given proper directions } \\
\text { Does not rely heavily on memory, and } \\
\text { thus may be good for the elderly } \\
\text { Can be obtrusive }\end{array}$ & $\begin{array}{l}\text { Food intake may be altered } \\
\text { Respondent burden is great } \\
\text { Individual must be literate and physically abie to write } \\
\text { Respondent may not record intakes on assigned days } \\
\text { Difficult to estimate portion sizes } \\
\text { Food models or pictures may help } \\
\text { Under-reporting is common } \\
\text { Number of sampled days must be sufficient to provide } \\
\text { usual intake } \\
\text { Records must be checked and coded in standardized way } \\
\text { Measured food intakes are more valid than records above } \\
\text { Costs of coding an analysis are high } \\
\text { Sex difference exists (i.e., women are more competent than } \\
\text { men in recording) } \\
\text { Number of days surveyed depends on the nutrient being } \\
\text { studied } \\
\text { The very act of recording may change what is eaten }\end{array}$ \\
\hline
\end{tabular}




\section{Summary}

In order to achieve health-promoting and disease-preventing dietary practices, individuals must have adequate nutrition knowledge about diet and health and appropriate skills in food selection and preparation. The Oklahoma Cooperative Extension Service developed and implemented a Healthy Living Nutrition Education Program in order to improve dietary habits that were conducive with the Dietary Guidelines for Americans and the Food Guide Pyramid as well as improve personal health status indicators for disease risk. The following study is an effort to advance nutrition education toward the community level, where social support is high, and deliver the messages in an appropriate manner for adults. 


\title{
CHAPTER III
}

\section{RESEARCH PROCEDURE}

\author{
Introduction
}

This chapter describes the procedure used in this study including the development of the Healthy Living Program, dietary assessment tools, subject recruitment, experimental study, and statistical analysis.

Nutrition plays an important part in health maintenance and the prevention of certain diseases, such as heart disease, stroke, arteriosclerosis, some cancers, and diabetes. (HHS, 1990) Although the Dietary Guidelines for Americans provide advise about healthy food choices that decrease the risk of chronic disease (Kennedy, Myers \& Layden, 1996), there is a high prevalence of nutrition-related health problems. Coronary heart disease and strokes kill over 10,000 Oklahomans each year. Oklahoma also has the second highest death rate in the nation for coronary heart disease (Brandt et al, 1994; AHA, 1994). Oklahoma Cooperative Extension Service nutrition education efforts are focusing on improving the overall health status of Oklahomans through a five-year Healtby Living Program (HLP), which has been designed to promote appropriate diets and healthy lifestyles.

The purpose of this study was to evaluate the effects of an eight-week Oklahoma Cooperative Extension Service nutrition education program, HLP, in a rural county in Oklahoma on food selection, preparation, and food safety practices and behaviors, dietary intake, and anthropometric and biochemical health measures. The objectives of the study include: 1) Payne County subjects will engage in healthy lifestyle practices that promote healthy living, 2) Payne County subjects will adopt 
the USDA Food Guide Pyramid Dietary Recommendations, 3) Payne County subjects will adopt the USDA-HHS Dietary Guidelines dietary recommendations, 4) Payne County subjects will adopt safe food selection, preparation, and storage practices, and 5) Payne County subjects will improve personal bealth status indicators.

The principal investigator and research assistants completed training sessions on laboratory safety and biological hazard disposal prior to the study. In addition, information was provided on Hepatitis B and the Human Immunodeficiency Virus. At this time, the research assistants signed a consent form for the Hepatitis B vaccine series. This study was approved by the Institutional Review Board (IRB) for human subjects research at Oklahoma State University (Appendix A).

Development of The Oklahoma Cooperative Extension Service Healthy Living Program

The HLP was developed by the Oklahoma Cooperative Extension Service to encourage lifestyle practices that would promote healthy living among Oklahomans. The HLP was an eight-week program that provided information on nutrition, label reading, food selection, food preparation, and food safety about specific food groups within the Food Guide Pyramid. The program consisted of eight 1 1/2 - 2 hour weekly sessions taught by the County Home Economists. The sessions are listed below along with additional information:

1) The Basics - Food Pyramid and Recipe Modification: An introduction to the Food Guide Pyramid along with the food label was provided in this session. 
Emphasis was placed on where foods and combination foods are placed within the Food Guide Pyramid. Ethnic foods were also addressed.

2) Supermarket Tour: This session involved a trip to the local supermarket. The tour focused on the following areas: the produce section, the meat department, the dairy case, the breads and cereals section, and the pasta section. Participants received handouts on fruits and vegetables, potatoes, bread, muffing and other pastries, grains, cereals, pasta, dairy products, frozen desserts, meats, and fats (Appendix B).

3) Breads: Special emphasis was placed on whole grains and learning how to read bread labels in order to determine the healthiest choice. Furthermore, participants became familiar with the functions of ingredients in quick breads, yeast breads, and rolls.

4) Grains, Cereals, and Pasta: Participants were introduced to a variety of grains, such as couscous, bulgur, barley, and quinoa. Helpful hints for choosing and preparing grains, cereals, and pasta were also provided. In addition, there were suggestions on ways to reduce sodium and increase fiber in recipes.

5) Fruits and Vegetables: This session emphasized the National Cancer Institute's Five-a-Day logo and listed the type of fruits and vegetables available. Also, the differences between fresh fruit, frozen fruit, canned fruit and dried fruit were explored. In addition, cooking methods were described and a guide to using herbs and spices was provided.

6) Meat. Poultry. Fish, Dry Beans, Eggs, and Nuts: Participants learned about bacteria that cause foodborne illness along with safe-handling practices. Also, participants studied wholesale cuts and the length of time meat can be safely stored. 
7) Dairy: Special emphasis was placed on the importance of calcium in this session. Participants became familiar with the types of milk and the classifications of cheese.

8) Fats, Oils, and Sweets: This session compared vegetable oils, explored claims on fats and sugars, and demonstrated how to lower the fat in baking. In addition, fat and sugar models (Appendix $\mathrm{C}$ ) were provided to illustrate the amounts of sugar and fat in one serving of a particular food.

Each session contained specific lesson objectives (Appendix D), handouts, visuals, activities, and additional resources for the subjects. In addition, each session illustrated how to modify recipes to reduce fat, cholesterol, sodium, sugar, and increase fiber.

Marketing the HLP consisted of printed materials, a news release (Appendix E), and video materials, which included a 29 second broadcast television public service announcement and a two minute loop promotional tape. In addition, T-shirts were. printed with the HLP logo.

A training session was also provided for counties that participated in the HLP. During the training session, information was provided on the eight-sessions and materials were distributed. In addition, assessment procedures were discussed. Assessment of the HLP included the Food and Nutrition Behavior Questionnaire. the Health Habits and History Questionnaire, and the Healthy Living Program Measurement Form. 
The Healthy Living Program Assessment Forms

The evaluation of the HLP included questionnaires that assessed nutritional status, food and nutrition practices and behaviors, dietary intake, anthropometric. biochemical, and clinical measures.

The Food and Nutrition Behavior Questionnaire (Appendix F) was developed to assess food selection, preparation, and food safety practices and behaviors. The Food and Nutrition Behavior Questionnaire was adapted from the USDA Expanded Food and Nutrition Education Program (EFNEP) survey (1993), which has been validated and tested for reliability.

The Health Habits and History Questionnaire (HHQ) (Appendix G) was used to assess participants' dietary intake. 'The Health Habits and History Questionnaire is a quantitative food frequency questionnaire and computer analysis system developed by Block et al. (1986), which has been tested for validity and reliability (Block et al, 1990).

The Healthy Living Program Measurement Recording Form (Appendix H) was used to record subjects' anthropometric, biochemical, and clinical measurements. Measurements included height, total body weight, and wrist circumference. In addition, sex, age, blood pressure, and total blood cholesterol was listed.

\section{Subject Recruitment}

After approval from the IRB for human subject research at Oklahoma State Unversity, subjects were solicited by the Payne County Home Economists using flyers, mailing enclosures, news releases, and television public service announcements. Subjects were instructed to contact their local county Extension 
Office if they were interested in participating in the HLP. A telephone script was used to inform subjects about the HLP along with the purpose of the study.

Subjects who would participate in the study were informed that the program consisted of taking blood samples at the beginning and end of the eight-week session to measure total serum cholesterol, LDL-cholesterol. HDL-cholesterol, glucose, and triglycerides. Subjects were also informed that in order for them to receive their blood values, a consent form would have to be read and signed before the first educational session. Subjects were required to pay a registration fee of $\$ 20$ to cover the cost of food demonstrations, program T-shirts, and educational materials.

\section{Experimental Study}

This research project evaluated the impact of the HLP in Payne County. Oklahoma using a Pretest-Posttest Control Group experimental design as seen in Figure 6 (Nieswiadomy, 1993).

$$
\begin{array}{llll}
\mathrm{R} & \mathrm{O}_{1} & \mathrm{X}_{2} & \mathrm{O} \text { (Experimental Group) } \\
\mathrm{R} & \mathrm{O}_{1} & & \mathrm{O} \text { (Comparison Group) }
\end{array}
$$

Figure 6. Experimental Design

Data were collected at baseline and after eight-weeks of the HLP. A total of 22 subjects participated in the study.

Pre-data were collected at the first session of the HLP for Payne County subjects on February 13, 1996. During this session, subjects who were participating in the study were instructed to read and sign the consent form (Appendix I). Afterward, 
subjects' physical measurements were obtained and recorded on the Healthy Living Program Measurement Form and blood was collected by a licensed phlebotomist. Subjects were then given instructions for filling out the Healthy Living Program Survey and the Health Habits and History Questionnaire, while a light snack consisting of juice and a carbohydrate was provided.

On each data collection form, subjects were instructed to check a box to indicate if they were beginning or completing the program. Subjects were instructed to enter a code on the evaluation forms. The code was the subjects' first, middle, and last initials with the last four digits of their phone number. This code was used to match beginning and ending data forms and to ensure data confidentiality. If a subject did not have a phone number, they were instructed to use any four digits as long as they could remember their code from the first and last session. The research assistants collected all completed evaluation forms and indicated which subjects were study controls.

Post-data were collected at the last HLP session eight-weeks later. At this time, subjects completed the Healthy Living Program Measurement Form, Food and Nutrition Behavior Questionnaire, and the Healthy Habits and History Questionnaire.

At both pre-data and post-data collections, the research assistants reviewed the Food and Nutrition Behavior Questionnaire and the Health Habits and History Questionnaire with each subject and answered any questions. In addition, the research assistants were available to clarify any questions and to verify that all forms were properly completed. At both pre and post data collections, 
anthropometric, biochemical, clinical, and dietary indicators of nutritional status were obtained.

\section{Anthropometric Measures}

Anthropometric measurements obtained at the beginning and end of the HLP included total body weight and height. In addition, Body Mass Index (BMI) was also calculated.

\section{$\underline{\text { Height }}$}

Subject's height was measured during the first session using a measuring stick affixed to the wall. The measuring stick was measured 36 inches ( 3 feet) from the floor allowing a total of 72 inches ( 6 feet). Subjects were measured standing erect. without shoes, with heels together. The measurement was read to the nearest $1 / 8$ inch.

Weight

Subjects were weighed on a beam scale without shoes and dressed in light-werght clothing. Weight was measured in pounds to the nearest $1 / 4$ pound.

Body Mass Index

BMI, an indicator of body fat, was calculated using the following formula (Basic Nutrition and Diet Therapy, 1993):

$$
\mathrm{BM}=\frac{\text { weight }(\mathrm{kg})}{\text { height }\left(\mathrm{m}^{2}\right)}
$$


The following table defines the points ranging from underweight to morbidly obese:

\begin{tabular}{|lcc|}
\hline Category & Women & Men \\
\hline Underweight & $<19.1$ & $<20.7$ \\
Acceptable Weight & 19.1 to 27.3 & 20.7 to 27.8 \\
Overweight & $>27.3$ & $>27.8$ \\
Severe Overweight & $>32.3$ & $>31.1$ \\
Morbid Obesity & $>44.8$ & $>45.4$ \\
\hline
\end{tabular}

(Witney, Hamilton, \& Rolfes, 1990)

\section{Frame Size}

Frame size was collected at the end of the eight-week program. Wrist circumference was obtained in order to estimate subjects' frame size. Frame size was determined using wrist circumference and height (Lee \& Nieman, 1996).

Subjects were instructed to position their right arm flexed at the elbow with the palm up. A narrow measuring tape was placed around the smallest part of the wrist distal to the styloid process of the radius and ulna (Figure 7). Measurements were recorded to the nearest 0.1 centimeter. The body frame size chart was consulted to determine subjects' frame size (Figure 8). 


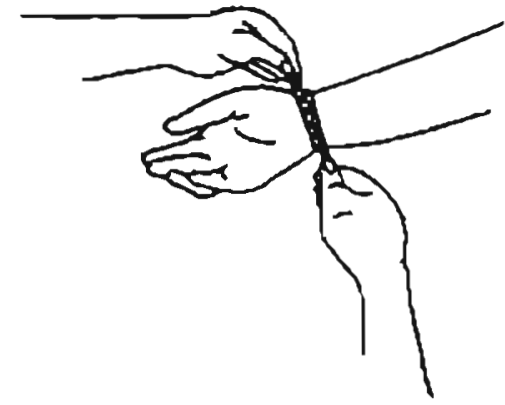

Figure 7. Wrist Círcumference Measurement
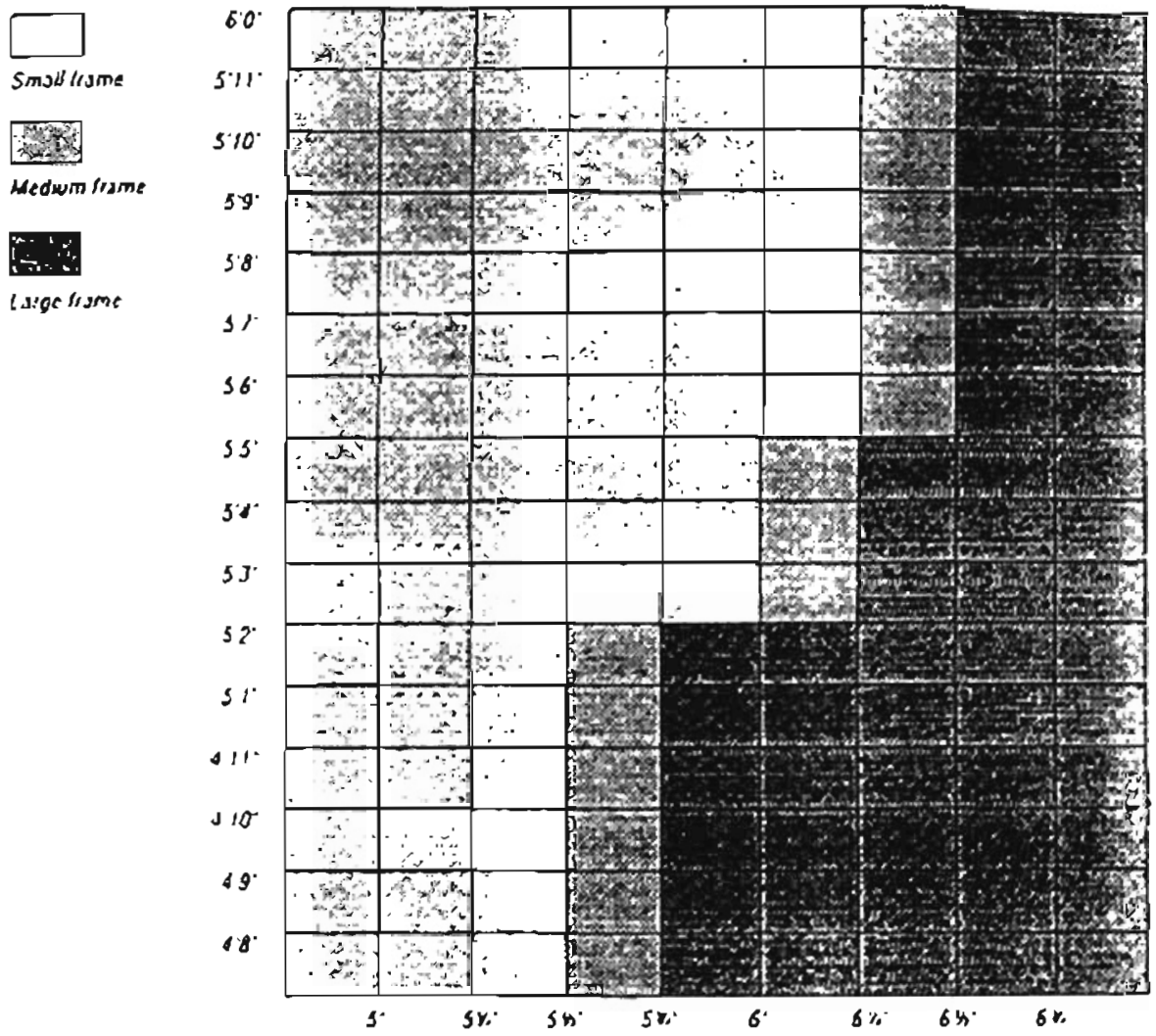

Figure 8. Body Frame Size Chart (Lee \& Nieman, 1996) 
Biochemical Measures

The following biochemical measures were obtained during the beginning and end of the HLP: Fasting total serum cholesterol, fasting serum LDL-cholesterol, fasting serum HDL-cholesterol, fasting serum triglycerides, and fasting serum blood glucose.

Blood Collection \& Analysis

Subjects fasted for 12 hours prior to each blood collection. A licensed phlebotomist drew a $10 \mathrm{~mL}$ blood sample. Blood was placed on ice for no more than 2 hours. To obtain the serum, the Beckman Centrifuge model TJ-6 was used at maximum speed for 1 hour at $4^{\circ}$ Celsius. The serum was frozen at $20^{\circ}$ Celsius for later analysis of total cholesterol, HDL-cholesterol, triglyceride, and fasting serum glucose.

Biochemical values were obtained using Sigma Diagnostic Procedures adapted for the Fara Clinical Analyzer (Roche Cobra Fara, Somerville, N.J.):

- Total Cholesterol was obtained using Sigma Diagnostic Procedure kit No. 352.

- HDL-cholesterol was obtained using Sigma Diagnostic Procedure kit No. 352-3.

- Triglycerides were obtained using Sigma Diagnostic Procedure kit No. 337.

- LDL-cholesterol was calculated using the following formula:

LDL $=$ Total Cholesterol $-[$ HDL-Cholesterol + Trig]ycerides / 5]

- Fasting glucose was obtained using Sigma Diagnostic Procedure kit No. 16-UV. 
Subjects received their individual blood values by mail (Appendix J). The following are the criteria used to evaluate serum lipids and glucose concentrations (Lee \& Nieman, 1996).

Table 7. Concentration values used in Healthy Living Nutrition Education Program

\begin{tabular}{|c|c|c|}
\hline Blood Component & Range & Value \\
\hline Total Cholesterol & $\begin{array}{c}<200 \mathrm{mg} / \mathrm{dl} \\
200-239 \mathrm{mg} / \mathrm{dl} \\
>240 \mathrm{mg} / \mathrm{dl}\end{array}$ & $\begin{array}{c}\text { Desirable } \\
\text { Borderline } \\
\text { High }\end{array}$ \\
\hline LDL-Cholesterol & $\begin{array}{c}<130 \mathrm{mg} / \mathrm{dl} \\
130-159 \mathrm{mg} / \mathrm{d} \\
>160 \mathrm{mg} / \mathrm{dl}\end{array}$ & $\begin{array}{c}\text { Desirable } \\
\text { Borderline } \\
\text { High }\end{array}$ \\
\hline HDL-Cholesterol & $\begin{array}{l}>60 \mathrm{mg} / \mathrm{dl} \\
<35 \mathrm{mg} / \mathrm{dl}\end{array}$ & $\begin{array}{c}\text { Desirable } \\
\text { Low }\end{array}$ \\
\hline Triglycerides & $\begin{array}{c}<200 \mathrm{mg} / \mathrm{dl} \\
200-339 \mathrm{mg} / \mathrm{dl} \\
400 \cdot 1000 \mathrm{mg} / \mathrm{dl} \\
>1000 \mathrm{mg} / \mathrm{dl}\end{array}$ & $\begin{array}{c}\text { Desirable } \\
\text { Borderline } \\
\text { High } \\
\text { Very High }\end{array}$ \\
\hline Fasting Blood Glucose & $\begin{array}{c}70 \cdot 120 \mathrm{mg} / \mathrm{dl} \\
120-140 \mathrm{mg} / \mathrm{dl} \\
>140 \mathrm{mg} / \mathrm{dl} \\
<70 \mathrm{mg} / \mathrm{dl}\end{array}$ & $\begin{array}{c}\text { Desirable } \\
\text { Borderline High } \\
\text { High } \\
\text { Low }\end{array}$ \\
\hline
\end{tabular}




\section{Clinical Measures}

Clinical measurements obtained at the beginning and end of the HLP included both systolic blood pressure and diastolic blood pressure.

\section{Blood Pressure}

Blood pressure was measured by the principle researcher. The following are the criteria used to evaluate blood pressure (HHS, 1994).

\begin{tabular}{ccc} 
& \multicolumn{2}{c}{ Blood Pressure Level $(\mathbf{m m} \mathbf{H g})$} \\
\hline Category & Systolic & Diastolic \\
\hline Normal & $<130$ & $<85$ \\
High Normal & $130-139$ & $85-89$
\end{tabular}

\section{Dietary Measures}

Dietary measures in the study included the Food and Nutrition Behavior Questionnaire and the Heaith Habits and History Questionnaire. Both forms were self-administered and required about 20 minutes to complete.

The Food and Nutrition Behavior Questionnaire, which was used to evaluate dietary practices, consisted of 18 questions. Using a 5-point Likert scale format ranging from "never" to "almost always", subjects were asked to check which statement best represented their practices. The 18 questions in the Food and Nutrition Behavior Questionnaire were subdivided into the following categories for analysis: 
Food Safety . . . . . . . . . . . . . . . . 3 questions

Food Selection and Preparation ............. 10 questions

Food Intake $\ldots \ldots \ldots \ldots \ldots \ldots \ldots \ldots \ldots \ldots$ questions

The Food and Nutrition Behavior Questionnaire Score was the total score obtained from answering all 18 questions. The Food Safety Score was the sum of the 3 food safety questions, the Food Selection and Preparation Score was the sum of the 10 food selection and preparation questions, and the Food Intake Score was the sum of the 5 food intake questions.

The Health Habits and History Questionnaire consisted of 99 questions and subjects were asked to report their serving size by placing a check in the box $S$ (small), M (medium), or L (large). A medium serving size was defined on the form as an example. In order for subjects to visualize serving sizes, food models constructed of dried beans wrapped in colored netting were used. Subjects were instructed to look at the bean bags to visualize what a small, medium, or large serving represented. In addition, subjects were asked to report how often, on average, they had consumed specific food items. The frequency responses included daily, weekly, monthly, yearly, or rarely/never. 
The categories of foods are listed below:

Fruits \& Juices . . . . . . . . . . . . . . . . . 13 questions

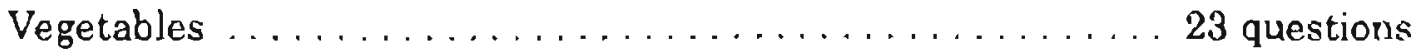

Meat, Fish, Poultry, \& Mixed Dishes............... 14 questions

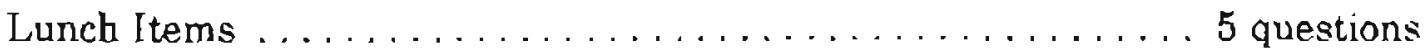

Breads, Salty Snacks, \& Spreads .................. 9 questions

Breakfast Foods . . . . . . . . . . . . . . . . 8 questions

Sweets . . . . . . . . . . . . . . . . . . . . 6 questions

Dairy Products ........................6 questions

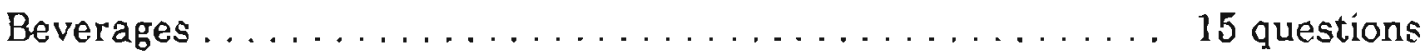

The Health Habits and History Questionnaire was coded and analyzed using the software provided by the National Cancer Institute (1987). This program calculated nutrient intakes based on frequency of consumption and portion sizes from the Health Habits and History Questionnaire (Appendix K). Data were used to determine the percentage of calories from fat, protein, and carbohydrate and mean servings from the Food Guide Pyramid food groups. 


\section{Statistical Analysis}

Data were analyzed using the Statistical Analysis System (SAS Inst. Inc., Cary NC, 1989) version 6.08. Mean values were compared between the control group and the education group using SAS analysis of variance to determine if the groups were similar. After participating in the eight-week HLP, changes in subjects' food and nutrition behavior, dietary intake, anthropometric measurements, and biochemical concentrations were compared to controls using the SAS General Linear Models procedure. Significant differences were determined using Least Squares Means. Significance level was set at 0.05 . 


\title{
CHAPTER IV
}

\section{RESULTS AND DISCUSSION}

\author{
Introduction
}

The purpose of this study was to evaluate the effects of an eight week Oklahoma Cooperative Extension Service nutrition education program, HLP, in a rural county in Oklahoma on food selection, preparation, and food safety practices and behaviors, dietary intake, and anthropometric and biochemical health measures. The objectives of the study were: 1) Payne county subjects will engage in healthy lifestyle practices that promote healthy living, 2) Payne County subjects will adopt the USDA Food Guide Pyramid Dietary Recommendations, 3) Payne County subjects will adopt the USDA.HHS Dietary Guidelines/Dietary Recommendations, 4) Payne County subjects will adopt safe food selection, preparation, and storage practices, and 5) Payne County subjects will improve personal health status indicators.

\section{Description of Subjects}

The subjects in the study were independently living volunteers from the community of Stillwater (a town of Payne County), Oklahoma. A total of 22 subjects participated in the HLP and were part of the study; however, only 21 subjects were included in the data analysis because one subject forgot to fast prior to the post data collection period. The control group consisted of ten females with a mean age of $51 \pm 10$ years, mean beight of $65 \pm 3$ inches, mean weight of $164 \pm 33$ pounds, and a 
mean BMI of $27.5 \pm 5.1\left(w_{\left.t / h t^{2}\right)}\right.$ (Table 8$)$. The education group consisted of 11 females with a mean age of $62 \pm 16$ years, mean height of $64 \pm 2$ inches. mean weight of $158 \pm 27$ pounds and a mean BMI of $27.6 \pm 4.6$ (wt/ht $t^{2}$ ) (Table 8). At baseline, the education group had a significantly higher mean age than the control group. Mean body weight for both the control group and the education group were considered to be above recommended ranges (Lee \& Nieman, 1996); however, mean body mass index values were considered as overweight (Cummings, et al., 1997).

Table 8. Baseline Characteristics of Subjects

\begin{tabular}{|l|c|c|}
\hline & $\begin{array}{c}\text { Control Group } \\
\mathbf{n}=11\end{array}$ & $\begin{array}{c}\text { Education Group } \\
\mathbf{n}=10\end{array}$ \\
\hline Characteristics & Pre & Pre \\
\hline Age (years) & $51 \pm 10$ & $62 \pm 16^{\circ}$ \\
\hline Height (inches) & $65 \pm 3$ & $64 \pm 2$ \\
\hline Weight (pounds) & $164 \pm 33$ & $158 \pm 27$ \\
\hline BMI (kg/m 2$)$ & $27.5 \pm 5.1$ & $27.6 \pm 4.6$ \\
\hline
\end{tabular}

${ }^{1}$ Means $\pm S D$.

- Significant difference in measurements at baseline between groups, $\mathrm{p} \leq 0.05$.

*Change in pre to post measurements significantly different from control group, $\mathrm{p} \leq 0.05$.

Baseline Data on Food and Nutrition Behavior

The Food and Nutrition Behavior Questionnaire scores were analyzed using SAS analysis of variance (Table 9). Subject's mean total score, and subscores for safety 
score, food selection and preparation score, and food intake score are reported in Table 9. At baseline, there were no sigaificant differences in total scores, food safety scores, food selection and preparation scores, or food intake scores between the control group and the education group from the Food and Nutrition Behavior Questionnaire.

Table 9. Survey Score and Subscores Education Group. ${ }^{1}$

\begin{tabular}{|c|c|c|c|c|}
\hline \multirow[b]{2}{*}{ Survey Score } & \multicolumn{2}{|c|}{$\begin{array}{c}\text { Control Group } \\
n=11\end{array}$} & \multicolumn{2}{|c|}{$\begin{array}{c}\text { Education Group } \\
n=10\end{array}$} \\
\hline & Pre & Post & Pre & Post \\
\hline Total Score: & $68 \pm 9$ & $59 \pm 21$ & $61 \pm 19$ & $74 \pm 5^{*}$ \\
\hline $\begin{array}{l}\text { Survey Subgroup } \\
\text { Scores: }\end{array}$ & & & & \\
\hline $\begin{array}{l}\text { Safety } \\
\text { Selection/Preparation } \\
\text { Food Intake }\end{array}$ & $\begin{array}{l}14 \pm 2 \\
37 \pm 7 \\
18 \pm 2\end{array}$ & $\begin{array}{c}12 \pm 4 \\
32 \pm 12 \\
16 \pm 6\end{array}$ & $\begin{array}{c}14 \pm 1 \\
33 \pm 12 \\
14 \pm 8\end{array}$ & $\begin{array}{l}14 \pm 1 \\
41 \pm 1^{*} \\
19 \pm 3^{*}\end{array}$ \\
\hline
\end{tabular}

${ }^{1}$ Means $\pm \mathrm{SD}$.

'Significant difference in measurements at baseline between groups, $p \leq 0.05$.

*Change in pre to post measurements significantly different from control group. $\mathrm{p} \leq 0.05$.

Effects of the HLP On Food And Nutrition Behavior

After the eight-week HLP, marked improvements in food and nutrition behavior were observed for the nutrition education group. A significant increase in the total Food and Nutrition Behavior Questionnaire score was observed within the education group compared to the control group $(p=0.0163)$ (Table 9 ). Additionally, within the 
education group, $82 \%$ had an increase in the total Food and Nutrition Behavior Questionnaire score.

No significant change in the food safety score was abserved for the education group compared to the control group; however, it is interesting to note that the mean food safety score remained the same in the education group whereas the mean food safety score decreased in the control group. A significant increase in the food selection and preparation score was observed in the education group compared to the control group ( $p=0.0174$ ) (Table 9). After completion of the HLP, $82 \%$ of the education group had an increase in their food selection and preparation score. A significant increase in the food intake score also was observed within the education group compared to the control group $(p=0.0177)$ (Table 9). Within the education group, $73 \%$ had an increase in their food intake score.

Within the education group, there was a lack of change in the survey subgroup score of food safety. There are a number of possible explanations for this. The Health Belief Model, which attempts to explain preventive health behavior, emphasizes that a person's beliefs about health determine readiness to take action (Holli \& Calabrese, 1991). According to the Health Belief Model, the higher the perceived threat, the more motivated the person will be to take necessary action to reduce the threat (Contento, et al., 1995). According to Food Marketing Institute (1997), there has been no increase in the number of people who have reported changing their behavior as a result of safe-handling labels placed on meat and poultry products. Of 1.011 surveyed, only $18 \%$ of people reported washing and disinfecting counters, cooking areas, and utensils after contact with meat. Furthermore, only $13 \%$ reported washing their hands more often. It is obvious from 
these surveys that most people do not view food safety as a personal threat, regardless of the recent outbreaks of $E$. coli. Perhaps another explanation is the fact that time was limited for teaching the HLP and many topics were covered during the one hour session. Food safety was covered last in both session six and session seven and there may not have been an adequate amount of time for teaching food safety lessons. Another possible explanation for the lack of change in food safety subscores could be that food safety problems often occur in the location where consumers are least likely to expect them. It may be that some people believe that threats to food safety occur in processing facilities or restaurants, instead of their own homes and disregard important food safety issues (Knabel, 1995). This is consistent with the findings from the Food Marketing Institute (1997) where $33 \%$ of 1,011 people surveyed thought that manufacturers and food processors were responsible for ensuring food safety and $31 \%$ of people thought that the government was primarily responsible. It is also noteworthy to mention the sample size was very small for the study and included older adults. As mentioned previously, Aitekruse et al. (1996) found that gender, age, and frequent food preparation were related to safe food handling practices. Although knowledge of food handling practices did not increase with age, safe practices did.

Since 1995, the HLP has now reached 498 individuals and has continued to impact the overall nutritional status of Oklahomans. According to the two-year statewide evaluation summary, the food and nutrition behavior questionnaire data have been received from 344 participants. A significant increase was observed in the Food and Nutrition Behavior Questionnaire Score $(p \leq 0,000$ l). Eighty-six percent of the HLP participants showed an increase in the Food and Nutrition 
Behavior Questionnaire Scores. Not only has there been a significant increase in the overall Food and Nutrition Behavior Questionnaire Scores, but a significant increase was observed in food selection and preparation scores $(p=\leq 0.0001)$, and food intake scores (p $\leq 0.0001$ ). Thus, $79 \%$ of the HLP participants are increasing their food selection and preparation scores, and $62 \%$ are increasing their food intake scores.

\section{Baseline Data On Dietary Intake}

Dietary intake estimates were calculated using the software developed by Block et al., (1986) and are provided in Table 10. At baseline, the education group had a significantly higher percent of calories from protein than the control group. No other significant differences were observed between the two groups for dietary intake variables at baseline. 
Table 10. Dietary Intake By Education Group ${ }^{1}$

\begin{tabular}{|c|c|c|c|c|}
\hline \multirow{2}{*}{$\begin{array}{l}\begin{array}{l}\text { Dietary Intake } \\
\text { Variables }\end{array} \\
\text { Percent of Calories } \\
\text { From: }\end{array}$} & \multicolumn{2}{|c|}{$\begin{array}{c}\text { Control Group } \\
n=11\end{array}$} & \multicolumn{2}{|c|}{$\begin{array}{c}\text { Education Group } \\
\mathbf{n}=10\end{array}$} \\
\hline & Pre & Post & Pre & Post \\
\hline $\begin{array}{l}\text { Fat } \\
\text { Protein } \\
\text { Carbohydrate }\end{array}$ & $\begin{array}{l}31 \pm 8 \\
16 \pm 3^{\circ} \\
53 \pm 9\end{array}$ & $\begin{array}{l}32 \pm 6 \\
17 \pm 2 \\
51 \pm 8\end{array}$ & $\begin{array}{c}30 \pm 7 \\
19 \pm 3^{a} \\
51 \pm 7\end{array}$ & $\begin{array}{l}32 \pm 7 \\
18 \pm 3 \\
50 \pm 7\end{array}$ \\
\hline $\begin{array}{l}\text { Servings from the } \\
\text { Food Guide Pyramid }\end{array}$ & & & & \\
\hline $\begin{array}{l}\text { Bread, Cereal, Rice and } \\
\text { Pasta } \\
\text { Vegetable } \\
\text { Fruit } \\
\text { Milk, Yogurt and Cheese } \\
\text { Meat, Poultry, Fish, Dry } \\
\text { Beans, Eggs and Nuts } \\
\text { Fats, Oils and Sweets }\end{array}$ & $\begin{array}{l}4.4 \pm 3.1 \\
3.5 \pm 1.6 \\
4.4 \pm 5.9 \\
2.6 \pm 2.3 \\
1.9 \pm 0.8 \\
3.0 \pm 2.5\end{array}$ & $\begin{array}{l}3.4 \pm 1.4 \\
\\
3.0 \pm 0.7 \\
2.5 \pm 1.0 \\
1.7 \pm 0.8 \\
1.7 \pm 0.7\end{array}$ & $\begin{array}{l}3.2 \pm 1.9 \\
3.2 \pm 1.5 \\
2.1 \pm 1.6 \\
2.0 \pm 1.2 \\
1.8 \pm 0.8 \\
2.2 \pm 1.6\end{array}$ & $\begin{array}{l}3.2 \pm 0.9 \\
3.5 \pm 1.9 \\
2.4 \pm 2.3 \\
2.3 \pm 1.0 \\
2.0 \pm 0.6\end{array}$ \\
\hline
\end{tabular}

'Means \pm SD.

${ }^{s}$ Significant difference in measurements at baseline between groups, $p \leq 0.05$.

${ }^{*}$ Change in pre to post measurements significantly different from control group, $\mathrm{p} \leq 0.05$.

\section{Effects of the HLP on Dietary Intake}

No significant changes were observed from pre to post in the education group compared to the control group in the number of servings from the Food Guide Pyramid food groups; however, when the education group's dietary intake was compared to the recommended number of servings from the Food Guide Pyramid food groups (Table 11), it was observed that participants' initial dietary intakes closely resemble the recommended number of servings. With the exception of the 
breads, cereals, rice, and pasta group, the participants in the education group met the number of servings recommended by the Food Guide Pyramid prior to the HLP. This, in itself, could help clarify why significant changes were not observed from pre to post in the education group compared to the control group.

Although significant changes were not observed in the education group compared to the control group, changes in the daily servings for each major food group were noted. These changes reflected an increased number of daily servings of bread. cereal, rice, and pasta (45\%), vegetables (45\%), fruit (54\%), meat, poultry, fish, dry beans, eggs, and nuts (45\%), milk, yogurt, and cheese (54\%), and a decreased number of daily servings of fats, oils, and sweets (64\%). Changes in the number of daily servings of milk, yogurt, and cheese group approached significance $(p \leq 0.088)$, with the control group having a slight decrease $(-0.9)$ in the number of daily servings and the education group having a slight increase $(+0.3)$.

No significant differences were observed in percent of calories from fat, protein, and carbohydrate in the education group compared to the control group; however, the education group already met dietary recommendations for percent of calories from fat prior to the HLP (Table 11). According to the dietary intake for percent of calories from protein and carbohydrate, participants were at the upper end of the dietary recommendations for protein and the lower end for carbohydrate (Table 11). 
Table 11. Dietary Intake Compared to Recommended Daily Values

\begin{tabular}{|c|c|c|}
\hline Dietary Intake & Mean & Goals \\
\hline \multicolumn{3}{|l|}{ Percent of Calories From: } \\
\hline Fat & $30 \pm 7$ & $\leq 30 \%$ \\
\hline Protein & $19 \pm 3$ & $10-20 \%$ \\
\hline Carbohydrate & $51 \pm 7$ & $50-60 \%$ \\
\hline \multicolumn{3}{|l|}{ Servings from the Food Guide Pyramid: } \\
\hline Breads, Cereals, Rice, and Pasta & $3.2 \pm 1.9$ & $6 \cdot 11$ \\
\hline Vegetables & $3.2 \pm 1.5$ & $3 \cdot 5$ \\
\hline Fruits & $2.1 \pm 1.6$ & $2 \cdot 4$ \\
\hline Milk, Yogurt, and Cheese & $2.0 \pm 1.2$ & $2 \cdot 3$ \\
\hline $\begin{array}{l}\text { Meat, Poultry, Fish, Dry Beans, Eggs, } \\
\text { and Nuts }\end{array}$ & $1.8 \pm 0.8$ & $2-3$ \\
\hline Fats, Oils, and Sweets & $2.2 \pm 1.6$ & Moderation \\
\hline
\end{tabular}

'Means \pm SD.

aSignificant difference in measurements at baseline between groups, $\mathrm{p} \leq 0.05$.

"Post values significantly different from pre measurements within a group, $p \leq 0.05$.

*Change in pre to post measurements significantly different from control group, $p \leq 0.05$. 
The researcher acknowledges the importance of increasing the number of servings of breads, cereals, rice, and pasta to at least 6 servings in the diet per day. If subjects were to increase their intake of breads, cereals, rice, and pasta, this may help bring the percent of calories from carbohydrate within the recommended intake. In order to maintain energy balance, low-fat choices along with physical activity is suggested. Albertson \& Tobelmann (1995) observed similar findings in a study evaluating the frequency in which Americans reported consuming grain foods and whole-grain foods. Researchers concluded that consumption of grain and wholegrain foods were low among the U.S. population. Millen et al. (1997) also found dietary intake levels of carbohydrates to fall short of Dietary Guidelines and suggests designing promotional efforts to increase consumption of not only whole grains, but also legumes, fruits, and vegetables.

The HLP two-year statewide evaluation summary reported that food intake data has been received from 275 participants. Significant increases were observed in the number of daily servings of breads, cereals, rice, and pasta (ps0.0001), vegetables ( $p \leq 0.0002)$, fruits $(p \leq 0.001)$, milk, yogurt, and cheese $(p \leq 0.0001)$, and meat, poultry, fish, dry beans, eggs, and nuts ( $p \leq 0.01)$. There was also a significant decrease in the number of daily servings of fats, oils, and sweets $(p \leq 0.0001)$. These changes reflected an increase in daily servings of breads, cereals, rice, and pasta (4.0 to 4.7), vegetables (2.3 to 2.8), fruits ( 1.9 to 2.3 ), milk, yogurt, and cheese ( 1.6 to 2.1 ), and meat, poultry, fish, dry beans, eggs, and nuts (1.9 to 2.1). Also, the number of daily servings of fats, oils, and sweets decreased from 2.5 to 1.8. Although this data indicates significant increases in servings from each of the food groups to reflect current Dietary Guidelines, it still falls short in achieving the recommended daily servings for both the breads, cereals, rice, and pasta group and the vegetable group. 


\section{Baseline Data on Anthropometric and Biochemical Measures}

Table 12 presents the data on anthropometric and biochemical measurements. At baseline, there was a significant difference in systolic blood pressure with the education group having a significantly higher systolic blood pressure than the control group. In addition, there was a significant difference in HDL-cholesterol concentration with the education group having significantly lower HDL-cholesterol level than the control group. It is noteworthy to mention that the control group was significantly younger, therefore making comparisons between the groups less reliable.

Effects of the HLP on Anthropometric and Biochemical Measures

Significant changes in anthropometric measurements were observed as a result of the HLP (Table 12). Within the education group, there was a significant difference in weight change compared to the control group $(p=0.037)$. An average decrease in total body weight of 1.2 pounds was observed in the education group. On the other hand, an average increase in total body weight of 1.3 pounds was observed in the control group. Within the education group, $55 \%$ had a decrease in total body weight at post data collection. A significant difference in BMI within the education group compared to the control group was also observed $(p=0.0471)$. The education group had an average decrease in BMI $(-0.2)$ whereas the control group had an average increase in BMI $(+0.2)$. Fifty-five percent of the education group had a decrease in BMI. 
Table 12. Anthropometric and Biochemical Measures By Education Group. ${ }^{1}$

\begin{tabular}{|c|c|c|c|c|}
\hline \multirow{2}{*}{$\begin{array}{l}\text { Measurements } \\
\text { Anthropometric: }\end{array}$} & \multicolumn{2}{|c|}{$\begin{array}{c}\text { Control Group } \\
n=11\end{array}$} & \multicolumn{2}{|c|}{$\begin{array}{c}\text { Education Group } \\
n=10\end{array}$} \\
\hline & Pre & Post & Pre & Post \\
\hline $\begin{array}{l}\text { Total Body Weight (lb) } \\
\text { BMI }\left(\mathrm{kg} / \mathrm{m}^{2}\right) \\
\text { Systolic Pressure }(\mathrm{mmHg}) \\
\text { Diastolic Pressure }(\mathrm{mmHg})\end{array}$ & $\begin{array}{c}164 \pm 33 \\
27.5 \pm 5.1 \\
124 \pm 10^{\circ} \\
85 \pm 7\end{array}$ & $\begin{array}{c}166 \pm 33 \\
27.7 \pm 5.0 \\
128 \pm 26 \\
86 \pm 10\end{array}$ & $\begin{array}{c}158 \pm 28 \\
27.6 \pm 4.6 \\
139 \pm 9 \circ \\
86 \pm 9\end{array}$ & $\begin{array}{c}157 \pm 27^{\star} \\
27.4 \pm 4.7^{\star} \\
133 \pm 8 \\
81 \pm 10\end{array}$ \\
\hline \multicolumn{5}{|l|}{ Biochemical: } \\
\hline $\begin{array}{l}\text { Cholesterol (mg/dl) } \\
\text { LDL-Cholesterol (mg/dl) } \\
\text { HDL-Cbolesterol (mg/dl) } \\
\text { Triglycerides (mg/dl) } \\
\text { Glucose (mg/dl) }\end{array}$ & $\begin{array}{c}236 \pm 33 \\
150 \pm 29 \\
64 \pm 16^{\circ} \\
108 \pm 44 \\
95 \pm 22\end{array}$ & $\begin{array}{c}231 \pm 28 \\
142 \pm 30 \\
69 \pm 21 \\
101 \pm 46 \\
114 \pm 19\end{array}$ & $\begin{array}{l}240 \pm 28 \\
166 \pm 35 \\
47 \pm 10^{4} \\
140 \pm 63 \\
107 \pm 31\end{array}$ & $\begin{array}{c}239 \pm 20 \\
161 \pm 27 \\
50 \pm 8 \\
143 \pm 82 \\
141 \pm 34\end{array}$ \\
\hline
\end{tabular}

lMeans \pm SD.

aSignificant difference in measurements at baseline between groups, $p \leq 0.05$.

"Post values significantly different from pre measurements within a group, $p \leq 0.05$.

*Change in pre to post measurements significantly different from control group, $\mathrm{p} \leq 0.05$.

Although not significant, a decrease in systolic blood pressure was observed in the education group compared to the control group and approached significance $(p \leq 0.075)$. Mean systolic blood pressure in the education group decreased from 139 $\mathrm{mm} \mathrm{Hg}$ to $133 \mathrm{~mm} \mathrm{Hg}$, while mean systolic blood pressure in the control group increased from $125 \mathrm{~mm} \mathrm{Hg}$ to $128 \mathrm{~mm} \mathrm{Hg}$. Overall, within the education group, $55 \%$ had a decrease in systolic blood pressure. Other changes observed in the education group, though not significant from the control group, included the following: Fifty-five percent of the participants in the education group had a 
decrease in diastolic blood pressure, total cholesterol, LDL-cholesterol, and $55 \%$ had an increase in HDL-cholesterol. Furthermore, $46 \%$ of the participants in the education group had a decrease in triglycerides and $25 \%$ of the education group had a decrease in glucose. It is interesting to point out that although participants had a low mean fat intake (30\%), mean fasting serum cholesterol concentrations were high (240 mg/dL).

Other studies have shown similar results. Gambera et al. (1995) reported significant reductions in cardiovascular disease risk factors in thirty-two Air Force members applying dietary modification, whicb focused on the Food Guide Pyramid and Dietary Guidelines, in combination with exercise training. Gambera et al. (1995) reported significant weight loss, a significant reduction in BMI, total cholesterol levels, and LDL-cholesterol. Marked improvements in dietary choices were also observed. Dahl \& Read (1995) also observed a reduction in serum cholesterol levels in 68 Veterans Administration (VA) patients following a healthy heart class tbat covered risk factors associated with coronary heart disease. Hermann et al. (1990) also observed significant decreases in body weight, total serum cholesterol, LDL-cholesterol, triglycerides, systolic blood pressure, and diastolic blood pressure as a result of a Cooperative Extension Service nutrition and exercise program for older adults.

The HLP two-year statewide evaluation summary indicates that anthropometric and biochemical data have been received from 342 participants. Significant decreases have been reported in total body weight, BMI, total cholesterol, and LDLcholesterol. Body weight was significantly reduced $(p \leq 0.01)$ from 170 pounds to 166 pounds with $65 \%$ of participants exhibiting a reduction in body weight. Although 
this does not represent a large number, the researcher points out that the HLP is an eight week program that acknowledges weight loss recommendations of $1 / 2$ to 1 pound per week. BMI also significantly decreased $(p \leq 0.001)$ from 29 to 28 with $65 \%$ of participants showing a decrease in BMI. A sigaificant decrease in blood cholesterol was also observed $(p \leq 0.0002)$. Average total cholesterol decreasing from $212 \mathrm{mg} / \mathrm{dl}$ to $202 \mathrm{mg} / \mathrm{dl}$ with $67 \%$ of participants having a decrease in blood cholesterol. Lastly, a significant decrease $(\leq 0.02)$ was observed in LDL.cholesterol with a decrease from $141 \mathrm{mg} / \mathrm{dl}$ to $133 \mathrm{mg} / \mathrm{dl}$. Sixty-three percent of the participants had a decrease in LDL cholesterol. Interesting, but not significant were decreases in both systolic and diastolic blood pressure, triglycerides, and glucose concentrations. Fifty-four percent of participants had a decrease in systolic blood pressure and $55 \%$ of participants had a decrease in diastolic blood pressure. According to the data, $53 \%$ of participants had a decrease in triglycerides with average triglycerides decreasing from $185 \mathrm{mg} / \mathrm{dl}$ to $180 \mathrm{mg} / \mathrm{dl}$. Furthermore, average glucose concentrations decreased from $104 \mathrm{mg} / \mathrm{dl}$ to $92 \mathrm{mg} / \mathrm{dl}$. 


\section{CHAPTER $V$}

\section{SUMMARY, CONCLUSIONS, AND RECOMMENDATIONS}

\section{Summary of Findings}

The purpose of this study was to evaluate the effects of an eight-week Oklahoma Cooperative Extension Service nutrition education program, HLP, in a rural county in Oklahoma on food selection, preparation, and food safety practices and behaviors, dietary intake, and anthropometric and biochemical health measures. This study also evaluated the impact of the HLP on food selection, food preparation and food safety behaviors, dietary intake, and anthropometric and biochemical measures.

The objectives of the Healthy Living Program were: 1) Payne County subjects will engage in healthy lifestyle practices that promote healthy living, 2) Payne County subjects will adopt the United States Department of Agriculture (USDA) Food Guide Pyramid dietary recommendations, 3) Payne County subjects will adopt the United States Department of Agriculture-Health \& Human Service (USDA. HHS) dietary guidelines/dietary recommendations, 4) Payne County subjects will adopt safe food selection, preparation, and storage practices, and 5) Payne County subjects will improve personal health status indicators.

An eight-week nutrition education program was shown to have a significant impact on rural county Oklahomans' food and nutrition behavior, dietary intake, and important health status indicators.

Hypothesis one stated: There will be no significant difference as a result of an eight-week Healthy Living Program on changes in subjects' Food and Nutrition Behavior Questionnaire Scores compared to controls for: 

a. Food Safety
b. Food Selection and Preparation
c. Food Intake

As seen in Table 9, a significant difference was observed in food selection and preparation scores and in food intake scores; however, there was not a significant difference in food safety scores. Therefore, the researcher rejected the null hypothesis for food selection and preparation and food intake and failed to reject the null hypothesis for food safety.

Hypothesis two stated: There will be no significant difference as a result of an eight-week Healthy Living Program on changes in subjects' number of servings from the Food Guide Pyramid groups compared to controls for:

a. Breads, Cereals, Rice, and Pasta group

b. Vegetable group

c. Fruit group

d. Milk, Yogurt, and Cheese group

e. Meat, Poultry, Fish, Dry beans, Eggs, and Nuts group

f. Fats, Oils, and Sweets group

As indicated in Table 10, there was no significant difference observed in servings from each of the food groups within the Food Guide Pyramid. Therefore, the researcher failed to reject the second null hypothesis.

Hypothesis three stated: There will be no significant difference as a result of an eight-week Healthy Living Program on changes in subjects' percentage of calories compared to controls for: 

a. Fat
b. Protein
c. Carbohydrates

As revealed in Table 11, there was no significant differences in percent of calories from fat, protein, and carbohydrate. Therefore, the researcher failed to reject the third null hypothesis.

Hypothesis four stated: There will be no significant difference as a result of an eight-week Healthy Living Program on changes in subjects' anthropometric and biochemical measures compared to controls for:

a. Total Body Weight

b. Body Mass Index

c. Blood Pressure

d. Fasting Total Serum Cholesterol

e. Fasting Serum LDL-Cholesterol

f. Fasting Serum HDL-Cholesterol

g. Fasting Serum Triglycerides

h. Fasting Serum Glucose

As seen in Table 12, significant differences were observed in total body weight and BMI; however, there was no significant difference observed in both systolic and diastolic blood pressure, total serum cholesterol, LDL-cholesterol. HDL-cholesterol, triglycerides, and glucose. Therefore, the researcher rejected the null hypothesis for total body weight and BMI and failed to reject the fourth null hypothesis for blood pressure, fasting total serum cholesterol, fasting serum LDL-cholesterol, fasting serum HDL-cholesterol, fasting serum triglycerides, and fasting serum glucose. 
The results observed in this study show that an eight-week Oklahoma Cooperative Extension service nutrition education program can be effective in improving food selection and preparation scores, total body weight, and BMI.

\section{Conclusions}

Health promotion and disease prevention goals have focused on diet, while nutrition education goals have focused on the individual. Dietary behavior change is complex and there are several factors to consider. An ecological approach for nutrition education implies that an individual's behavior is influenced by a variety of factors such as intrapersonal, interpersonal, institutional, community, and public policy (McLeroy et al., 1988). Nutrition education research is vital in identifying food-related behaviors and motivations and selecting appropriate behavioral change strategies to achieve and maintain optimal nutritional health (ADA position paper, 1996). Behavioral change strategies involve a combination of theories to encourage the development of new behavior (Holli \& Calabrese, 1991). Nutrition education is a significant factor for improving dietary behavior when goals include behavioral change strategies as well as educational strategies and are designed with that purpose in mind.

The HLP demonstrates how an eight-week Cooperative Extension nutrition education program can make an impact in a rural county in Oklahoma by combining resources from the community, such as the media, health professionals, professional organizations, and local supermarkets. In addition, the HLP was conducive to social networks and social support systems, such as friends, family, and co-workers. Changes in food and nutrition behavior, dietary intake, total body weight. BMI, blood pressure, and serum lipid concentrations were observed as a result of dietary 
intervention strategies. Dietary intervention strategies included dietary educational tools, such as the Food Guide Pyramid and the Dietary Guidelines for Americans and education strategies such as recipe modification, supermarket tours, and cooking demonstrations.

\section{Recommendations}

In order for Oklahomans to achieve and maintain optimal nutritional health, it is imperative for Oklahoma Cooperative Extension to continue to assess food and nutrition concerns, behaviors, and practices within the community, design food and nutrition education programs based on current scientific research, and deliver them in a clear, simple, and motivating way. From the two-year state-wide summary, it is apparent that nutrition education efforts focus on promoting an increase in the breads, cereals, rice, and pasta group within the Food Guide Pyramid. Furthermore, from the recent outbreaks of foodborne illness in the U.S., it is clear that food safety education be provided to change current food behaviors and practices. Future recommendations for the developmenl of a food and nutrition education program should consider a larger randomized sample size, a theoretical framework for understanding attitudes and beliefs, an exercise component, and methods introducing specific behavioral change strategies that focus on goal setting and modeling. Other considerations include increasing food safety questions on the Food and Nutrition Behavior Questionnaire and administering a food-frequency questionnaire of shorter length. In addition, a follow up evaluation after six months is recommended to determine if changes are permanent and easily maintained. 
The costs to the American public for chronic diseases is astronomical. Coronary heart disease accounts for more than $\$ 100$ billion in direct care expenditure alone. The Oklahoma Cooperative Extension Service is a vital part in the continual process for improving Oklahomans' nutritional status by developing nutrition education programs that increase food and nutrition knowledge, food safety practices, and overall health status, which may reduce the number of deaths due to coronary hearl disease. 


\section{BIBLIOGRAPHY}

Achterberg, C., \& Clark, K. L. (1992). A retrospective examination of theory use in nutrition education. Journal of Nutrition Education 24(5), 227-233.

Achterberg, C., McDonnell, E., \& Bagby, R. (1994). How to put the Food Guide Pyramid into practice. Journal of American Dietetic Association, 94(9), 1030-1035.

Albertson, A. M.. \& Tobelmann, R. C. (1995). Consumption of grain and wholegrain foods by an American population during the years of 1990 to 1992. Journal of American Dietetic Association, 95(6), 703-704.

Altekruse, S. F., Street, D. A., Fein, S. B., \& Levy, A. S. (1996). Consumer knowledge of foodborne microbial hazards and food-handling practices. Journal of Food Protection, $\underline{59}(3), 287-294$.

ADA. (1993). 1993 Survey of American Dietary Habits. Chicago, Il.

ADA. National Nutrition Month@--Fact Sheet \{On-line\}. Available: htttp://www.eatright.org/pressnnm01.html.

ADA. (1995). Position Paper: Food and nutrition misinformation. Journal of American Dietetic Association, 95(6), 705-707.

ADA. (1993) Position Paper: Health implications of dietary fiber. Journal of American Dietetic Association, 93(12), 1446-1447.

ADA. (1990). Position Paper: Nutrition and health information of food labels. Journal of American Dietetic Association, 90(4), 583.585.

ADA. (1996). Position Paper: Nutrition education for the public Journal of American Dietetic Association, 96 (11), 1183-I 187 .

ADA. (1997). Position Paper: Weight management. Journal of American Dietetic Association, 97(1), 71-74.

AHA. (1994). Heart and Stroke Facts: 1994 Statistical Supplement. p. 8.

Anderson, S. A., \& Waters, J. H. (1996). Executive summary from the third report on nutrition monitoring in the United States. Journal of Nutrition, 126(suppl.). 1907S-1936S. 
Baldwin, T. T., \& Falciglia, G.A. (1995). Application of cognitive behavioral theories to dietary change in clients. Journal of American Dietetic Association, 95(11), 1315-1317.

Basic Nutrition and Diet Therapy. (1973). (7th ed). (pp. 56.57). MacMillan Publishing Co.

Bender, M. M., \& Derby, B. M. (1992). Prevalence of reading nutrition and ingredient information on food labels among adult Americans: 1982-1988. Journal of Nutrition Education, 24(6), 292-297.

Bialostosky, K., \& St. Jeor, S. T. (1996). The 1995 Dietary Guidelines for Americans. Nutrition Today, $\underline{31}(1), 6-11$.

Block, G., Hartman, A. M., Dresser, C. M., Carroll, M. D., Gannon, J., \& Gardner, L. (1986). A data-based approach to diet questionnaire design and testing. American Journal of Epidemiology, 124(3), 453-469.

Block, G., Woods, M., Potosky, A., \& Clifford, C. (1990). Validation of a selfadministered diet history questionnaire using multiple diet records. Journal of Clinical Epidemiology, $\underline{43}(12), 1327 \cdot 1335$.

Brandt, E. N., Broyles, R. W., Falcone, D. J., \& Hann, N. E. (1994). Progress toward Healthy People 2000: A preliminary look at Oklahoma. Journal of Oklahoma State Medical Association, 87, 555-558.

Briefel, R. R., Flegal, K. M., Winn, D. M., Loria, C. M., Johnson, C. L., \& Sempos, C. T. (1992). Assessing the nation's diet: Limitations of the lood frequency questionnaire. Journal of American Dietetic Association, $\underline{92}(8)$, 959-962.

CDC (Center for Disease Control). (1993). Health Promotion and Disease Prevention: United States 1990. Vital and Health Statistics, 10(185), 1.23.

Contento, I., Balch, G. I., Bronner, Y. L., Lytle, L. A., Maloney, S. K., Olson, C. M.. \& Swadener. S.S. (1995). The effectiveness of nutrition education and implications for nutrition education policy. programs, and research: a review of research. Journal of Nutrition Education, 27(6), 277.422.

Dahl, B. R., \& Read, M. H. (1995). Effect of a nutrition education program on the reduction of serum cholesterol level in Veterans Administration outpatients. Journal of American Dietetic Association, 95(6), 702-703.

Danford, D. E., \& Stephenson, M. G. (1991). Healthy People 2000: Development of nutrition objectives. Journal of American Dietetic Association, $\underline{91}(12), 1517-1519$. 
Daniels, P. (1994). Reaching out to all America: Coordinated Nutrition Education across USDA programs. Journal of Clinical Nutrition (suppl.).

Dittus, K. L.. Hillers, V. N., \& Beerman, K. A. (1995). Benefits and barriers to fruit and vegetable intake: Relationship between attitudes and consumption. Journal of Nutrition Education, 27(3), 120-126.

Fein, S. B., Lin, T. J., \& Levy, A. S. (1995). Foodborne illness: Perceptions, experience, and preventive behaviors in the United States. Journal of Food Protection, 58(12), 1405-1411.

Feinleib, M. (1995). Setting and monitoring health objectives for the nation. Public Health Reviews, $23,127-138$.

Fleming, K. H. \& Heimbach, James. (1994). Consumption of calcium in the U.S.: Food sources and intake levels. Journal of Clinical Nutrition (suppl.).

FDA. (1993). An Introduction to the New Food Label. (Brochure\}. DHHS Publication No. 94-2271. Rockville, MD: Author.

FDA Backgrounder. (1995). The new food label. \{On-line\}. Available: http://vm.cfsan.fda.gov/ Lrd/newlabel.html.

FMI. (1996). Shopping for Health 1996: Americans look for answers about the foods they eat. Food Marketing Institute. Washington, D.C.

FMI. (1997). Trends in the United States: Consumer Attitudes and the Supermarket 1997. Food Marketing Institute. Washington, D.C.

Foulke, J. (1992). Wide-sweeping FDA proposals to improve food labeling. FDA Consumer, 9-13.

Frankle, R. T., \& Owen, A. L. (1993). Managing change with nutrition education. In Nutrition in the Community (3rd ed.). (pp. 255-270). St. Louis: Mosby.

Galuska, D. A., Serdula, M., Pamuk, E,, Siegel, P. Z., \& Byers T. (1996). Trends in overweight among U.S. adults from 1987 to 1993: A multistate telephone survey. American Journal of Public Health, $\underline{86}$ (12), 1729-1735.

Gambera, P. J., Schneeman, B. O., \& Davis, P. A. (1995). Use of the Food Guide Pyramid and U.S. Dietary Guidelines to improve dietary intake and reduce cardiovascular risk in active-duty Air Force members. Journal of American Dietetic Association, 95(11), 1268-1273. 
Glanz, K., \& Eriksen, M. P. (1993). Individual and community models for dietary behavior change. Journal of Nutrition Education. 25. (2), 80-86.

Glanz, K., \& Mullis, R. M. (1988). Environmental interventions to promote healthy eating: A review of models, programs, and evidence. Health Education Quarterly, 15(4), 395-415.

Glanz, K., \& Rudd, J. (1993). Views of theory, research, and practice: A survey of nutrition education and consumer behavior professionals. Journal of Nutrition Education, 25(5), 269-273.

Glanz, K., Hewitt, A. M., \& Rudd, J. (1992) Consumer behavior and nutrition education: An integrative review. Journal of Nutrition Education, 24(5), 267-277.

Guthrie, J.F., Fox, J.J., Cleveland, L. E., \& Welsh, S. (1995). Who uses nutrition labeling, and what effects does label use have on diet quality? Journal of Nutrition Education, 27(4), 163-172.

Havas, S., Heimendinger, J., Reynolds, K., Baranowski, T., Nicklas, T. A., Bishop, D., Buller, D., Sorensen, G., Beresford, S. A., Cowan, A., \& Damron, D. (1994). 5 A Day for Better Health: A new research initiative. Journal of American Dietetic Association, 94(1), 32-36.

Health care reform legislative platform: economic benefits of nutrition services. Journal of American Dietetic Association. (1993). 93(1), 686-690.

Heaton, A. W., \& Levy, A. S. (1995), Information sources of U.S. adulis trying to lose weight. Journal of Nutrition Education. 27(4), 182-190.

Hermann, J. R., Kopel, B. H., McCrory, M. L., \& Kulling, F. A. (1990). Effect of a cooperative extension nutrition and exercise program for older adults on nutrition knowledge, dietary intake, anthropometric measurements, and serum lipids. Journal of Nutrition Education, 22(6), 271-274.

HHS. (1994). How to Prevent High Blood Pressure. (NIH Publication No. 94-3281).

HHS. (1994). Strategic Development Workshop for Public Education on Weight and Obesity. (NIH Publication No. 94-3314).

HHS. (1990). Healthy People 2000. Nutrition Today, 25(6), 29-39.

HHS. (1993). Working Group Report on Primary Prevention of Hypertension. (NIH Publication No. 93-2669). 
Holli, B. B., \& Calabrese, R. J. (1991). Communication and education skills: the dietitian's guide. (2nd ed.). Philadelphia: Lea \& Febiger.

Howat. P. M., Mohan, R., Champagne, C., Monlezun, C., Wozniak, P., \& Bray, G. A. (1994). Validity and reliability of reported dietary intake data. Journal of American Dietetic Association, 94(2), 169-173.

Hudnall, M., \& Wellman, N. (1992). Missing the nutrition message of balance, variety, and moderation. Journal of Nutrition Education $\underline{24}$ (6), 320-322.

IFIC. (1994). How are Americans making food choices? International Food Information Council. Washington, D.C.

IOM. (1991). Improving America's Diet and Health: From Recommendations to Action. Washington, D.C.: National Academy Press.

Kennedy, E., Meyers, L., \& Layden, W. (1996) The 1995 Dietary Guidelines for Americans: An overview. Journal of American Dietetic Association, 96(3), 234-237.

Klontz, K. C., Timbo, B., Fein, S., \& Levy A. (1995). Prevalence of selected food consumption and preparation behaviors associated with increased risks of foodborne disease. Journal of Food Protection, 58(8), 927-930.

Knabel, S.J. (1995). Foodborne illness: Role of home food handling practices. Food Technology, $\underline{49}(4), 119-131$.

Krebs-Smith, S. M., Cook, A., Subar, A. F., Cleveland, L., \& Friday, J. (1995). U.S. adults' fruit and vegetable intakes, 1989 to 1991: A revised baseline for the Healthy People 2000 objectives. American Journal of Public Health, 85(12), 1623-1629.

Kuczmarski, R. J., Flegal, K. M., Campbell, S. M., \& Johnson, C. L. (1994). Increasing prevalence of overweight among US adults. Journal of the American Medical Association, 272(3), 205-211.

Kurtzweil, P. (1994). Food label close-up. FDA Consumer, 15-19.

LaRosa, J. C., Hunninghake, D., Bush, D., Criqui, M. H., Getz, G. S., Gotto, A. M., Grundy, S. M. Rakita, L., Robertson, R. M., Weisfeldt, M. L., \& Leeman, J. I. (1990). The Cholesterol Facts. American Heart Association, 81(5), 1721-1733.

Lee, R., \& Nieman, D. (1996). Nutritional Assessment. (2nd ed.).

St. Louis: Mosby.

Lefebvre, R.C., Lurie, D., Goodman, L. S., Weinberg. L., \& Loughrey, K. (1995). Social marketing and nutrition education: inappropriate or misunderstood? Journal of Nutrition Education, 27(3), 146-150. 
Lewis, C. L., Crane, N. T., Moore, B. J., \& Hubbard, V. S. (1994). Healthy People 2000: Report on the 1994 nutrition progress review. Nutrition Today 29(6), 6-13.

McCarron, D. A., \& Reusser, M. E. (1996). Body weight and blood pressure regulation. American Journal of Clinical Nutrition, 63(suppl.), 423S-425S.

McGinnis, J. M., \& Lee, P. R. (1995). Healthy People 2000 at mid decade. Journal of the American Medical Association, 273(14), 1123-1129.

McLeroy, K. R., Bibeau, D., Steckler, A, \& Glanz, K. (1988). An ecological perspective on health promotion programs. Health Education Quarterly, $\underline{15}$ (1), $351-377$.

Meier, C., \& Straub, H. R. (1993). Comparison of the FDA's definitions for energy and nutrient content claims on food labels with consumers' perceptions. Journal of American Dietetic Association, 96(7), 807-808.

Meisler, J. G. \& St. Jeor, S. (1996). Summary and recommendations from the American health foundation's expert panel on healthy weight. American Journal of Clinical Nutrition, 63 (suppl.), 474S-477S.

Mertz, W. (1992). Food intake measurements: Is there a "gold standard"? Journal of American Dietetic Association, 92(12), 1463-1465.

Millen, B. E., Quatromoni. P. A., Franz, M. M., Epstein, B. E., Cupples, A. L., \& Copenhafer, D. L. (1997). Population nutrient intake approaches dietary recommendations: 1991 to 1995 Framingham Nutrition Studies. Journal of American Dietetic Association, 97(7). 742-749.

Morreale, S. J., \& Scwartz, N. E. (1995). Helping Americans eat right: Developing practical and actionable public nutrition education messages based on the AUA Survey of American Dietary Habits. Journal of American Dietetic Association. 95(3), 305-308.

NAS. Criteria and dietary reference intake values for calcium by life-stage group (1997). \{On-line\}. Available: http://www2.nas.edu/new/216a.html.

NCI. National 5 A Day-for Better Health Program (1997). \{On-line\}. Avaílable: http://www.dcpc,nci.nih.gov/5aday/factpage/FACTPG.html.

NHLBI. National Cholesterol Education Program (1997). \{On-line\}. Available: http://www.nhlbi.nih.gov/nhlbi/othcomp/opec/ncep/ncep_pd.htm.

NHLBI. National High Blood Pressure Education Program (1997). \{On-line\}. Available: http://www.nhlbi,nib.gov/nhlbi/othcomp/opec/nbbpep/nhbp_pd.htm. 
National Live Stock and Meat Board. (1994). Eating in America today: A dietary pattern and intake report. National Live Stock and Meat Board, Chicago, IL.

National Research Council. (1989). Recommended dietary allowances (10th ed.). Washington, DC: National Academy Press.

Nieswiadomy, R. M. (1993). Quantitative Research Designs. In Foundations of Nursing Research. (2nd ed.). (p 135). Norwalk: Appleton \& Lange.

O'Donnell, M. P., \& Harris, J. S. (1994). Theoretically based strategies for health behavior change. In Health Prornotion in the Workplace. (2nd ed.). (pp 185-203). Albany: Delmar.

Parraga, I. M. (1990). Determinants of food consumption. Journal of American Dietetic Association, 90(5), 661-663.

Posner, B. M., Franz, M .M., Quatromoni, P.A., Gagnon, D. R., Sytkowki, P. A.,, D’Agostino, R. B., \& Cupples, A. (1995). Secular trends in diet and risk factors for cardiovascular disease: The Framingham Study, Journal of American Dietetic Association 95(2), 171-179.

Rimm. E. B., Ascherio, A., Giovannucci, E., Spiegelman, D., Stampfer, M. J., \& Willett. W. C. (1996). Vegetable, fruit, and cereal fiber intake and risk of cornonary heart disease among men. Journal of the American Medical Association, 275(6), 447-451.

Saltos, E., Welsh, S., \& Davis, C. (1994). The new food label as a tool for healthy eating. Nutrition Today, $\underline{29}(3), 18-22$.

Santrock، J.W. (1991). What is Psychology? Psychology: The Science of Mind and Behavior. (3rd ed.). (pp. 10-14). Dubuque, IA: Wm. C. Brown Publishers.

Schuette, L. K., Song, W.O., \& Hoerr, S. L. (1996). Quantitative use of the Food Guide Pyramid to evaluate dietary intake of college students. Journal of American Dietetic Association, $\underline{96}(5), 453.457$.

Schwartz, N. E. (1996). Communicating nutrition and dietetics issues: Balancing diverse perspectives. Journal of American Dietetic Association, 96(11), $1137 \cdot 1139$.

Sempos, C. T., Cleeman, J. I., Carroll, M. D., Johnson, C. L., Bachorik, P. S., Gordon, D. J., Burt, V. L., Briefel, R. R., Brown, C. D., Lippel, K., \& Rifkind, B. M. (1993). Prevalence of high blood cholesterol among U.S. adults. Journal of the American Medical Association, 269(23), 3009-3014.

Shils, M. E., Olson, J. A., \& Shike, Moshe. (1994). Dietary Assessment. Modern Nutrition in Health and Disease (8th ed.). (pp. 847-848). Philadelphia: Lea \& Febiger. 
Slawson, D. L. \& Eck, L. H. (1997). Intense practice enhances accuracy of portion size estimation of amorphous foods. Journal of American Dietetic Association.

Smith, J. L., \& Lopez, L. M. (1991). The application of theory and its relationship to program effectiveness in nutrition education research. Journal of Nutrition Education $\underline{23}(2), 59.64$.

Statistical Analysis System Institute (1989). Version 6.08. Cary, NC.

Steinmetz, K. A., \& Potter, J. D. (1996). Vegetables, fruit, and cancer prevention: A review. Joumal of American Dietetic Association, 96(10), 1027-1039.

Subar, A. F., Ziegler, R. G., Patterson, B. H., Ursin, G., \& Graubard, B. (1994). U.S. dietary patterns associated with fat intake: The 1987 National Health Interview Survey. American Journal of Public Health, 84 (3), 359-366.

Thompson, F. E., \& Byers, T. (1994) Dietary assessment resource manual. The Journal of Nutrition, 124 (suppl.1IS), 2245S-2317S.

Todd, E. C. (1989). Preliminary estimates of costs of foodborne disease in the United States. Journal of Food Protection, $\underline{52}(8), 595.601$.

USDA. (1995). The Dietary Guidelines for Americans. (4th ed.). \{Brochure\}. Home and Garden Bulletin No. 232. Washington, D.C.: U.S. Government Printing Office.

USDA. (1992). The Food Guide Pyramid. \{Brochure\}. Home and Garden Bulletin No. 252. Washington, D.C.: U.S. Government Printing Office.

USDA. (1995, July). Report card on the American Diet. Release No. 0568.95 \{On-line\}. Available: http://www.usda.gov/fcs/ibrary/hei.txt.

USDA. (1997). Food Safety Educator, 2(3). \{On-line\}.

Available: http://www.usda.gov/agency/fsis/educa2-3.htm.

USDA. Foodborne Illness Education Information Center $\{0 n$-line\}. Available: http://www.nal.usda.gov/fnic/foodborne/statemen.html.

Van Horn,L., Bujnowski, M., Schwaba, J., Mathieu-Harris, M., Donato, K., \& Cleeman, J. (1995). Dietitians' Contributions to cholesterol education: A decade of progress. Journal of American Dietetic Association 95(11), 1263-1267.

Whitney, E. N., Hamiiton, E. N., \& Rolfes, S. R. (1990). Understanding Nutrition (5th ed.). (p. E-24). St. Paul: West Publishing Company. 
Wylie-Rosett, J., Wassertheil-Smoller, S., \& Elmer, P. (1990). Assessing dietary intake for patient education planning and evaluation. Patient Education and Counseling, 15, 217-227.

Zulkifli, S. N., \& Yu, S. M. (1992). The food frequency method for dietary assessment. Journal of American Dietetic Association, g2 (6), 681.685. 
APPENDIX A 


\section{OKLAHOMA STATE UNIVERSITY \\ INSTITUTIONAL REVIEW BOARD \\ HUMAN SUBJECTS REVIEW}

Date: $12-12-95$

IRB\#: HE-96-026

Proposal Title: EVALUATION OF AN EIGHT WEEK OKLAHOMA COOPERATIVE EXTENSION FOOD AND NUTRITION EDUCATION PROGRAM ON FOOD AND NUTRITION PRACTICES, DIETARY INTAKE AND HEALTH STATUS IN AN URBAN AND RURAL COUNTY

Principal Investigator(s): Janice Hermann

Reviewed and Processed as: Expedited

Approval Status Recommended by Reviewer(s): Approved

ALL APPROVALS MAY BE SUBJECT TO REVIEW BY FULL INSTTTUTTONAL REVIEW BOARD AT NEXT MEETING.

APPROVAL STATUS PERIOD VALID FOR ONE CALENDAR YEAR AFTER WHICH A CONTINUATION OR RENEW AL REQUEST IS REQUTRED TO BE SUBMTTTED FOR BOARD APPROVAL.

ANY MODIFCATIONS TO APPROVED PROJECT MUST ALSO BE SUBMITTED FOR APPROVAL.

Comments, Modifications/Conditions for A pproval or Reasons for Defermal or Disapproval are as follows:

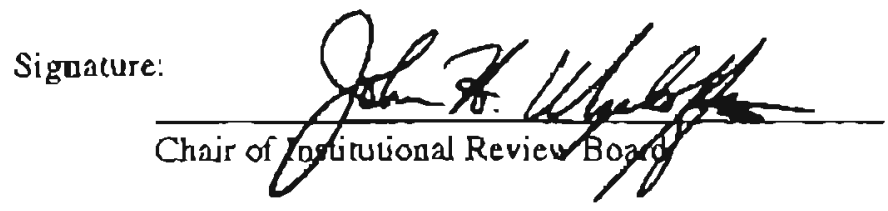

Date: January 29. 1996 
APPENDIX B 


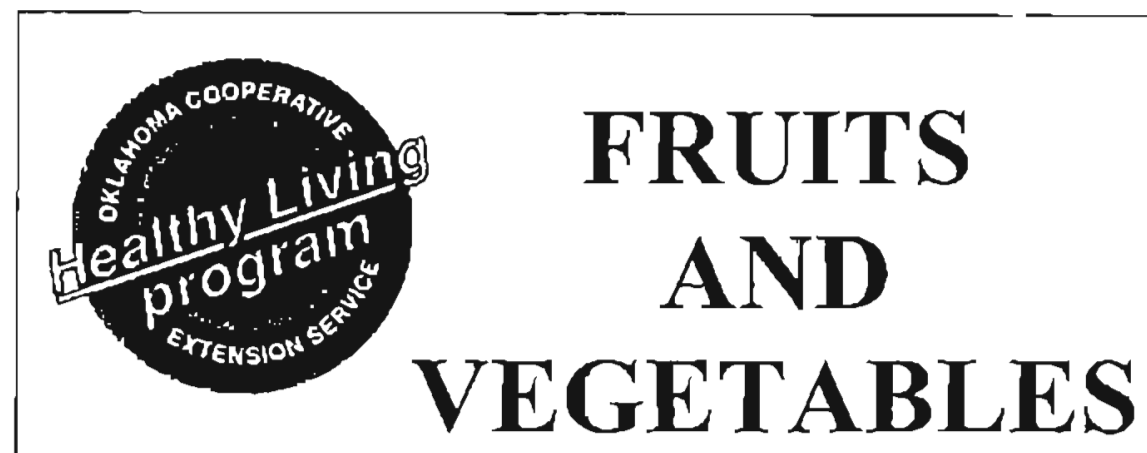

\section{Fruits and Vegetables...}

$\Delta$ are an essential pan of your diet. Fruits and vegetables supply you with many important nutrients such as Vitamin A (Beta Carotene), Vitarnin C, and fiber.

- are nutrient dense and are low in fat, sodium, and calories.

However, when you add butter (margarine), salt, cheese, sauces, salad dressings, and whipped cream they become high in fat, sodium, and calories.

A provide dictary fiber, which aids in digestion and helps to keep you regular.

A provide protection against many diseases. Consuming 5 or more servings of fruits and vegetables per day may reduce your risks of cancer and hear disease.

\section{Shopping Tips}

A When in season, choose fresh produce over canned and frozen.

$\Delta$ Fresh vegetables contain small amounts of sodium compared to frozen and canned. For example, fresh green beans contain $0 \mathrm{mg}$ sodium, frozen green beans contain $0 \mathrm{mg}$ sodium and canned green beans contain $400 \mathrm{mg}$ sodium.

A When trying to decide which fruits to buy, keep in mind that fresh fruits are your best choice. Frozen unsweetened fruits and fruits canned in theic own juices are also a healthy selection.

- Fresh fruits are a bener choice because canned fruils in heavy syrup and frozen sweetened fruits contain large amounts of sugar. Fruits in light syrup are a better option, but also contain added sugar.

A Dried fruirs are more concentrated in nutrients therefore, the calorie and sugar contents are higher compared to fresh fruits.

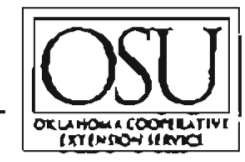




\begin{tabular}{|c|c|c|c|c|}
\hline FRUITS & $\begin{array}{c}\text { Serving } \\
\text { Size }\end{array}$ & Calories & $\begin{array}{c}\text { Fiber } \\
\text { gm }\end{array}$ & $\begin{array}{c}\text { Sugar } \\
\text { gm }\end{array}$ \\
\hline \multicolumn{5}{|l|}{ FRESH } \\
\hline Apple & 1 each & 80 & $s$ & \\
\hline Banana & 1 each & 120 & 3 & \\
\hline Peach & l each & 70 & 1 & \\
\hline Pineapple & $1 / 2$ cup & 90 & 2 & \\
\hline \multicolumn{5}{|l|}{ CANNED } \\
\hline \multicolumn{5}{|l|}{ Del Monte } \\
\hline Pear Halves with Heavy Syrup & $1 / 2$ cup & 100 & 1 & 23 \\
\hline Pear Halves with Light Syrup & 1/2 cup & 60 & 1 & 14 \\
\hline Peach Slices with Heavy Syrup & 1/2 oup & 100 & 1 & 23 \\
\hline Peach Slices with Light Syrup & $1 / 2$ cup & 60 & 1 & 14 \\
\hline Pineapple (Sliced) & 2 slices & 60 & 1 & 14 \\
\hline \multicolumn{5}{|l|}{ Motts } \\
\hline Apple Sauce & $\mathrm{t} / 2$ cup & 100 & 1 & 23 \\
\hline \multicolumn{5}{|l|}{ wilderness } \\
\hline Counery Apple Pie Filling & $1 / 3$ cup & 100 & 2 & 22 \\
\hline Peach Pie Filling & $1 / 3$ cup & 100 & 1 & 17 \\
\hline VEGETABLES & $\begin{array}{c}\text { Serving } \\
\text { Size }\end{array}$ & $\begin{array}{c}\text { Total Fat } \\
\text { gm }\end{array}$ & $\begin{array}{c}\text { Fiber } \\
\text { gm }\end{array}$ & $\begin{array}{c}\text { Sodium } \\
\mathrm{mg}\end{array}$ \\
\hline \multicolumn{5}{|l|}{ FRESH } \\
\hline Broccoli & 1 med stalk & 1.0 & 5 & 75 \\
\hline Cartots & 1 med carror & 1.0 & 1 & 40 \\
\hline Green Beans & $3 / 4$ cup & 0.0 & 3 & 0 \\
\hline \multicolumn{5}{|l|}{ CANNED } \\
\hline \multicolumn{5}{|l|}{ Del Monte } \\
\hline Green Beans & $1 / 2$ cup & 0.0 & 2 & 360 \\
\hline Moxed Vegetables & 1/2 cup & 0.0 & 2 & 360 \\
\hline \multicolumn{5}{|l|}{ Green Giant } \\
\hline Cream Style Com & $1 / 2$ cup & 0.5 & 1 & 430 \\
\hline Com Niblets & 1/2 cup & 0.0 & 2 & 230 \\
\hline \multicolumn{5}{|l|}{ Trappey's } \\
\hline Okra & $1 / 2$ cup & 0.0 & 3 & 400 \\
\hline \multicolumn{5}{|l|}{ FROZEN } \\
\hline \multicolumn{5}{|l|}{ Birds Eye } \\
\hline Broccoli with Cheese Sauce & $1 / 2$ cup & 3.0 & 2 & 430 \\
\hline Broccoli & $1 / 2$ cup & 0.0 & 3 & 30 \\
\hline Green Bears & $1 / 2 \operatorname{cup}$ & 0.0 & 2 & 0 \\
\hline \multicolumn{5}{|l|}{ Picksweet } \\
\hline Mixed Vegetables & $2 / 3$ cup & 0.5 & 2 & 40 \\
\hline Okra & $3 / 4$ cup & 0.0 & 3 & 35 \\
\hline
\end{tabular}




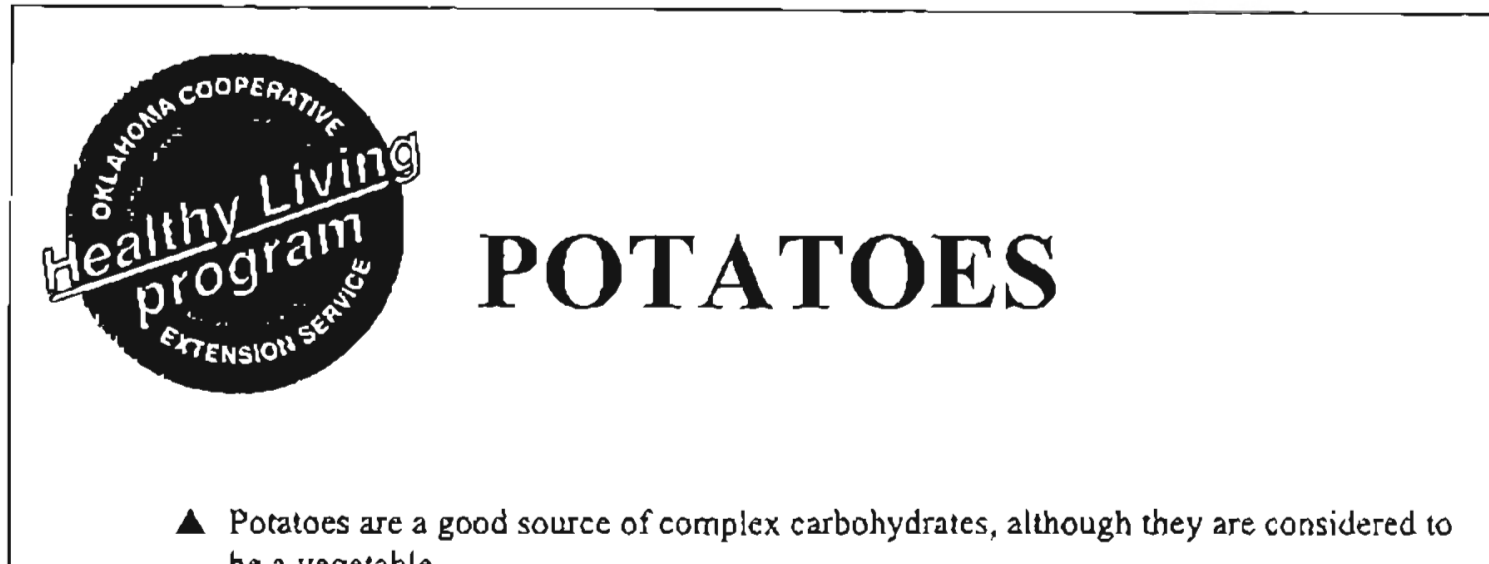
be a vegetable.

A Potatoes are rich sources of Vitamin C, Vitamin B6, potassium and fiber.

- Potatoes can be prepared in a variety of different ways, including baked, mashed, stuffed, au gratin, and scalioped. By leaving the skins on, you can save time and add extra fiber and minerals.

A Potatoes are low in fat, but can become high in fat with your choice of soppings. Top your potatoes with the lower fat versions of sour cream, cheese and margarine. Other low fat alternatives are low fat yogurt, low fat coltage cheese, picante sauce, and buter substitures.

- Tater tots, fiench fries, hash browns, and potato chips are high in fat and sodium, along with other instant mixes. Be creative and find new ways to use the whole potato in a low fat way. For example, oven baked fries and oven roasted potatoes.

Handous 22

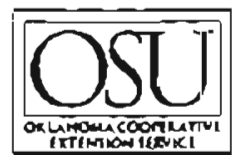




\section{POTATOES}

Plain Whole Russet

Canned New Potatoes

Chips

Lay's

Lay's KC BBQ

Louise's Fat Free

Pringles Original

Pringles Right Crisps

Mixes

Au Gratin - Betty Crocker

Julienne - Betty Crocker

Mashed - Idahoan

Mashed - Ore Ida

Scalloped - Betry Crocker

Suffed with Cheese - On Boys

Stuffed with Sour Cream \& Chives -

Larry's

Twice Baked Cheddar - Ore Ida

Twice Baked Sour Cream \& Chives -

Ore Ida

Frozen Products

Ore Ida

Crispy Crown

Deep Fries Crinkle Cut

Dinner Fries

Country Fries

Fast Fries

Hash Browns

Hot Tots

Potato Wedges

Shoe String

Steak Fries

Tater Tots

Texas Crispers

Waffle Fries

Zesties

Act II

French Fries Micro

\section{Serving Total Fat Sodium Calories Size}

1 medium

gm

0.0

0.0

220

2 medium

20 chips

10.0

10.0

0.0

30 chips

10 chips

16 chips

11.0

7.0

$1 / 2$ cup

$1 / 2$ cup

$1 / 3$ cup

2/3 cup

$1 / 2$ cup

1 potato

I potato

1 baker

I baker

6.0

6.0

2.0

2.5

7.0

5.0

8.0

9.0

7.0

440

360

180

200

300

I50

135

620

670

310

240

620

320

520

60

150

160

100

160

140

150

140

100

150

160

160

150

200

190

3 ounces

11.0

450

190

3 ounces

7.0

3.0

15

160

3 ounces

3.5

20

280

110

3 ounces

6.0

230

120

140

3 ounces

0.0

7.0

25

350

70

150

3 ounces

2.5

3 ounces

3 ounces

3 ounces

3 ounces

3 ounces

3 ounces

1 box

12.0

125
150

110

160

150

$\begin{array}{ll}260 & 160 \\ 370 & 160\end{array}$

$\begin{array}{ll}260 & 160 \\ 370 & 160\end{array}$

230 


\section{BREAD}

A 6 to 11 servings of bread, cereal, and grains are needed each day to provide energy.

A Bread is a low fat complex carbohydrate. Complex carbohydrates are our body's best source of time released, long term energy.

A Breads most commonly found in grocery siores are white, wheat, and whole wheac.

$\Delta$ Did you know that whole wheat bread and wheat bread are not the same?

- Wheat bread usually contains $75 \%$ white flour, whereas whole wheat bread contains $100 \%$ whole wheat flour.

- Whole wheat bread contains more protein, fiber, vitamins, and minerals compared to white and wheat bread.

- Whole wheat bread provides 2.0 grams of fiber and white bread provides .5 grams of fiber.

A Bread is a low fat food; however, what you choose to put on it can increase the amount of fat. For example, adding one teaspoon of regular margarine will increase the fat content by $38 \%$.

\section{Shopping Tips}

- When shopping for bread it is important to read the label. Choose products that list whole wheat flour as the first ingredient.

$\Delta$ 'Light' bread refers to having at least one-third fewer calories per serving or no more than half the fat per serving compared to 'regular' bread.

A Be sure to read the label carefully since 'light' can also refer to the color or texture of the bread. 


\section{BREAD}

Earth Grains

English Muffins

French Rolls

Honeywheat BerTy

Jewish Rye

Pizza Rounds

Whole Wheat 100\%

Good Earth

Honey Wheat Berry

Oat Bran Bread

Stone Ground Wheat Bread

Mission

Com Tortillas

Flour Torillas

Four Torillas Fat Free

Soft Wheat Torillas

\section{Orowheat}

Brannola

English Muffins (Health Nut)

Pita Bread

Pita Bread Whole Wheas

Whole Wheat 100\%

Rainbo

Croissants

Dinner Rolls

Enriched Bread (sliced)

Grant's Farn Whole Wheat

Grant's Farm 12 Grain

Hot Dog Buns

Honey Buttered Wheat

Rainbo Light

Wheat Fields

Bagel Blueberry

Bagel Plain

Wonder

Calcium Enriched Wheat

Enriched White

Hamburger Buns

Sour Dough San Francisco

Sour Dough Light
Serving Calories Total Fat Fiber Size

I each

I each

1 slice

I slice

I each

I slice

I slice

I slice

I slice

1 each

1 each

1 each

1 each

I slice

1 each

1 each

1 each

1 slice

1 each

1 each

I slice

1 slice

I slice

1 each

I slice

2 slices

1 each

1 each

2 slices

1 slice

l each

I slice

2 slices gm

gm

140

220

100

80

210

100

60

60

60

70

210

70

160

90

180

160

160

40

260

90

70

70

70

110

70

80

160

160

80

60

170

90

80
1.5

2.5

1.5

1.0

4.0

2.0

1.0

1.0

1.0

1.0

5.0

0.0

5.0

1.0

4.0

0.5

1.0

1.0

17.0

3.0

1.0

1.0

1.0

1.5

1.0

1.0

0.5

1.0

0.5

1.0

2.5

2.5

1.0
4

2

2

$$
1
$$$$
2
$$$$
3
$$

1

$<1$

2$$
1
$$$$
1
$$$$
1
$$$$
2
$$

\section{2}

2

2

3

2

2

1

$$
1
$$$$
\text { ( }
$$$$
2
$$$$
2
$$$$
2
$$$$
\text { I }
$$$$
5
$$

\section{2}

2

6

$<1$

1

$<1$ 


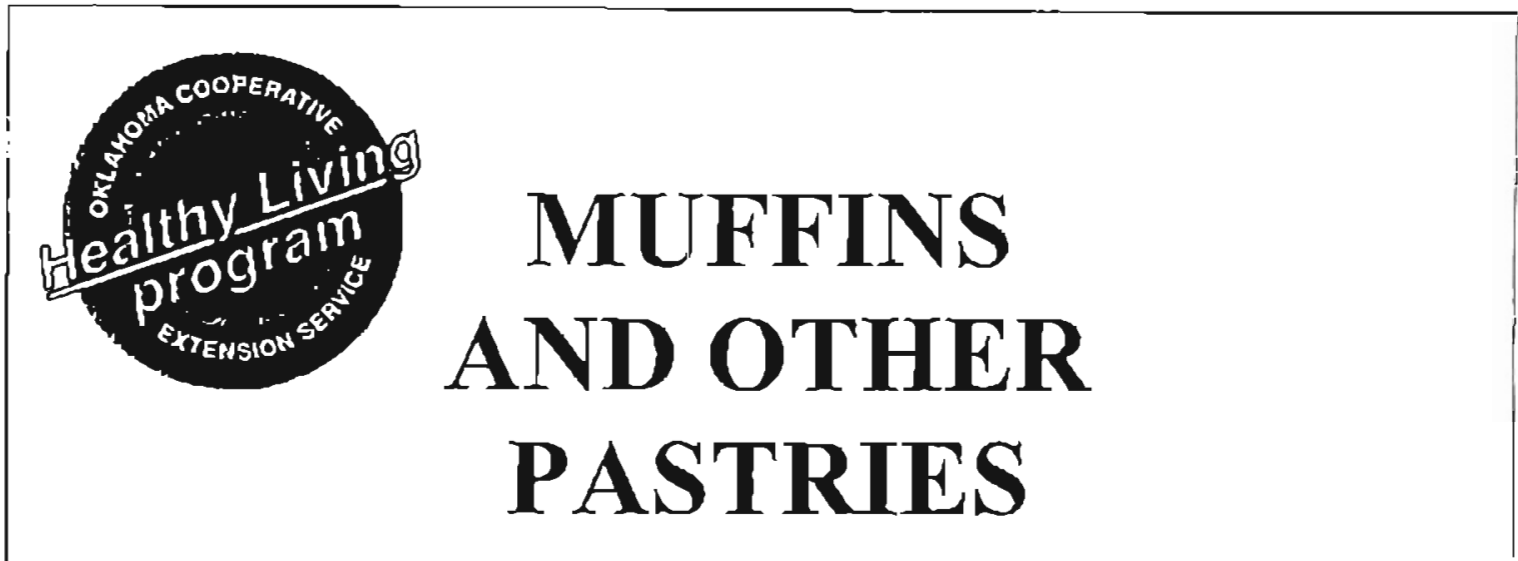

MYTH: all muffins are healthy and nutritious.

FACT: the most popular brands of muffins contain very large amounts fat and sugar and contain very few nutrients.

FOOD FOR THOUGHT: be creative and develop a healthy homemade muffin with the use of low fat and high tiber ingtedients.

MYTH: bagels are high in fat.

FACT: bagels contain about 1 gram of fat.

FOOD FOR THOUGHT: what you add to the bagel can make it high in fat. For example try fat free or low fat cream cheese instead of regular cream cheese.

MYTH: croissants are a healthy choice.

FACT: croissants are high in fat resulting in a light and flaky texture.

FOOD FOR THOUGHT: instead choose a slice of whole wheat bread or a bagel.

MYTH: donuts, cinnamon rolls, coffee cakes, and danishes are healthy breakfast items. FACT: all of these items are high in fat and sugar and contain very little numitional value.

FOOD FOR THOUGHT: some healthy breakfast options can include toast, bagels, cereal, homemade muffins, and English muffins. 


\section{MUFFINS}

Aunt Fanny's

Cinnamon Twirls

Pecan Twirls

Dolly Madison

Cherry Sweet Ralls

Cinnamon Rolls

Danish Rollers Sweet Rolls

Donuv/Cinnamon Sugar

Donue/Plain

DonuUSugar

Dunkin Stix

Encenmann's

Cinnamon Twist Fat Free

Crunch Cake Fat Free

Donuv Cinramon

Donut/Crumb Topped

DonuURich Frosted

Eostess

Minimuffins/Banana Walnut

Munimuffins/Chocolate Chip

Otis Spunkmeyer

Almond Poppy Seed

Banana Nut

Chocolate Chocolate Chip

Wild Blueberty

Pillsbury

Apple Cinnamon Rolls

Apple Tumovers

Caramel Rolls/Grands

Cherry Tumovers

Cinnamon Rolls

Cinnamon Rolls/Grands

Orange Sweet Rolls

\section{Rainbo}

Apple Sweet Rolis

Cinnamon Sweet Rolls

Donuts/Gem Powder Sugar

DonuvGem Chocolate

Sara Lee

Cheese Danish
Serving size

1 each

1 each

1 each

1 each

2 each

1 each

1 each

1 each

1 each

$1 / 5$ twist

1/6 cake

1 each

1 each

1 each

5 each

5 each

1/2 each

1 each

1 each

l each

1 each

2 each

1 each

2 each

1 each

l each

I each

1 each

1 each

4 each

4 each

$1 / 8$ danish
Calories

Total Fat

Sugar

gm

110

100

220

220

200

220

230

230

170

150

220

230

260

300

260

260

420

470

460

410

150

350

310

360

150

310

170

210

210

240

280

190

$\begin{array}{rr}\text { gm } & \text { gm } \\ 4 & 7 \\ 4 & 8\end{array}$

6

7

11

10

12

9

20

$\begin{array}{rr}10 & 20 \\ 7 & 10\end{array}$

7

15

7

12

17

10

8 


\section{GRAINS}

A Grains consist of wheat, oat, nice, com, barley, rye, millet, amaranth, buckwheat, quinoa, and kamut.

- Grains are rich complex carbohydrates that fuel the body.

- Grains are a nutritious food that are low in calories, fat, sodium and cholesterol. Grains also contain fiber and many essential vitamins and minerals.

A The U.S. Depanment of Agriculure recommends that your diet consists of 6 to 11 servings of grains, breads, and cereals each day. Therefore, $50 \%$ or more of your calories per day should come from this group.

Rice...

A is the most widely used grain. It is inexpensive, easy to prepare, and can be used in a wide variety of dishes.

$\Delta$ is available in many different varieties. For example, white, brown, wild, long and short grain, instant, and converted.

A either brown or white is nutritious. Since brown rice is a whole grain. it contains more fiber, vitamin $\mathrm{E}$, phosphorus and calcium than white rice.

A is found in flavored or seasoned mixes. Although mixes are convenient, they contain high amounts of sodium and require the addition of fat in preparation.

$\Delta$ can be prepared in soups, er.trees and desserts. [t is important to follow instructions in rice preparation. The fat content can be decreased or eliminaced. This can be done by preparing the recipe with half the fat or less.

Hand out 2.5

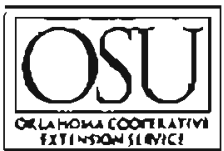




\section{RICE}

Comet

Long Grain

Narral Brown

Minuce Brand

Boil in a Bag

Instant Brown

Instant Enriched White

Premium Long Grain

Lipton/Seasoned Mixes

Beef Flavor

Cajun Style

Cheddar Broccoli

Chicken Broth and Herb's

Creamy Chicken Flavor

Herb's and Seasoning

Oriental Style

Red Beans and Rice

Savory Herb's Pilaf with Garlic

Sparish

Mahatma/Seasoned Mixes

Black Bears and Rice

Saffron Yellow Long Grain

Near East

Rice Pilaf Max

Ranch Style (canned)

Spanish Rice

Rice Select

Jasmati

Texmati

Texmati Royal Blend

Rice-A-Roni/Seasoned Mixes

Beef Flavor

Broccoli Au Gratin

Chicken Flavor

Spanish Rice

Uncle Ben's/Seasoned Mixes

Converted Rice

Butter and Herb's

Chicken and Broccoli

Long Grain and Wild

\section{Serving Total Fat Sodium Calories Size}

\begin{tabular}{|c|c|c|c|}
\hline & gm & $\mathrm{mg}$ & \\
\hline 1 cup & 0.0 & 0 & 160 \\
\hline 1 cup & 1.0 & 0 & 150 \\
\hline 1 cup & 0.0 & 10 & 190 \\
\hline $2 / 3$ cup & 1.5 & 10 & 170 \\
\hline $3 / 4$ cup & 0.0 & 5 & 170 \\
\hline 1 cup & 0.0 & 5 & 170 \\
\hline 1 cup & 7.0 & 1010 & 230 \\
\hline 1 cup & 7.0 & 1000 & 230 \\
\hline 1 cup. & 9.0 & 1010 & 300 \\
\hline 1 cup & 9.0 & 740 & 280 \\
\hline 1 cup & 11.0 & 840 & 310 \\
\hline 1 cup & 9.0 & 1100 & 310 \\
\hline $1 / 2 \operatorname{cup}$ & 8.0 & 940 & 280 \\
\hline 1 cup & 70 & 1195 & 290 \\
\hline 1 eup & 8.5 & 940 & 270 \\
\hline 1 cup & 7.0 & 1010 & 290 \\
\hline 1 cup & 10.5 & 930 & 200 \\
\hline 1 cup & 0.0 & 970 & 190 \\
\hline 3/4 cup & 4.0 & 865 & 200 \\
\hline 1 cup & 0.0 & 2070 & 180 \\
\hline $1 / 2$ cup & 0.0 & 0 & 150 \\
\hline $1 / 2$ cup & 1.0 & 0 & 170 \\
\hline I cup & 0.5 & 0 & 160 \\
\hline 1 cup & 9.5 & 1165 & 320 \\
\hline 1 cup & 11 & 590 & 320 \\
\hline 1 cup & 9.5 & 1095 & 320 \\
\hline I cup & 8.0 & 1210 & 270 \\
\hline l cup & 0.0 & 0 & 170 \\
\hline l cup & 7.0 & 835 & 200 \\
\hline$i$ cup & 6.0 & 815 & 240 \\
\hline 1 cup & 6.0 & 905 & 190 \\
\hline
\end{tabular}




\section{CEREALS}

\section{When choosing a dry cereal...}

A look for a cereal that lists the grain as the first ingredient.

- look for a cereal that contains less than 5 grams of sugar per serving. However, if the cereal contains fruit, or is sweetened with fruit juice this number may be higher.

$\Delta$ consider the fiber content. A high fiber cereal is one that contains more than 7 grams of fiber per serving.

$\Delta$ check the label for the fat content. Cereals tend to be low in fat with the exception of granola. Granola is high so fat due to oils, nuts, and seeds. If you like granola, try the low fat varieties.

\section{When choosing a hot cereal...}

A experiment with different varieties such as cream of rice, cream of wheat, malt-omeal, oatmeal, wheatena, grits, quinoa, and kamut.

$\Delta$ be aware of the individually packaged flavored oameal, which contains high amounts of sugar and salt.

$\Delta$ pay close attention to the cooking instructions. Most hot cereals say to add salt and butter (margarine) to the cooking water, but this is not necessary.

A by eliminating the salt and butter (margarine) you will reduce your fat intake by $21 \%$ and your sodium intake by $100 \%$.

$\Delta$ for added flavor, try substituting fnit juice or skim milk instead of water.

A how you top your cereal is important. Try topping cereal with fresti or dried fruits instead of butter or marganne.

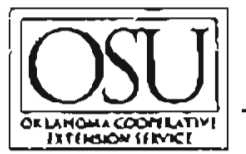




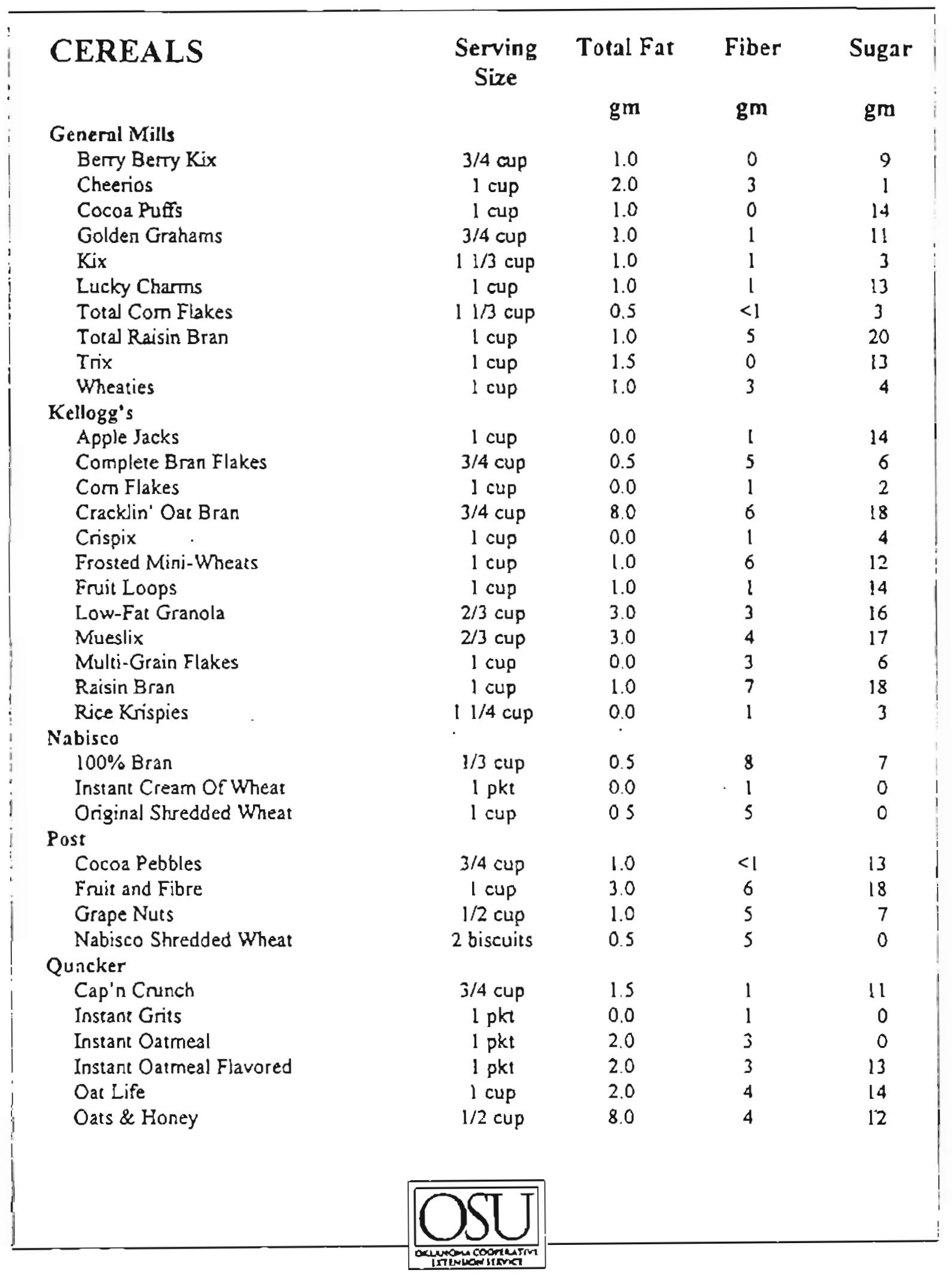




\section{PASTA}

A 61011 servings of pasta, breads and cereals are needed each day to provide energy.

- Pasta is a complex carbohydrate that is a good source of protein and is low in fal. However, pasta is not a complete protein.

- When shopping for pasta, try to buy pasla made with whole grain flour.

A Complete proteins are foods that contain the necessary building blocks needed to build and repair the body. To make a complete protein, pasta should be combined with grains or legumes.

A Pasta can also be served with complete protein sources such as meat, fish, poultry, eggs, and dairy products. When pasta is served with complete protein the need to combine is eliminated.

- Contrary to popular beliefs, pasta is not fattening! However, it can be fattening when topped with high fat ingredients such as cheese, butter, oil, high fat meats, and cream sauces.

\section{Cooking Tips}

$\Delta$ Be creative and use a wide variety of shapes and sizes. For example, try bow ties, wagon wheels, spirals, shells, and alphabets.

$\Delta$ When cooking pasta, it is not necessary to add salt or oil to the water. Try adding fresh lemon juice to the water to add flavor.

A Choose low-fat cheese, fal free cheese and skım milk in preparing your favorite dishes.

A When preparing boxed sauces or mixes, use skim milk and cut the amount of added fat. 


\begin{tabular}{|c|c|c|c|c|}
\hline \multirow[t]{2}{*}{ PASTA } & $\begin{array}{c}\text { Serving } \\
\text { Size }\end{array}$ & Total Fat & Sodium & Calories \\
\hline & & gm & mg & \\
\hline Pasta (all Brands) & 1 cup & 1.0 & 0 & 210 \\
\hline \multicolumn{5}{|l|}{ Contadina } \\
\hline Fresh Pasta & $11 / 4$ cup & 3.5 & 30 & 250 \\
\hline Fresh Four Cheese Ravioli & 1 cup & 12.0 & 350 & 280 \\
\hline \multicolumn{5}{|l|}{ NoYolks } \\
\hline Egg Noodle Substicute & I cup & 0.5 & 30 & 210 \\
\hline \multicolumn{5}{|l|}{ R\&F Borden } \\
\hline Wide Egg Noodles & $11 / 4$ cup & 3.0 & 15 & 220 \\
\hline \multicolumn{5}{|l|}{ Betty Crocker/ Pasta Mixes } \\
\hline Classic Suddenly Salad & $3 / 4$ cup & 7.0 & 830 & 220 \\
\hline Garden Italian Suddenly Salad & $3 / 4$ cup & 1.0 & 520 & 130 \\
\hline Ranch \& Bacon Suddenly Salad & $3 / 4$ cup & 19.0 & 450 & 320 \\
\hline \multicolumn{5}{|l|}{ Chef Boyardee } \\
\hline Beefaroni & I cup & 7.0 & 950 & 240 \\
\hline Cheese Ravioli & I cup & 3.0 & 1280 & 220 \\
\hline Spaghetti \& Meat Balls & l cup & 9.0 & 940 & 240 \\
\hline $\mathrm{X}$-Men Pasta in Tomato \& Cheese & 1 cup & 0.0 & 880 & 200 \\
\hline \multicolumn{5}{|l|}{ Krafu/Pasta Mixes } \\
\hline Broccoli \& Cheese Dinner & 1 cup & 16.0 & 1240 & 400 \\
\hline Creamy Caesar Pasta Salad & $3 / 4$ cup & 22.0 & 650 & 350 \\
\hline Deluxe Macaroni \& Cheese & 1 cup & 10.0 & 730 & 320 \\
\hline Italian Light Pasta Salad & $3 / 4$ cup & 2.0 & 660 & 190 \\
\hline Macaroni \& Cheese & 1 cup & 16.5 & 730 & 390 \\
\hline Mild White Cheddar Macaroni \& Cheese & 1 cup & 18.0 & 610 & 170 \\
\hline \multicolumn{5}{|l|}{ Lipton/ Pasta Mixes } \\
\hline Garlic \& Butter Linguini & 1 cup & 9.0 & 880 & 260 \\
\hline Alfedo & 1 cup & 14.0 & 1000 & 340 \\
\hline Butter \& Herb & 1 cup & 13.0 & 930 & 300 \\
\hline Chicken Broccoli & l cup & 11.0 & 850 & 310 \\
\hline Chicken Flavor & 1 cup & 10.5 & 830 & 280 \\
\hline Chicken Primavera & 1 cup & 10.0 & 830 & 300 \\
\hline Chicken \& Pasta Angel Hair & 1 cup & 7.5 & 920 & 270 \\
\hline Siroganoff & I cup & 11.0 & 950 & 300 \\
\hline Three Cheese Rotini & 1 cup & 12.0 & 970 & 330 \\
\hline \multicolumn{5}{|l|}{ Rice-A-Roni Pasta Roini } \\
\hline Fettucini with Alfredo Sauce & 1 cup & 25.0 & 1110 & 470 \\
\hline Lemon \& Butter Sauce & l cup & 15.5 & 975 & 360 \\
\hline Pamesan Cheese Sauce & 1 cup & 14.5 & 895 & 320 \\
\hline Rigatoni with Tomato Basil Sauce & 1 cup & 9.0 & 700 & 240 \\
\hline Vermicelli with Garlic \& Olive Oil & I cup & 15.5 & 1010 & 360 \\
\hline
\end{tabular}




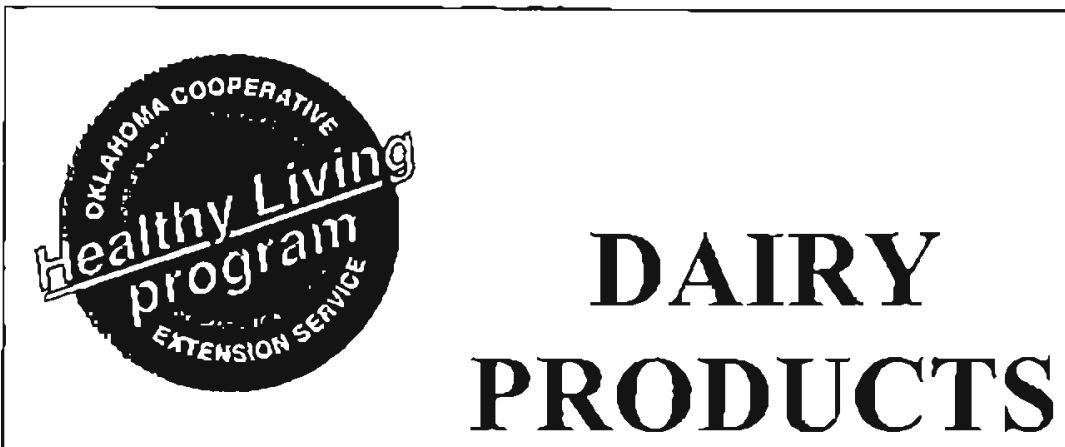

- 2 to 3 servings of dairy products are an essential part of the diet.

$\Delta$ Dairy products include milk, yogurt, and cheese. Dairy products are good sources of protein, calcium and other essential vitamins and minerals.

A When shopping for dairy producss choose the nonfat or low fat products. The following are examples of available products:
- skim or $1 \%$ milk
- nonfac or low fat yogurt
- nonfat or low fat cottage cheese
- nonfat or low fat sour cream
- nonfat, part skim ar reduced fat cheeses
- nonfat or low far cream cheese

A It is especially imporant that women consume at least 2-3 servings per day to protect themselves against osteoporosis. 


\begin{tabular}{|c|c|c|c|c|}
\hline DATRY PRODUCTS & $\begin{array}{l}\text { Serving } \\
\text { Size }\end{array}$ & $\begin{array}{l}\text { Total Fat } \\
\qquad \mathrm{gm}\end{array}$ & $\begin{array}{c}\text { Saturated } \\
\text { Fat } \\
\text { gm }\end{array}$ & $\begin{array}{c}\text { Cholesterol } \\
\text { mg }\end{array}$ \\
\hline \multicolumn{5}{|l|}{ Milk } \\
\hline Whole & 1 cup & 8.0 & 5.0 & 35 \\
\hline $2 \%$ & l cup & 5.0 & 3.5 & 25 \\
\hline $1 \%$ & 1 cup & 2.5 & 1.5 & 15 \\
\hline Skim & 1 cup & 0.0 & 0.0 & 5 \\
\hline Burermilk & 1 cup & 1.0 & 1.0 & 10 \\
\hline Chocolate & 1 сup & 8.0 & 5.0 & 35 \\
\hline \multicolumn{5}{|l|}{ Cream } \\
\hline Heavy Whipping Cream & I tbsp & 5.0 & 4.0 & 20 \\
\hline Half \& Half & L tbsp & 3.0 & 2.0 & 15 \\
\hline \multicolumn{5}{|l|}{ Sour Cream } \\
\hline Regular & 2 tbsp & 5.0 & 3.5 & 20 \\
\hline Light & $2 \mathrm{lbsp}$ & 2.5 & 2.0 & 10 \\
\hline Nonfat & 2 tbsp & 0.0 & 0.0 & 0 \\
\hline \multicolumn{5}{|l|}{ Cortage Cheese } \\
\hline $4 \%$ milk fat & $1 / 2$ cup & 5.0 & 3.0 & 25 \\
\hline Low-fat & $1 / 2$ cup & 1.0 & 1.0 & 10 \\
\hline Fat Free & $1 / 2 \operatorname{cup}$ & 0.0 & 0.0 & 5 \\
\hline \multicolumn{5}{|l|}{ Cream Cheese } \\
\hline Regular & 2 tosp & 10.0 & 6.0 & 30 \\
\hline 1/3 Less Fat & 2 ibsp & 6.0 & 4.0 & 20 \\
\hline Free & 2 ibsp & 0.0 & 0.0 & $<5$ \\
\hline \multicolumn{5}{|l|}{ Cheese (Kralt) } \\
\hline Free & I șlice & 0.0 & 0.0 & $<5$ \\
\hline Healthy Favorites Cheddar & I slice & 0.0 & 0.0 & $<5$ \\
\hline Mild Cheddar & 1 ounce & 9.0 & 6.0 & 30 \\
\hline Monterey Jack & I ounce & 9.0 & 6.0 & 30 \\
\hline Part Skim Mozzarella & I ounce & 5.0 & 35 & 15 \\
\hline Reduced Fat Colby & I ounce & 5.0 & 3.0 & 20 \\
\hline Reduced Fat Milk Cheddar & I ounce & 6.0 & 4.0 & 20 \\
\hline Reduced Fac Monterey Jack & 1 ounce & 5.0 & 3.0 & 20 \\
\hline Singles American & 1 slice & 4.5 & 3.0 & 15 \\
\hline Singles $1 / 3$ Less Fat & I slice & 3.0 & 2.0 & 10 \\
\hline Swiss & 1 slice & 13.0 & 9.0 & 45 \\
\hline Velveeta & 1 ounce & 6.0 & 4.0 & 20 \\
\hline Velveeta Light & I ounce & 3.0 & 2.0 & 10 \\
\hline \multicolumn{5}{|l|}{ Yogurt } \\
\hline Yoplait Custard Style & I container & 2.5 & 1.5 & 10 \\
\hline Yoplait Original & 1 container & 1.5 & 1.0 & 10 \\
\hline Yoplait Light & I container & 0.0 & 0.0 & $<5$ \\
\hline Yoplait Fat Free & I container & 0.0 & 0.0 & $<5$ \\
\hline
\end{tabular}




\section{FROZEN DESSERTS}

A Frozen desserts can be incorporated into a healthy diet using the following gurdelines:

A Choose far free or low fat ice cream and frozen yogurt.

A Choose sherbets and sorbets as they are low in fat.

A Choose popsicles made with fruit juices.

- Premium ice cream products can be included occasionally; however, it is best to try to choose a product with less than 4 grams of fat per serving (1/2 cup).

- Choose low fat topping such as fresh fruit, fat free cookies, and fat free hot fudge and butterscotch. 
FROZEN DESSERTS

Serving Total Fat Saturated Sugar

Size

Fat

ICE CREAM PRODUCTS

\section{Blue Bell}

Bullets

Bullets Sugar Free

Diet Chocolate

Light Cookjes n Crean

Low-fat Yogurt Cookies a Cream

Ice Cream Cookies n Cream

Ice Cream Sandwich

Rainbow Sherber

Eskímo Pie

Butrer Pecan Frozen Dessert

Hnagen-Dazs

Ice Cream Vanilla

Vanilla \& Almond Bars

Chocolate Sorbet

Healthy Choice

Triple Chocolate Chunk

Yarnell's

Ice Cream Death By Chocolate

Low-fat Yogurt Vanilla

Non-fat Ice Cream Vanilla

Columbo

Sof Serve White Chocolate Almond

Low-fat Yogur Caramel

FROZEN DESSERT BARS

Breyer's Vienne:ta Chocolate

Dole Fruit Juice Bar

Dove Bar Milk Chocolate

Fudgsickle Original

Fudgsickle Sugar Free

KJondike Original

KJondike Light

Marna Tish's Iralian Ice

Nestle Drumstick Vanilla

Reese's Ice Cream Cups

Snickers Ice Cream Bars

Starburst Frit Juice Bars

Weight Watchers Mousse

Weight Watchers Bars

1 bar
1 bar
$1 / 2$ cup
$1 / 2$ cup
$1 / 2$ cup
$1 / 2$ cup
sandwich

$1 / 2$ cup

$1 / 2 \operatorname{cup}$

1/2 cup

1 bar

$1 / 2$ cup

$1 / 2$ cup

1/2 cup

$1 / 2$ cup

$1 / 2$ cup

1/2 cup

$1 / 2$ cup

I slice

1 bar

1 bar

1 bar

I bar

I bar

1 bar

$4 \mathrm{oz}$

1 each

1 each

l bar

1 bar

2 each

l sandwich gm

0.0

0.0

0.0

3.0

2.5

10.0

6.0

1.0

9.0

18.0

22.0

0.0

2.0

8.0

2.0

0.0

8.0

1.5

12.0

0.0

17.0

0.5

0.5

20.0

5.0

0.0

20.0

11.0

12.0

0.0

1.0

3.5

gor

gm

0.0

0.0

0.0

2.5

2.0

7.0

4.0

0.5

4.0

11.0

12.0

0.0

14

0

18

23

17

13

28

5

21

19

22

1.0

18

5.0

15

1.0

0.0

20

6

5.0

22

1.0

2)

8.0

15

0.0

11.0

3

0.0

23

0.0

14.0

4.0

0.0

11.0

6.0

4.0

0.0

0.5

2.0 


\section{MEATS}

A 5 to 7 ounces of meat per day make up a healthy diet.

A Meat is an excellent source of protein, vitamins and minerals, especially vitamin B-12, iron and zinc.

- When shopping for meats, choose lean cuts. Use the following table as a guideline.

\section{LEAN CUTS OF MEAT}

BEEF: top round, round tip, eye of round, top loin, tenderloin, sirloin

POULTRY: skinless chicken breast and leg, skinless dark and light turkey

PORK: center loin chop, tenderloin, boneless top loin chop, boneless ham ( $95 \%$ lean), Canadian bacon

LAMB: leg, loin chop

VEAL: all cuts except ground

A When preparing meat, trim visible fat and choose a low fat cooking method. For example, grilling, broiling, baking, sautéing, roasting, stir frying, and steaming.

A Processed luncheon meats contain high amounts of sodium and fat. Look for the light or low fat varieties.

A Follow these guidelines for food-safery and handing procedures when preparing meats:

- meats should always be refrigerated or frozen

- place meat in refrigerator to thaw

- keep raw meats separate from other foods

\ after handling raw meats, wash hands, suriace area, and utensils thoroughly

- cook meats to proper temperature and refrigerate leftovers promptly

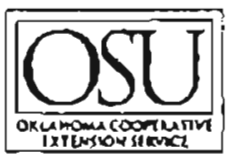

Handoul 2.10 


\begin{tabular}{|c|c|c|c|c|}
\hline MEATS & $\begin{array}{l}\text { Serving } \\
\text { Size }\end{array}$ & $\begin{array}{c}\text { Total Fat } \\
\text { gm }\end{array}$ & $\begin{array}{c}\text { Saturated } \\
\text { Fat } \\
\text { gm }\end{array}$ & $\begin{array}{c}\text { Sodium } \\
\text { mg }\end{array}$ \\
\hline \multicolumn{5}{|l|}{ Healthy Cboice } \\
\hline Honey Ham & 6 slices & 1.5 & 05 & 510 \\
\hline Low Fat Jumbo Franks & I each & 15 & 0.5 & 530 \\
\hline Oven Rosrted Turkey Breast & I slice & 1.0 & 0.5 & 250 \\
\hline \multicolumn{5}{|l|}{ Billshire Farm } \\
\hline Oven Roasted Turkey Breast & 6 slices & 0.0 & 0.0 & 620 \\
\hline Pastrami & 6 slices & 0.5 & 0.0 & 560 \\
\hline Smoked Chicken Breast & 6 slices & 0.0 & 0.0 & 580 \\
\hline Smoked Sausage & 2 ounces & 17.0 & 8.0 & 460 \\
\hline Turkey Smoked Sausage & 2 ounces & 4.5 & 2.5 & 790 \\
\hline \multicolumn{5}{|l|}{ Hormel } \\
\hline Bacon & 2 pieces & 7.0 & 2.5 & 330 \\
\hline Comed Beef Hash & I cup & 24.0 & 10.0 & 930 \\
\hline Hot Smoked Sausage & 6 each & 11.0 & 5.0 & 380 \\
\hline Litule Sizzlers Pork Saussage & 3 each & 20.0 & 7.0 & 570 \\
\hline Span & 2 ounces & 16.0 & 6.0 & 750 \\
\hline Spam Lite & 2 ounces & 8.0 & 3.0 & 560 \\
\hline \multicolumn{5}{|l|}{ Louis Rich } \\
\hline Baked Chicken Bresst & 2 slices & 05 & 0.0 & 530 \\
\hline Baked Ham & 2 slices & 1.5 & 0.5 & 550 \\
\hline Grilled Chicken Breast & 2 slices & 0.5 & 0.0 & 530 \\
\hline Smoked Ham & 2 slices & 1.5 & 0.5 & 570 \\
\hline Turkey Bologna & I slice & 4.0 & 1.0 & 250 \\
\hline Turkey Ham & 1 slice & 1.0 & 1.0 & 300 \\
\hline Turkey Smoked Sausage & 2 ounces & 5.0 & 1.5 & 500 \\
\hline \multicolumn{5}{|l|}{ Oscar Mayer } \\
\hline Bacon & 2 pieces & 5.0 & 1.5 & 250 \\
\hline Central Cut Bacon & 3 slices & 7.0 & 2.5 & 380 \\
\hline Beef Colto Salami & 2 slices & 7.0 & 3.0 & 590 \\
\hline Beef Bologna & 1 slice & 8.0 & 3.5 & 300 \\
\hline Beef Bologna Light & I slice & 4.0 & 1.5 & 310 \\
\hline Bologna Fat Free & I slice & 0.0 & 0.0 & 280 \\
\hline Braunschweiger & 2 aunces & 17.0 & 6,0 & 610 \\
\hline Boiled Ham & 3 slices & 2.5 & 1.0 & 820 \\
\hline Hain \& Cheese Loaf & I slice & 5.0 & 2.5 & 350 \\
\hline Нолеу Нат & 3 slices & 2.5 & 1.0 & 760 \\
\hline Hard Salami & 3 slices & 9.0 & 30 & 510 \\
\hline Oven Roast Turkey Breast & 4 slices & 0.0 & 0.0 & 610 \\
\hline Wiener Original & I each & 22.0 & 9.0 & 690 \\
\hline Wieners/Turkey, Pork, Beef & I each & 9.0 & 3.0 & .590 \\
\hline
\end{tabular}




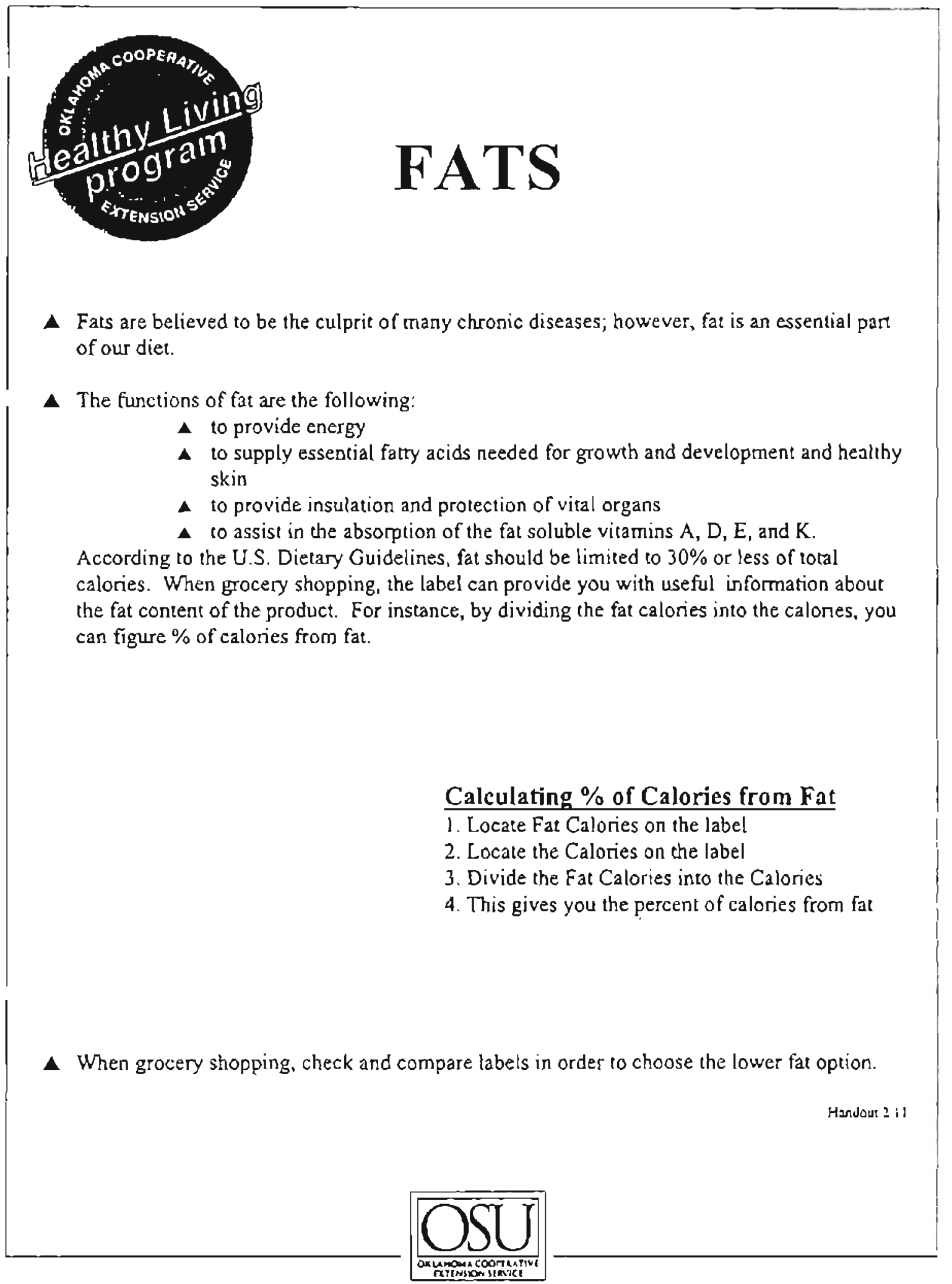


APPENDIX C 


\section{VISUAL MODELS}

The Healthy Living Program includes several visual models to assist you in your educational programs. Visual models include; fat models, sugar models, sait and sodium models, and unbiased food serving size models.

\section{Fat Models}

Each fat model sepresents one teaspoon, or approximately 5 grams fat. The fat model was made to represent a one teaspoon pat of butter or margarine. You can stack the fat models to represent $5,10,15$ etc. grams of fat.

\section{Sugar Models}

The set of sugar models are test tubes with $1,2,3,4,5,6,7,8,9$, and 10 gm of sugar. The set also includes a test tube with 1 teaspoon sugar (approximately $4.5 \mathrm{gm}$ sugar). You can combine the $10 \mathrm{gm}$ and $2 \mathrm{gm}$ test ubes to represent $12 \mathrm{gm}$ sugar.

\section{Salt and Sodium Models}

A separate set of models were prepared for salt and sodium to help consumers understand the difference between salt and sodium The set of test tube models containing white material (salt) represents salt, whereas the set of test tube models containing colored material (colored salt) represents sodium. Salt is approximately $40 \%$ sodium. This way you can demonstrate how much sodium is contained in a specific amount of salt. For exempt, l teaspoon of salt or $6000 \mathrm{mg}$ salt (white test tube with $6000 \mathrm{mg}$ salt or $1 \mathrm{t}$ salt), contains approximately $2400 \mathrm{mg}$ sodium (colored test tube with $2400 \mathrm{mg}$ sodium).

The following is a list of the amounts of salt and sodium represented with the test tube models, and how they relate to each other..

\section{Sodium}

(test tubes containing colored material)

$35 \mathrm{mg}$ sodium (35 mg/serving-very low sodium) $140 \mathrm{mg}$ sodium ( $140 \mathrm{mg} / \mathrm{serving}$-low sodium) $500 \mathrm{mg}$ sodium $1000 \mathrm{mg}$ sodium $2000 \mathrm{mg}$ sodium $2400 \mathrm{mg}$ sodium
Salt

(test tubes containing white material)

\author{
$88 \mathrm{mg}$ salt \\ $350 \mathrm{mg}$ salt \\ $1250 \mathrm{mg}$ sall \\ $2500 \mathrm{mg}$ salt \\ $5000 \mathrm{mg}$ salt \\ $6000 \mathrm{mg}$ salt (1 teaspoon salt)
}




\section{Unbiased Food Models}

The following is a list of the bean bag serving size models:

Green bag 1 cup

Red bag 1/2 cup

Blue bag 1/4 cup

One of the Healthy Living Program, pre and post evaluation instruments is a blank pyramid in which paricipants will indicate the number of servings they consumed in each food group. This will require however, that the paricipants can accuracely remember or visual the amount of a particular food they consumed. Participants often over or under estimate serving sizes. A consumer may under estimate how much they consumed because for example one cup sounds too large. On the other hand, a consumer may over estimate how much they consumed because they know they should have a serving and one serving is one cup. Using plastic food models can be helpful; however, most plastic food modeis represent a serving, and consumers tend to indicate they consumed the amount represented by the food model. Another method is to have $1,1 / 2,1 / 4$ etc. measuring cups available; however, consumers are mislead by the height of measuring cups. One cup of spaghetti in a measuring cup looks different than one cup of spaghetti spread out on a plate.

The bean bag serving size models are more realistic to how food would look spread out on the plate. The green bag represents 1 cup, red bag represents $1 / 2$ cup, blue bag represents $1 / 4$ cup. When using the bean bag models do not cell the paricipant the green bag is one cup, just let the paricipant indicate which color of bag best represents how much they consumed of a food. This will hopefully let participants indicate the serving size without being biased by "oh, I didn't have a whole cup." or "a serving of vegetables is $1 / 2$ cup, so I had 1/2 cup green beans." 
APPENDIX D 


\title{
SESSION 1: THE BASICS - THE FOOD PYRAMID AND RECIPE MODIFICATION
}

\author{
Teacher's Guide
}

\section{Lesson Objectives}

After completion of this lesson, Healthy Living Program participants will:

- learn which diet and lifestyle changes could improve their bealth

- understand the benefizs of using the food pyramid as a guide for eating

- be aware that they can modify recipes to reduce total fat, sanurated fat, sodium and sugar and to increase fiber, vitamins and mineral in foods prepared at home

\section{Introduction}

Note: Having one or more assistants at this lesson is advised to help with body measurements and data collection.

\section{Visual 1.1: Healthy Living Program Logo}

The Healthy Living Program is designed to help OXdahomans make lifestyle choices that will improve or maintain their health for as long as possible. We will focus on the chings that you can change, modify, or continue to emphasize as you work for a healthy life. Thuse topics will include nutrition, making food choices, looking at healthful ways to prepare foods, food safety, and fitness.

Before we start into the lessons you need to know where you are at this point in your life as far as your health is concemed. We cannol give you a tolal physical, but we are going to take some critical measurements to get an idea where you are now and so you can see if you have made some healthy changes by the time the series of eight lessons has ended.

\section{Activity 1.1: Body measurements and pretest}

(Refer to Evaluation Section of Healthy Living Program Notebook.) Take weight and height measurements of program participants. Other measurements are optional. While completing those measurements have class complete pretest and fill out a food pyramid recall sheet. Use food models if available to help decermine serving sizes. Then have each place the names of the foods and number of servings of each on a pyramid drawing. Collect pretests before continuing. Have participants keep their pyrarnid for use later in the lesson. 


\section{SESSION 2: SUPERMARKET TOUR}

Teacher's Guide

\section{Lesson Objectives}

After completion of this lesson, Healthy Living Program participants will:

- know how to use food labels to choose foods that fit their nutritional needs

- understand some terms on food labels

\section{Introduction}

This lesson is a walking/teaching tour through the grocery store. You are the guide. Your job is to help participants learn to read food labels, cut through advertising "hype," learn to shop based on the food pyramid and dietary guidelines, and select lower-fat foods. You need to help them understand that a healthier diet begins at the grocery store.

You car probably handle a tour of ten or fewer people. If your Healthy Living enrollment is larger, you will need to have two or more tours at different times or other trained guides to assist you.

\section{Selting Up A Supermarket Tour}

Contact a supernarketgrocery store within the community several weeks ahead of the planned tour. Explain the Healthy Living Program and its objectives. Have available some of the promotion materials. Discuss how the store will benetit from paricipation. Potential benefits may include:

- Sponsor of the Healthy Living Program in promotion materials.

- Good will toward the community.

- Improved image of the store as a parner of shoppers in their search for good nutrition.

- Improved cornmunication with consumers.

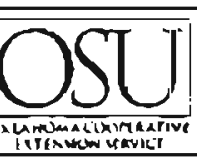




\title{
SESSION 3: BREADS
}

\author{
Teacher's Guide
}

\section{Lesson Objectives}

After completion of this lesson, Healthy Living School participants will be able to:

- increase the number of servings of whole grain breads eaten each day

- read produci labels to choose whole grain breads

- madify recipes to reduce the fat and increase the fiber in homemade breads

\section{Introduction}

\section{Visual 3.1: Food Guide Pyramid with Breads level highlighted}

The base of the Food Guide Pyramid consists of the Bread, Cereals and Other Grains Group. Just as a pyramid's strength comes from its wide bottom layer, so too does a healthy diet benefit from eating 6 to 11 servings of breads, cereals or other grains every day. In the United States, the most common food in this group is bread.

\section{Nutrition and Breads}

Breads are made mostly of earbohydrates. These supply energy for body processes and physical activity. Carbohydrates allow the body to use protein for growth and to maincain its cells.

\section{Visual 3.2: Graphic of wheat kernel}

There are two forms of carbohydrates: simple and complex. The simple carbohydrates are sugars. It is common to find sugars in bread. They add flavor, tendemess, help bread brown, and can help retain moistness. The white flour used to make ordinary white bread is mainly starch. a complex carbohydrate. In the processing of white flour, the kemel of wheat is crushed. The outer layer of bran, which contains nondigestible fiber and $B$ vitamins, is removed. The germ, which contains the oil and vitamin $E$, is also separated. White or refined whest brends are

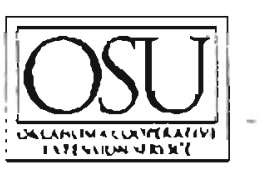

November, 1995 


\section{SESSION 4: GRAINS, CEREALS, AND PASTA}

Teacher's Guide

\section{Lesson Objectives}

After completion of this lesson, Healthy Living School participants will be able to:

- increase the number of servings of whole grains, cereals, and pasta eaten each day

- read product labels to choose whole grain foods

- modify recipes to reduce fat and increase fiber in grain, cereal, and pasta dishes and to use unfarniliar grains

\section{Introduction}

Visual 4.1: Pyramid with highlighted base (same as Visual 3.1)

Whole grains, cereals and pastas are among the bess sources of complex carbohydrates, yet despice advice from health professionals to increase complex carbohydrates in the diet, OkJahomans still fall two servings shy of the recommended six to eleven daily servings of grains or grain products.

Economic conditions are primarily responsible for differences in levels of grain consumption between countries. As a country becomes wealthier, its population can afford to use more of its grains for feeding livestock to provide meat; poorer countries on the ocher hand, are almost torally dependent upon their crops to feed people. This relationship can be seen in our own past. In 1910, when Americans had fewer material resources, our per capita consumption of wheat flour was about 210 pounos. This rate steadily declined as the nacion grew wealthier. reaching a low in the early 1970 s of about 110 pounds of wheat flour per person. During the same period, meac consumption increased to 170 pounds per person.

Affluent countries also rely more and more on convenience foods. In the case of grain products, many of these are now heavily refined, or processed to remove their outer bayers. making them easier to chew and quicker to cook. The parts that are taken off, however, contain most of the fiber, B vitamins, and trace minerals found in the whole grain, along with a fair amount of protein. Today, most refined grains are "enriched" with the addition of key

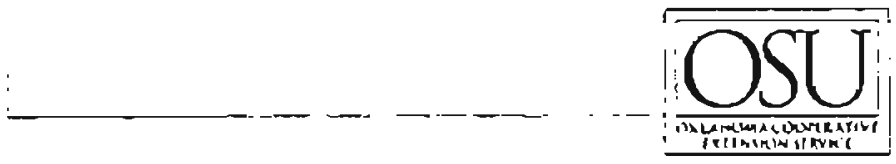

November, 1995 


\section{SESSION 5: FRUTTS AND VEGETABLES}

Teacher's Guide

\section{Lesson Objectives}

After completion of this lesson, Healthy Living Program panicipants wiJl:

* understand the healch benefits of eating five or more servings of fruits and vegetables daily,

* increase the number of servings of fruits and vegetables eaten each day,

* be able to read and understand labels of foods containing fruits and vegecables,

* be able to modify recipes to reduce fat, cholesterol and/or sodium and to increase fiber. vitamins, minerals and/or flavor in fruit/vegetable recipes

\section{Introduction}

\section{Visual 5.1: Pyramid with highlighted fruit/vegetable section}

Eating more fruits and vegetables is a good idea year round. Eating at least five servings every day may help you reduce your risk of chronic diseases such as hear disease and cancer. The U.S. Surgeon General, the National Cancer Institute, the American Hean Association, the American Cancer Sociery and the American Dietetic Association all recommend that Americans should eat a diel low in fat and high in fiber which includes loss of fruits and vegetables.

There are literally hundreds of varieries to choose from. They can supply nearly all of the vitamins and minerals required for good health. Many contain complex carbohydrates and sugars which provide energy. Most also provide dielary fiber, and a few such as beans and potatoes, can contribute to your protein needs. At the same time they contain no cholesterol. most have very licte fac. and are low in calories. Fruits and vegetables are "nutrient dense." which means they provide a lot of nutrition for the number of calories they supply. When you consider the inexpensive cost of most produce in comparison wo meats and other animal foods, you get a nutrition bargain. Still, many Americans eat two or less servings per day. Children often repor eating one or less servings and the one they eat is often a form of fried potato.

To get the greatest benefits from fruits and vegetables you need to prepare them in ways that add no fat. Many are good raw. Others can be steamed, boiled, baked,

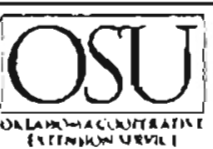

November, 1995 


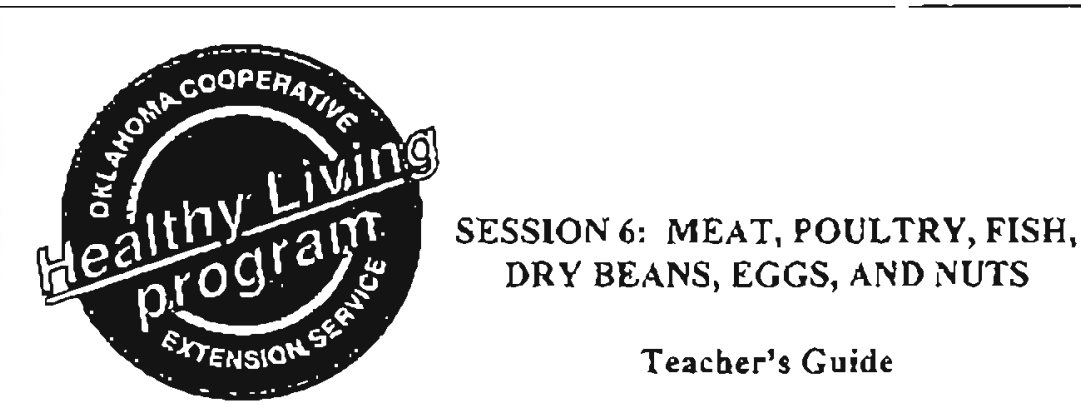

\section{Lesson Objectives}

After completion of this lesson, Healthy Living Program participants will:

- understand the health benefits of eating two ta three servings of protein foods daily,

- choose proteir foods lower in fat more often

- be able to read and understand labels of protein foods

- be able to modify recipes to reduce fat, cholesterol and/or sodium and to increase fiber, vitamins, minerals and/or flavor in protein recipes,

- be aware of safe handling practices for prorein foods.

\section{Iatroduction}

Visual 6.1: Pyramid with highlighted meat group

The foods in this section of the food pyramid are all high in protein. Dairy foods also provide excellent quality protein but because they are also high in calcium, they will be covered separately. Proteins are one of the essential nutrients. The body uses protein in more ways than it does any other nutrient. It is used as fuel, as part of tissues and body pars, in hormones, in enzymes, as antibodies, as a transponation system for other nutrients, in helping to maintain fluid balance, as part of mother's milk, and in forming blood clots and sear tissue.

Muscle meats are primary sources of protein in the diets of many Oklahomans. They can also be primary sources for fat and cholesterol. Some people now consider muscle meats. especially red meats, as "bad" foods. However, these foods are goods sources vitamins and minerals, especially iron, zinc, niacin, riboflavin, vitumin $B_{6}$, and vitamin $B_{12}$. As a result of these nutrients, lean meat can contribute to a balanced diet. Knowing how to choose lean muscle foods, how to keep the fat content low during cooking, and how to control portion size is important.

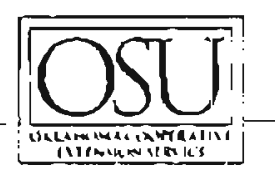




\section{Session 7: Dairy Foods}

Teacher's Guide

\section{Lesson Objectives}

After completion of this lesson, Healuby Living Prograro participants will:

- understand the kealth benefits of eating two to three servings of dairy foods dajly,

- choose low-fat dairy foods more often

- be able to read and understand labels of dairy foods

- be able to modify recipes to reduce fat, cholesterol and/or sodium and to increase fjber, vitamins. minerals and/or flavor in dairy recipes

- be aware of safe handling practices for dairy foods

\section{Introduction}

\section{Visual 7.1: Pyramid with highlighted dairy group}

Milk is the leading source of calcium in the American diet. Just wo cups of milk per day provides 75 percent of the adult RDA for calcium. Milk is high in vitamins A and D. riboflavin, other $\mathrm{B}$ vitamins, phosphorus, and magnesium. Milk provides high quality protein. If skim milk is cbosen the protein is not accompanied by the fat found with some other protein foods. Two cups of skim milk provide 27 percent of the RDA for protein for men and 33 percent for women.

Dietary calcium is nearly as important for adults as it is for children. The body continues to replace bone all througbout life. While calcium is found in other foods such as green leafy vegetables, it is in its most usable form in milk. The phosphorus in milk works in balance with calcium to build bone. This is a good reason to get caleium from dairy foods rather than from supplements.

\section{Visual 7.2: Nutrients in milk}

Low-fat and skim milk are required by the Food and Drug Administration (FDA) to be forified with vitamin A. Vitamin A is a fat soluble vitamin that is lost when the fat is removed. All milk is fortified with vitamin $D$, which is present naturally in milk in small

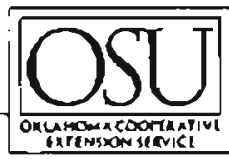

November, 1995 


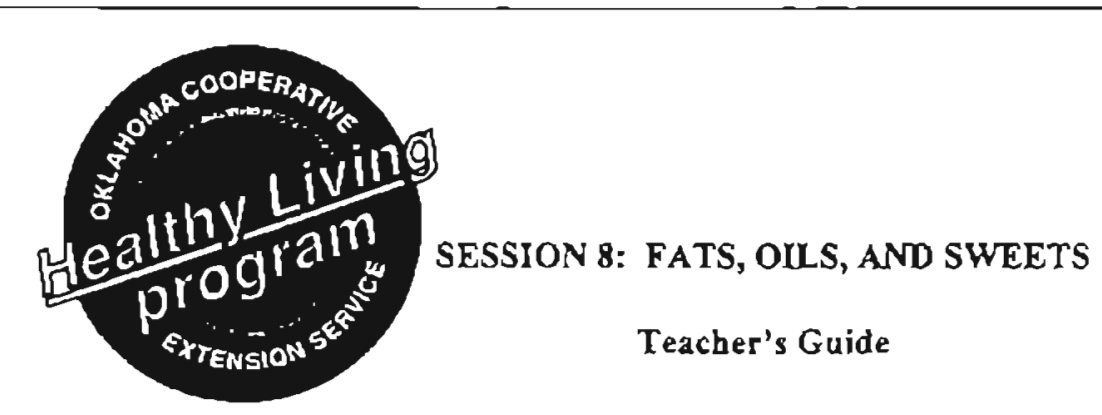

\section{Lesson Objectives}

After completion of this lesson, Healthy Living Program participants will:

- understand the healthy benefits of eating moderate amounts of fats and sweets

- better understand the different types of fats and oils and the functions of different levels of saturation in food products

- choose low-far foods more often

- be able to identify ingredients which add fat to foods on labels and use the terminology on food labels to make better nutrition choices

- be able to modify recipes to reduce total fat, saturated fat, and sugar content

\section{Introduction}

\section{Visual 8.1: Pyramid with bighlighted fats, oils and sweets group}

The tip of the Pyramid may represent the majority of calories for many Oklahomans. Foods such as salad dressings and oils, cream, burter, margarine, sugars, sott drinks, candies, and sweet dessercs provide calories but offer linte else from a nutritional point of view. Fats may also be found in meats, dairy products, baked goods and cereals. Vegetables are often served with added fat. Elimination of these foods is not necessary, but moderation is.

Americans eat sugars in many forms. Sugars are carbohydrates. Dietary carbohydrates also include the complex carbohydrates starch and fiber. During digestion all carbohydrates except fiber break down into sugars. Sugars and starches occur narually in many foods including milk, fruits, some vegetables, breads, cereals, and grains. Americans eat sugars in many forms. Sugars provide calories and most people like their taste. Some serve as natural preservatives, thickeners, and baking aids in foods. The body cannot tell the difference between naturally occurring and added sugars because they are identical chemically. The Dietary Guidelines for Americans cautions about eating sugars in large amounts and about frequently earing snacks of foods containing sugars and starches.

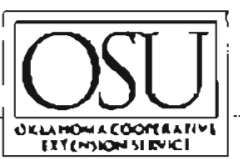


APPENDIX E 


\title{
A NTINTS DIVISION Of AGRICULTURAL 1 I LVV SCIENCES and NATURAL RESOURCES
}

Agricultural Communicatians - Oklahoma State University - Stillwater, OK 74078-0222 - 405-744-4081 - FAX 405.744-5739

NEWS RELEASE

\author{
EXTENSION SERVICE TO OFFER \\ HEALTHY LIVING PROGRAM \\ by Trisha Gedon
}

STILLWATER - There is growing concern about the link between nutrition, diet and health. Over the past few years. more and more evidence is coming to light about what we eat and how it affects our health.

The Oklahoma Cooperative Extension Service will soon be offering a new program to shed some light on the correlation between disease and diet.

Slated to kick off (fill in date) - the "Healthy Living Program" will feature eight sessions which cover a variety of topics concerning good health and a nutritious diet.

The lessons include The Food Pyramid and Recipe Modification: Supermarket Tour: 8reads: Quick. Yeast. Whole Grain: Grains. Cereals and Pasta: Fruits and Vegetables: Meats. Poultry, Fish. Dry Beans and Nuts: Dairy Foods: and Fats, $0 i 1$ and Sweets.

"Healthy Living Program" will include information on nutrition, label reading, recipe modification, food selection and preparation, and food safety. Each session also will feature a fitness segment.

Research has shown that the five leading causes of death due to diseases and diet include coronary heart disease, some types of cancer. stroke, diabetes mellitus and atherosclerosis. 
In addition, obesity is a risk factor in all leading causes of death. It afflicts 30 percent of women, 15 percent of men and 25 percent of adolescents. The highest rate is among the poor and minority groups. Consumers are seeking credible sources of information to overcome these problems and the "Healthy Living Program" is designed to provide accurate information and to help get individuals on the road to healthier living.

The "Kealthy Living Program" is on a five year plan. The primary audience for the first year is adults. The programming will be adapted the second year for youth and $4 \cdot \mathrm{H}$ audiences. The third year will feature a Master Shopper program. Special needs such as diabetes, heart disease and obesity will be the focus for the fourth and fifth years.

For more information about the "Healthy Living Program." contact the Oklahoma Cooperative Extension Service county office.

\section{\#\#}


APPENDIX F 


\section{Healthy Living Program Survey}

Code

(First, Middle, Last Initial - Last Four Digits Of Home Phone Number)

Check If Beginning Healthy Living Program Check If Completing Healthy Living Program Check If Follow up

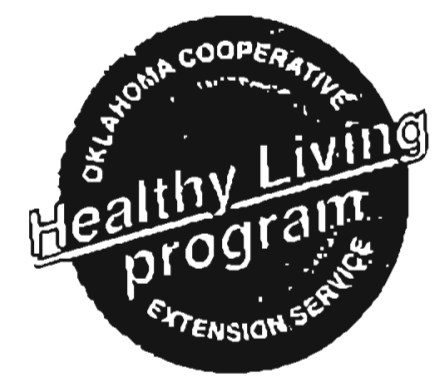

\begin{tabular}{|c|c|c|c|c|c|}
\hline $\begin{array}{l}\text { Put a check in the box that best } \\
\text { answers each question. }\end{array}$ & Never & Seldon & Sometimes & $\begin{array}{l}\text { Most of } \\
\text { The } \\
\text { Tine }\end{array}$ & $\begin{array}{l}\text { Almost } \\
\text { Always }\end{array}$ \\
\hline $\begin{array}{l}\text { 1. Do you compare food labels } \\
\text { before buying food? }\end{array}$ & & & & & \\
\hline $\begin{array}{l}\text { 2. Do you think about healthy food } \\
\text { choices when deciding what to } \\
\text { feed your family? }\end{array}$ & & & & & \\
\hline $\begin{array}{l}\text { 3. Do you let meat or dairy foods sit } \\
\text { out for more than two hours? }\end{array}$ & & & & & \\
\hline $\begin{array}{l}\text { 4. Do you thaw frozen foods at roor } \\
\text { temperature? }\end{array}$ & & & & & \\
\hline $\begin{array}{l}5 \text { Do you eat ground meat that still } \\
\text { has some pink color to it? }\end{array}$ & & & & & \\
\hline $\begin{array}{l}\text { 6. In the past two weeks, did you } \\
\text { read food labels to select foods } \\
\text { with less far? }\end{array}$ & & & & & \\
\hline $\begin{array}{l}\text { 7. In the past two weeks, did you } \\
\text { read food labels to select foods } \\
\text { with less salt or sodium? }\end{array}$ & & & & & \\
\hline $\begin{array}{l}\text { 8. In the past two weeks, did you } \\
\text { read food labels to select foods } \\
\text { wirh less sugar? }\end{array}$ & & & & & \\
\hline
\end{tabular}




\begin{tabular}{|c|c|c|c|c|c|}
\hline $\begin{array}{l}\text { Put a check in the box that best } \\
\text { answers each question. }\end{array}$ & Never & Seldom & Sometimes & $\begin{array}{l}\text { Most of } \\
\text { The } \\
\text { Time }\end{array}$ & $\begin{array}{l}\text { Almose } \\
\text { Always }\end{array}$ \\
\hline $\begin{array}{l}\text { 9. In the past two weeks, did you } \\
\text { read food labels to select foods } \\
\text { with more fiber? }\end{array}$ & & & & & \\
\hline $\begin{array}{l}\text { 10. In the past two weeks, did you } \\
\text { prepare foods with less fat? }\end{array}$ & & & & & \\
\hline $\begin{array}{l}\text { 11. In the past two weeks, did you } \\
\text { prepare foods with less sait? }\end{array}$ & & & & & \\
\hline $\begin{array}{l}\text { 12. In the past two weetcs, did you } \\
\text { prepare foods with less sugar? }\end{array}$ & & & & & \\
\hline $\begin{array}{l}\text { 13. In the past two weets, did you } \\
\text { prepare foods with more fiber? }\end{array}$ & & & & & \\
\hline $\begin{array}{l}\text { 14. In the past week, did you eat six } \\
\text { or more bread, cereai, rice or } \\
\text { pasta servings daily? }\end{array}$ & & & & & \\
\hline $\begin{array}{l}15 \text { In the past week, did you eat } \\
\text { five or more fnuit and vegetable } \\
\text { servings daily? }\end{array}$ & & & & & \\
\hline $\begin{array}{l}\text { 16. In the past week did you eat } \\
\text { two or more dary servings daily? }\end{array}$ & & & & & \\
\hline $\begin{array}{l}\text { 17. In the past week, did you eat } \\
\text { two or more servings of meat, } \\
\text { poultry, fish, or dry beans daily? }\end{array}$ & & & & & \\
\hline $\begin{array}{l}\text { 18. Do feel your family's nutritional } \\
\text { needs are being met? }\end{array}$ & & & & & \\
\hline
\end{tabular}

Adapted from USDA EFNEP SURVEY, 1993 
APPENDIX G 
COOE

\begin{tabular}{|c|c|c|c|c|c|c|c|}
\hline Check If Beginning & Medium & You & & Hon & woten & en? & \\
\hline Check If Completing & Serving & $\begin{array}{c}\text { Sernng } \\
\text { size }\end{array}$ & & $\bar{\varepsilon}$ & $\underline{\underline{E}}$ & $=$ & $\bar{z}$ \\
\hline FRUITS \& JUICES & & $\mathbf{S}|\mathbf{M}| \mathrm{L}$ & 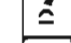 & $\mathbf{z}$ & $\underline{\Sigma}$ & $\Sigma$ & \& ż \\
\hline EXAMPLE - Apples, applesuuce, pears & \{Ilor ks cup & 7 & & 14 & & & \\
\hline Apples, applessuce, pears & (1) or ks cup & & & $i$ & & & \\
\hline Bamanas & 1 medium & & & $\perp$ & & & \\
\hline Peaches. apricols (canned, trozen or dried, whole vear) & (1) or shap & & & & & & \\
\hline Peaches, apricols, nectannes (fiesh. in season) & 1 medium & & & & & & \\
\hline Cantaloupe (in season) & W. medium & & & & & & \\
\hline Wateruelon (in season) & I slice & & & & & & \\
\hline Scrawbernes (fresh, in season) & incup & & & & & & \\
\hline Oranges & 1 nedium & & & & & & \\
\hline Orange junce or grapeltrul juice & 60z.glass & & & 1 & & & \\
\hline Grapelmit & (h) & & & & & & \\
\hline Tang, Start breakfast drinks & 6 or gliss & & & & & & \\
\hline Olher frul juces, lortiked fruit drinks & 6 oz.glass & & & & & & \\
\hline Any other truit, including berres, fruit cocktal & hap & & & & & & \\
\hline VEGETABCES & & \begin{tabular}{|l|l|l|}
$S$ & $M$ & $L$ \\
\end{tabular} & D: & $\left|w_{k}\right|_{2}$ & Mo & $\mathbf{r}$ & Nv \\
\hline Strng besns, green beans & incup & & & & & & \\
\hline Peas & hap & & & & & & \\
\hline Chili with beans & 1/4cup & & & & & & \\
\hline Other beans such as baked besns, puntos. kidnew beans, limss & Hocuf & & & 1 & & & \\
\hline Com & houp & & & & & & \\
\hline Winter squash, baked squash & ix cup & & & & 1 & & \\
\hline Tomalces, tomato juice & (1) 01602. & & & & & & \\
\hline Red chili sauce, iaco sauce, sals picante & 2 Tolsp. sauce & & & - & & & \\
\hline Braccoli & 1hape & & & & & & \\
\hline Cauliflower or bruasel sprouts & $1 / 2$ alp & . & & L. & & & \\
\hline Spinach (raw) & visup & & & & & & \\
\hline Spinuch (cooked) & hasp & & & & & & \\
\hline Mustard greens, rumup greens, collards & houp & & & & & & \\
\hline Cole slaw, cobbage, sauerkraul & heup & & & & & & \\
\hline i Carross, or mixed vegelables conturing artois & $1 / 2$ cup & & & & & & \\
\hline Green salad & 1 med. bowl & & & & & & \\
\hline Solad dressing, mavonnuive (induding an send wiches) & 2 Tolsp. & & & & & & \\
\hline French fries and fried potatoes & Xusup & .1 & & & & & \\
\hline Sweet pouloes, yams & hap & & & & & & \\
\hline Other potaroes, including boiled, baked, potato solad & (1) or incup & & & & & & \\
\hline Ruce & H/a cup & & & & & & \\
\hline Anv ocher vege bable, induding cooked onions, summet aquash & 1/2up & & & & & & \\
\hline Buner, margsine or ocher fat on vegetables, potatoes, elc. & 2 pals & & & & & & \\
\hline MEA \%, FISH, POULTRY \& MDED DISHES & & $\mathbf{S}|\mathbf{M}| \mathrm{L}$ & $D_{2}$ & Wkit & M.S1 & $\mathrm{Yr}_{\mathrm{r}}$ & Nv \\
\hline Hamburgers. chesebungers, mest loaf & 1 medium & & & & & & \\
\hline Beel-steaks, rousts & 402. & & & & & & \\
\hline Beel stew or pot pie with carrok, ocher vegetsbles & 1 cup & & & & & & \\
\hline Lver. induding chicken livers & $40 z$. & & & i & & & \\
\hline Pork. induding chops, roasts & 2 chops or 4 oz. & & & T & & & \\
\hline Fried chicken & $2 \mathrm{sin}$. or l lg. piect & & T & T & & & \\
\hline IChicken or turkey, rossled, stewed or broiled & $2 \mathrm{sm}$. or l lg. preced & & & 1 & & & \\
\hline Fned hish or fish sandwich & 4 oz or 1 sind. & & & $i$ & & & \\
\hline Turu tish, rura saiad, runs casserole & is cup & & & & & & \\
\hline Shell hah (shuing. lobster, cab, ovsters. elc.) & (5) y, cup or $30 z$ & $!$ & & & & & \\
\hline Other fish, broiled. baked & $40 z$ & & & & & & \\
\hline Spagherti. Lasagra, other pasta with tomalo souce & $1 \mathrm{cup}$ & & L & & & & \\
\hline Piozes & 2 stices & & & & & & \\
\hline Mixed dishes mith cheese (such as macaroni and cheese) & I rup & T & & $\cdot$ & & & \\
\hline
\end{tabular}




\begin{tabular}{|c|c|c|c|c|}
\hline & \\
\hline & $\begin{array}{l}\text { Medium } \\
\text { Serving }\end{array}$ & \multicolumn{3}{|c|}{$\begin{array}{c}\text { Your } \\
\text { Serving } \\
\text { Size }\end{array}$} \\
\hline LINCH TEMS & & & & \\
\hline Lverwurst & 2 slíces & & & \\
\hline Hol dogs & 2 dogg & & & \\
\hline Ham. lunch meats & 2 slices & & & \\
\hline Vegetable soup. vegeiable beel minestone, lomslo soup & 1 med. bowl & & & \\
\hline Other soups & 1 med, bowl & & & \\
\hline BREADS / SALTY SNACKS / SPREADS & & 5. & $\mathrm{M} / \mathrm{L}$ & \\
\hline giscuits. muttins, burger rolls (ind. fast foods) & 1 med. piece & & & \\
\hline While bread (induding sandwiches), bagels, elc, crackers & 2 slices, 3 cracks & & & \\
\hline Dark bread, induding whole wheal, rye, pungerniekel & 12 slices & & & \\
\hline Com bread com muffins, com tortillss & 1 med. piece & & & \\
\hline Sa'r snacks (such as chips, papcom) & 2 hardfuls & & & \\
\hline Pesnuks, peanut butter & 2 Tbisp. & & & \\
\hline Butler on bread or rolls & 2 pats & & & \\
\hline Margarine on bread or rolls & 2 gats & & & \\
\hline Graves made with great drigpings. or white sauce & 2 Jolsp. & & & \\
\hline BREAKFAST FOOOS & & S & $\mathrm{ML}$ & \\
\hline High fiber, bran or granals cereals, shredded whesl & I laed. bowl & & & \\
\hline Highiy fortibed cereals. such as Product 19, Tovl, or Most & 11 med. bowl & & & \\
\hline Other cold cereals, such as Com Flakes. Rice Krispies & II med. bowl & & & \\
\hline Cooked cereals & 1 med. bowl & & & \\
\hline Sugay added to cereal & 2 teaspn. & & & \\
\hline legg = small. & 2 eggs - medium & & & \\
\hline Bacan & 2 slices & & & \\
\hline Sausage & 2 paties or links & & & \\
\hline SWEETS & & S & $\bar{M} \mathbf{L}$ & \\
\hline Ice crean & 1 scoop & & & \\
\hline Doughruts, cookies, cokes, pasty & 1 pc. or 3 cooties & & & \\
\hline Pumplan pie, sweel poulo pie & I med. slice & & & \\
\hline Other pies & 1 med. slike & & & \\
\hline Chocolate ondy & small bar, 1 oz. & & & \\
\hline Other andy, jelly, honey, brown supar & 3 p. or 1 THsp. & & & \\
\hline DAIRY PRODUCTS & & & $M[$ & \\
\hline Corrge cherse & hap cup & & & \\
\hline OLher cheeses and cheese soreads & 2 slices or 202. & & & \\
\hline Flavored yogur & laup & & & \\
\hline Whole millk and bers. whth whole mill (not ind. on cered) & 802. gass & & & \\
\hline 29 milk and bevs. with 2\% milk (not ind. an ceres) & $8 \mathrm{oz}$.glnss & & & \\
\hline Skun milk. 19 milk or butreturilk (not und. on cereal) & $80 x . g$ gass & & & \\
\hline BEVERAGES & & & MI & \\
\hline Regular soft drinixs & 12 oz. an or botule & & & \\
\hline Diel soft drinks & 12oz:an or bonk & & & \\
\hline Beer & 12 oz can or bottle. & & & \\
\hline Wue & 1 med. glass & & & \\
\hline Lquor & Ishol & & & \\
\hline Decalifeinated colite & 1 med. ap & & & \\
\hline Cofíee, nol decaffesnated & 1 med.cup & & & \\
\hline Tea (hol or iced) & I med. cup & & & \\
\hline Lemon in tes & 1 teaspn. & & & \\
\hline Non-diary creamez un colfee or tea & 1 Tblsp. & & & \\
\hline Milt in colfee or tes & 1 Tolsp. & & & \\
\hline Cream (real) or Haffeand-Half in colfee or tea & 1 Tolsp. & & & \\
\hline Sugur in cofier or tes & 2 teaspn. & & & \\
\hline Antical sweeterier in coflece or tes & 1 pacier & & & \\
\hline Glasses of water. nol counting in colfee or ted & 8 or. plass & & & \\
\hline
\end{tabular}
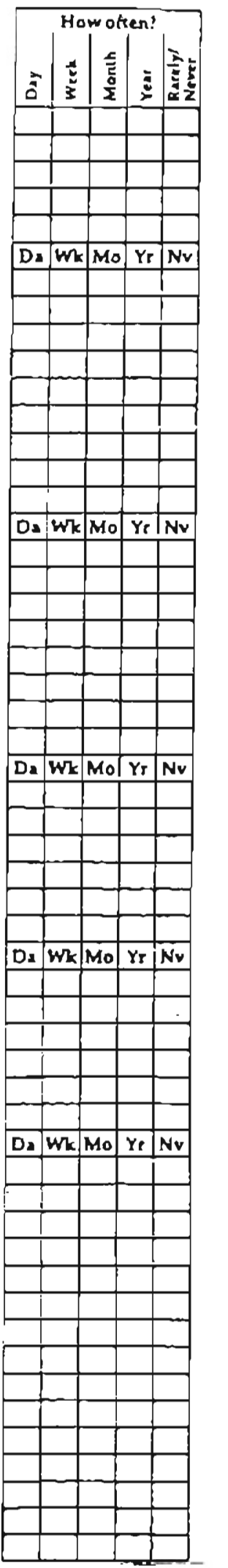
APPENDIX H 


\section{Healthy Living Program Measurement Form}

Code

(First, Middle, Last Inítial - Last Four Digirs Of Home Phone Number)

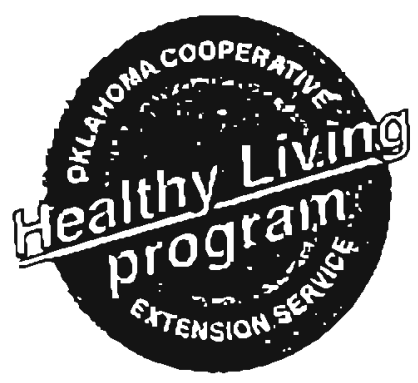

Check If Beginning Healthy Living Program

Check If Completing Healthy Living Program

Check If Follow Up

Check if: Male

Female

Age years

Heigbt in

- Measure height using a measuring stick or tape affixed to a true verical tlat surface, such as a wall or a rigid, free-standing measuning device. When using a measuring stick, measure 36 inches ( 3 feet) from the floor using the measuring stick and make a mark. Then affix the measuring stick at the 36 inch mark, this allows at least a 72 inch measure ( 6 feet).

- Participart should be measured without shoes.

- Paricipart stand on bare foor, with heels together, back as straight as possible. The heels, butrocks, and shoulders should touch the wall or verical surface of the measuring device.

- Participants line of sight should be horizontal.

- Measure height in inches to the nearest $1 / 8$ th inch using a movable block squared at right angles against the vertical flat surface, that can be brought down to the crown of the head.

Weight lb

- Body weight should be measured with beam scales with non-detachable weights. If you use spring scales try not to move scales around. Be sure co use the same scale for beginning and ending weight measurements.

- Scale should be calibrated to zero.

- Participant should be weighted at approximately the same time of day

- Participant should be dressed in light clothing, without shoes.

- Measure weight in pounds, while paricipant standing on scale withour moving.

Blood Pressure mm Hg (Optional)

Blood Cholesterol $\mathrm{mg} / \mathrm{dl}$ (Optional) 
APPENDIX I 


\section{Healthy Living Program \\ Informed Consent}

"L voluntarity agsee to paricipate in the evaluarion of the educational program "Heatehy Living Progran" which is sponsored by Oklahoma Cooperauve Extension Service.

I understand that:

(1) the purpose of the program evaluation is to measure the effect of the eight session "Heal thy Living Progtam" on food selection and preparation practices, dietary intake, and health stabus measures of weight, blood pressure and blood lipids including total-cholesteroh HDL-cholesterol, LDL-cholesterol and triglycerides;

(?) I will attend eight "Healthy Living Program" educational sessions;

(J) at the first and last session I will have physical measurements of height, weight, and blood pressure;

(4) a licensed phlebotomist will draw a fasting blood sample of $10 \mathrm{ml}$ (about 2 teaspoons) by venipuncture before and after the eight session Healthy Living Program, and that slight bruising or discomfort may result from the venipuneture;

(5) all records are confidential and that my name will nor be associated with any reports or data record's at the end of the evaluation

(6) Participation in the program evaluation is voluntary and that I have the right to withdraw form the program evaluation at any cime and still participate in the Heaithy Living Program educational sessions.

(7) the program evaluation will be beneficial to the public in that it will help to determine if the educational program helps consumers apply the Dietary Guidelines recorrmendations to food selection and preparation practices, and helps consumers eat the reconmended number of servings from the Food Guide Pyramid food groups. This evaluation will also determine if making these types of seleczion, preparation and dietary changes results in healthy weight, blood pressure, and blood cholesterol which can reduce the risk of many types of diet relared diseases including heart disease, hypernension, diabetes, and possibly certain types of cancer

(9) I may contact Dr. Janice Hermann at (405) 744-6824 should I wish funher information. I may also contact the office of University Research Services, 001 Life Sciences East, Oklahoma State University, Stillwater, OK 74078 Ielephone (405) 744-5700.

I have read and fully understand the consent form. I sign freely and voluntarily. A copy has been given to me.

Dare:

Time: (a.m./p.m.)

Signed:

$$
\text { Signature of Subject }
$$

I cerify that I have personally explained all elements of this fom to the subject or his/her representative before requesting the subject or hisher representacive 10 sign it,"

Signed:

Project Director of hisher authorized representative 
APPENDIX J 


\section{HEALTHY LIVING PROGRAM}

\section{Fasting Blood Values}

Subject Code:

\begin{tabular}{|c|c|}
\hline Blood Measurement & Your Values \\
\hline $\begin{array}{l}\text { Total Cholesterol } \\
\text { Classification: } \\
\begin{array}{l}\text { Desirable }<200 \mathrm{mg} / \mathrm{dl} \\
\text { Borderline } 200-239 \mathrm{mg} / \mathrm{d} \text { ) } \\
\text { High }>240 \mathrm{mg} / \mathrm{dl}\end{array}\end{array}$ & \\
\hline $\begin{array}{l}\text { LDL Cholesterol } \\
\text { Classification: } \\
\text { Desirable }<130 \mathrm{mg} / . \mathrm{dl} \\
\text { Borderline } \quad 130-159 \mathrm{mg} / \mathrm{dl} \\
\text { High }>160 \mathrm{mg} / \mathrm{d} \text { ! }\end{array}$ & \\
\hline $\begin{array}{l}\text { HOL Cholesterol } \\
\text { Classification: } \\
\text { Desirable } \geq 60 \mathrm{mg} / \mathrm{dl} \\
\text { Low } \quad<35 \mathrm{mg} / \mathrm{dl}\end{array}$ & \\
\hline $\begin{array}{l}\text { Triglycerides } \\
\text { Classification } \\
\text { Desirable }<200 \mathrm{mg} / . \mathrm{dl} \\
\text { Borderline } \quad 200-399 \mathrm{mg} / \mathrm{dl} \\
\text { High } \quad 400-1000 \mathrm{mg} / \mathrm{dl} \\
\text { Very High }>1000 \mathrm{mig} / \mathrm{dl}\end{array}$ & \\
\hline $\begin{array}{l}\text { Glucose } \\
\text { Expected Values: } \\
70-105 \mathrm{mg} / \mathrm{dl}\end{array}$ & \\
\hline
\end{tabular}

Source for blood values: Summary of the second report of the National Cholesterol Education Program Expert Panel on Detection, Evaluation, and Treatment of High Blood Cholesterol in Adults. Joumal of the American Dietetic Association, 1993:269;3015-3023. 
APPENDIX K 


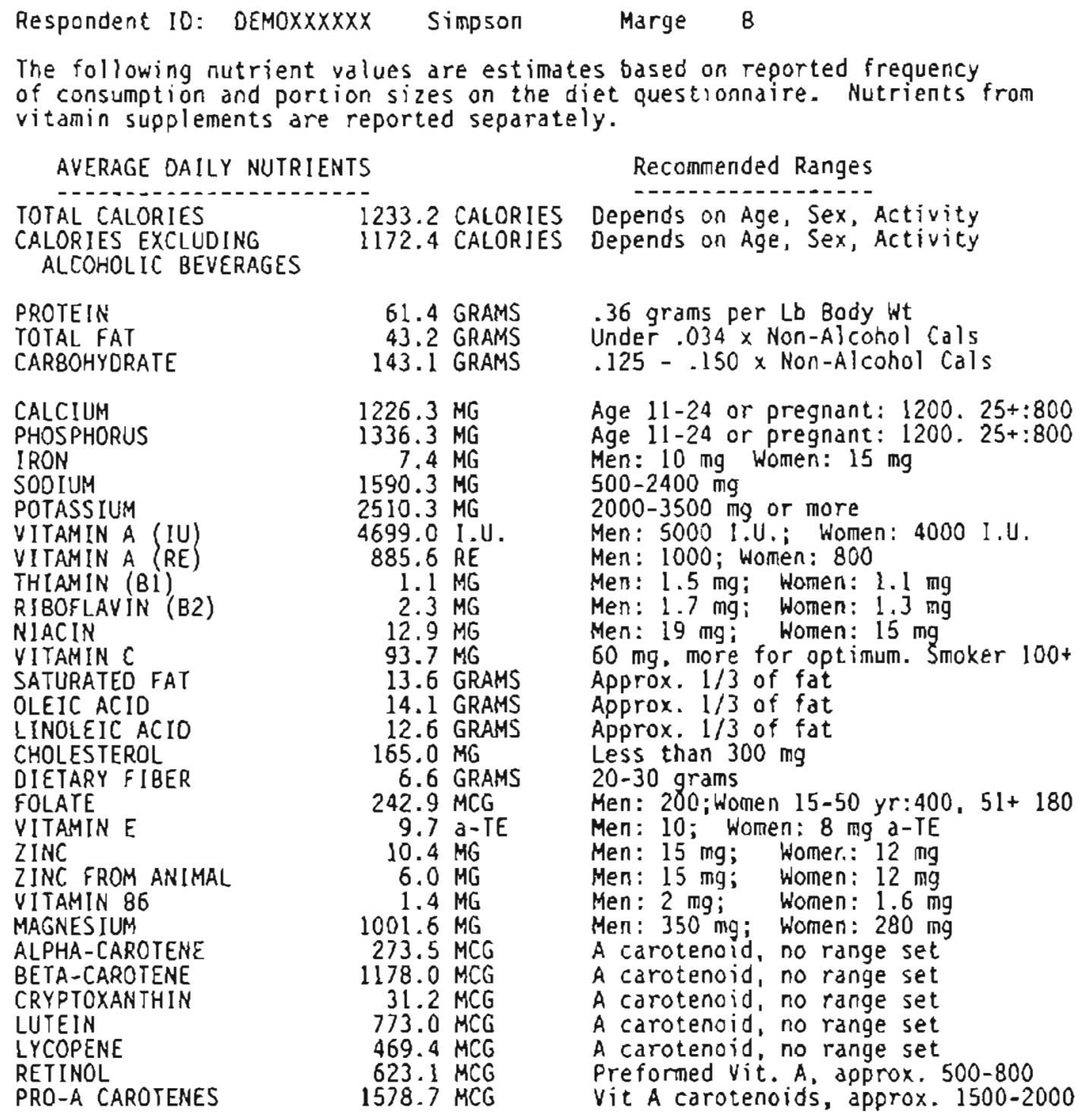




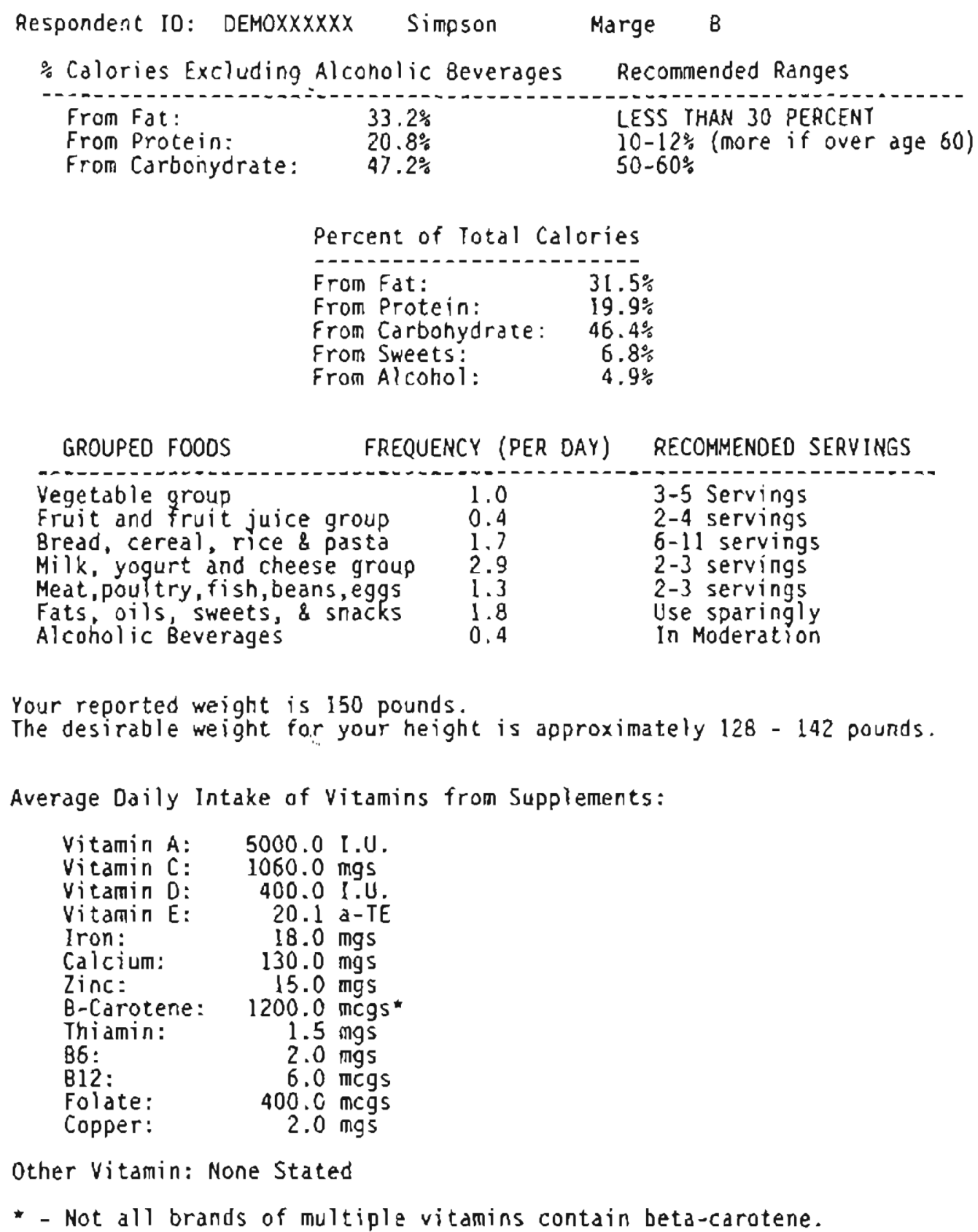




\author{
VITA \\ Starlette Lynn Heintz \\ Candidate for the Degree of \\ Master of Science
}

Thesis: EFFECTS OF AN EDUCATION PROGRAM UTILIZING THE DIEIAIRY GUIDELINES AND FOOD GUIDE PYRAMID ON DIET AND HEALTH

Major Field: Nutritional Sciences

Biographical:

Personal Data: Born in Fort Collins, Colorado, September 24, 1967, the daughter of Jack R. and Shelby J. Morrison. Married David A. Heintz November 28, 1992.

Education: Graduated from Loveland High School, Loveland, Colorado in May 1986; received a Bachelor of Arts degree in Dietetics and a Bachelor of Arts degree in Psychology from University of Northern Colorado, Greeley, Colorado in May 1994; completed requirements for the AP4 Dietetic Internship at Oklahoma State University, May 1995; completed requirements for the Master of Science degree with a major in Nutritional Sciences at Oklahoma State University in May, 1998.

Professional Experience: Food Technologist for University of Northern Colorado; Test Kitchen Manager for University of Northern Colorado; completed Dietetic Internship at Midwest City Regional Hospital in May 1995; obtained R.D. status in November 1995; Graduate Research Assistant for Oklahoma State University, Department of Nutritional Sciences, 1995.

Professional Organizations: American Dietetic Association. 